NBER WORKING PAPER SERIES

\title{
A DOSE OF MANAGED CARE: CONTROLLING DRUG SPENDING IN MEDICAID
}

\author{
David Dranove \\ Christopher Ody \\ Amanda Starc \\ Working Paper 23956 \\ http://www.nber.org/papers/w23956 \\ NATIONAL BUREAU OF ECONOMIC RESEARCH \\ 1050 Massachusetts Avenue \\ Cambridge, MA 02138 \\ October 2017
}

The authors would like to acknowledge the valuable advice and suggestions provided by Craig Garthwaite, Ben Jones, Victoria Marone, Brad Shapiro, Ashley Swanson, and Pietro Tebaldi and would further like to thank workshop participants at Northwestern University, Haverford College, and the University of Chicago for their comments and feedback. The views expressed herein are those of the authors and do not necessarily reflect the views of the National Bureau of Economic Research.

NBER working papers are circulated for discussion and comment purposes. They have not been peer-reviewed or been subject to the review by the NBER Board of Directors that accompanies official NBER publications.

(C) 2017 by David Dranove, Christopher Ody, and Amanda Starc. All rights reserved. Short sections of text, not to exceed two paragraphs, may be quoted without explicit permission provided that full credit, including $(\odot$ notice, is given to the source. 
A Dose of Managed Care: Controlling Drug Spending in Medicaid

David Dranove, Christopher Ody, and Amanda Starc

NBER Working Paper No. 23956

October 2017

JEL No. I11,I13,L10

\begin{abstract}
$\underline{\text { ABSTRACT }}$
Effectively designed market mechanisms may reduce growth in health care spending. In this paper, we study the impact of privatizing the delivery of Medicaid drug benefits on drug spending. Exploiting granular data that allow us to examine drug utilization, we find that drug spending would fall by 22.4 percent if the drug benefit was fully administered by Medicaid Managed Care Organizations (MCOs), largely through lower point-of-sale prices and greater generic usage. The effects are driven by MCOs' ability to design drug benefits and steer consumers toward lower cost drugs and pharmacies. MCOs do not appear to skimp on performance, either by reducing overall drug consumption as measured by prescriptions per enrollee or reducing utilization of drugs that offset other medical spending.

David Dranove

Department of Strategy

Kellogg School of Management

Northwestern University

2001 Sheridan Road

Evanston, IL 60208

d-dranove@kellogg.northwestern.edu

Christopher Ody

Strategy Department

Kellogg School of Management

Northwestern University

2001 Sheridan Road

Evanston, IL 60208

c-ody@kellogg.northwestern.edu

Amanda Starc

Kellogg School of Management

Northwestern University

2001 Sheridan Road

Evanston, IL 60208

and NBER

amanda.starc@kellogg.northwestern.edu
\end{abstract}




\section{Introduction}

In this paper, we examine how market institutions and mechanisms can control health care costs. Within the next decade, national health expenditures are expected to represent $20 \%$ of gross domestic product; these costs strain household and government budgets alike (Keehan et al. [2017]). As a result, many payers - ranging from states to employers - have explored various approaches to control costs and lower spending. One such approach is managed competition among private managed care organizations (MCOs). Relative to direct administration by government agencies, private firms may have better tools to reduce overall medical consumption; MCOs may also be better able to "say no" to costly providers, including hospitals (Shepard [2016]) and drug manufacturers (Duggan and Scott Morton [2010]). Many proponents further argue that effectively designed market mechanisms are likely to produce better allocations of health care goods and services than an administrative price system.

Nowhere is the pattern of increased spending and experimentation with cost control mechanisms more salient than in the market for prescription drugs. In recent years, price spikes among both generic and branded drugs have led for calls for policies ranging from greater price transparency to trade liberalization. We study one approach to reducing drug costs: the outsourcing of Medicaid pharmacy benefits to private MCOs. Medicaid is a large program, covering one in five low-income Americans, and thus the impact of privatization on both state budgets and enrollee health is critical from a policy perspective. States increasingly rely on MCOs to provide insurance benefits to program enrollees: as of 2010, roughly half of Medicaid beneficiaries were enrolled in comprehensive, risk-bearing private plans. We use plausibly exogenous, policy-induced changes in contracting decisions to study the impact of privatization of drug benefits within the Medicaid program.

Historically, state Medicaid programs offered indemnity-style benefits that reimbursed providers, pharmacies, and drug makers on a fee-for-service basis. Even as states shifted coverage for medical services to private MCOs, they continued to maintain the public pharmacy benefit programs separately as states were entitled to large drug rebates from drug manufacturers for beneficiaries enrolled in government provided plans, but not private MCOs. A key policy change occurred in March 2010: the Affordable Care Act (ACA) permitted states to also collect these drug rebates for MCO enrollees, making it weakly better to allow MCOs to administer Medicaid drug benefits post-ACA. Many states responded by "carving-in" the pharmacy benefit, either by adding it to the existing medical-only MCO plans, or by moving from full public coverage of 
the combined drug and medical benefit to full coverage through an MCO. We argue that this "carving-in" was a response to the exogenous ACA rule change. By leveraging variation in whether and when states acted, we identify the causal impact of private provision of drug benefits on utilization and costs.

We find that full privatization of a state's Medicaid drug benefit decreases program drug spending by 22.4 percent. Utilization, as measured by prescriptions per enrollee, is unchanged. We find a large reduction in the average price per prescription: one third of the overall effect is due to lower point-of-sale prices at pharmacies for identical drugs. The remaining two thirds of the reduction in average price per prescription is due to greater use of generic substitutes. These price differences reflect the ability of MCOs to negotiate drug prices with pharmacies, rather than relying on administratively set prices, and the ability to steer patients toward more cost-effective drugs. ${ }^{1}$ These savings are larger in states in which MCOs are allowed to create their own formularies for Medicaid patients.

Critically, we find no evidence to suggest that MCOs achieve savings by skimping on non-contractible product attributes. Privatization does not lead to an overall decrease in the number of prescriptions that enrollees are receiving, and the shift toward less expensive drugs is weaker among drugs believed a priori to lower medical utilization. Finally, there are no systematic differences in our results between states that riskadjust payments to private MCOs and states that do not, and the patterns in the data are not easily explained by MCOs cream-skimming profitable enrollees.

Our paper adds to growing evidence on the important role of institutions and mechanisms for purchasing health care goods and services. The within-drug price reductions we measure are similar in magnitude to those in Duggan and Scott Morton [2010], indicating that private firms generate similar savings on prescription drugs in both the Medicare and Medicaid programs. Curto et al. [2017] find substantial reductions in medical utilization within privatized Medicare; in our setting, we do not find reductions in overall drug utilization, though we do measure substantial substitution to lower cost alternatives. ${ }^{2}$

Taken together, our results show that private firms lower the cost of providing prescription drugs in the Medicaid program because they are better able to steer demand away from high cost branded drugs and high cost pharmacies. Our results indicate that market mechanisms can control health care costs and lower upstream prices. Furthermore, numerous policy interventions - such as price caps, limits on consumer out-

\footnotetext{
${ }^{1}$ Roughly one third of the increased use of generics results from greater within-molecule use of generics, whereas the other two thirds results from substitution from branded molecules not facing generic competition. Depending upon the assumptions underlying our calculations, the greater use of generics is responsible for another one third to two thirds of decreased spending.

${ }^{2}$ There may also be less scope for aggressive price negotiation in the Medicare Advantage program, as out-of-network rates are regulated to be equal to traditional Medicare rates.
} 
of-pocket costs, and direct price negotiation between government programs and drug manufacturers - may be less effective than the type of intervention we study. Therefore, our results also have broad implications for the debates about the proper role of the public and private sectors in providing essential services; this issue arises in settings as diverse as education, utilities, transportation, and prisons. Our setting - health care - is especially salient: in the United States, Medicare and Medicaid account for nearly half of all health care spending, and the market and administrative mechanisms used to allocate care have significant public policy implications.

The paper is organized as follows. In Section 2, we provide an overview of the relevant features of the Medicaid program, particularly the role of managed care in Medicaid and the structure of pharmacy benefits. Section 3 provides evidence on the quasi-experimental variation that underlies our analysis, describes the data and our empirical strategy. Section 4 details the paper's central results measuring the effect of privatization on drug spending, utilization, and point-of-sale price. Section 5 explores the robustness of our results and includes extensions. Section 6 concludes.

\section{Setting}

\subsection{Medicaid Drug Benefits}

As of December 2016, the Medicaid program enrolled over 68 million individuals - roughly one in five Americans (Centers for Medicare and Medicaid Services [2017]). Medicaid enrollees are diverse in their reasons for eligibility and medical needs: Medicaid covers many infants, children, pregnant women, and some parents of Medicaid eligible children, but also many people with disabilities, and elderly people with very low incomes. The ACA expanded Medicaid coverage of low-income, non-disabled, childless adults. ${ }^{3}$

States increasingly use MCOs to manage the provision of Medicaid beneficiary care. As of 2010, roughly 50 percent of Medicaid enrollees were covered by an MCO that bore risk for most of an enrollee's medical spending. ${ }^{4}$ While MCOs cover a large percentage of Medicaid lives, they are responsible for a relatively small share of spending. Duggan and Hayford [2013] note that 71.2 percent of Medicaid recipi-

\footnotetext{
${ }^{3}$ Medicaid spending is highly skewed, with the elderly and disabled accounting for roughly a quarter of enrollees, but nearly two thirds of spending. Even this number substantially understates the degree to which spending in the Medicaid population is skewed because many of the disabled and elderly also have Medicare coverage, which provides them with most medical and drug coverage, leaving Medicaid to cover only services that are not covered by Medicare (such as non-acute long term care) or Medicare premiums and/or cost sharing that these individuals are unable to afford (Young et al. [2013]).

${ }^{4}$ Roughly 16 percent more Medicaid patients are covered by a primary care case management (PCCM) program, which is a managed care arrangement for primary care, but with providers bearing little risk for other care (Gifford et al. [2011]). The comparable figure for Medicare Advantage is one third (Duggan et al. [2016]).
} 
ents received some managed care in 2009 , but that payments to managed care organizations were only 21.5 percent of program spending in that year. ${ }^{5}$ This is for two reasons: states are more likely to contract with MCOs for lower-cost eligibility groups, and some expensive categories of spending are excluded from the MCOs' contracts.

Though it is technically optional, all states provide Medicaid enrollees with drug coverage at minimal cost sharing. Federal regulation limits cost sharing for individuals with incomes below 150 percent of the federal poverty level to $\$ 4$ for preferred drugs and $\$ 8$ for non-preferred drugs, and states often set even lower cost sharing (Medicaid and CHIP Payment and Access Commission [2017]). Drugs are a small, but growing share of Medicaid spending, increasing from roughly 6 percent of spending to roughly 9 percent from 2010 to $2015 .^{6}$

Prior to 2010, prescription drug coverage was often excluded from MCO contracts. States directly reimbursed pharmacies with a fixed fee for filling a prescription, as well as a payment to cover the estimated ingredient cost, typically set as a percentage ( $85 \%-95 \%$, depending on the state) of the average wholesale price (AWP). However, ingredient costs have been calculated in multiple ways over time, including AWP, wholesale acquisition costs (WAC), average manufacturer price (AMP), actual acquisition cost (AAC), and National Average Drug Acquisition Cost (NADAC). Pharmacies could earn profits on the "spread" between the estimated ingredient cost as reimbursed by state Medicaid programs and the actual acquisition cost, which is often substantially lower. These reimbursement schemes give pharmacies no incentive to utilize lower cost drugs, and Medicaid programs have experienced increased utilization of drugs with inflated estimated ingredient costs (Alpert et al. [2013]).

Meanwhile, drug manufacturers are obligated to provide rebates to states according to statutory formulas. Pre-ACA, rebates for branded drugs were either 15.1 percent of the average manufacturer price (AMP) or the difference between AMP and the best price the manufacturer offered, whichever was higher. Critically, drug manufacturers were not required to provide rebates to states for drugs purchased by MCOs for Medicaid patients. The presence of mandatory rebates for state drug purchases, but not MCO purchases, provided a strong incentive for states to retain control of drug spending, and in 2010 under 15 percent of

\footnotetext{
${ }^{5}$ The main reason for the difference between the 71.2 percent of Medicaid recipients with some managed care and the 50 percent with an MCO that bore meaningful risk is that some Medicaid enrollees receive only specific types of services from a managed care organization (such as primary care or behavioral health benefits).

${ }^{6}$ Net of rebates, drugs increased from 3.6 percent of Medicaid spending in 2010 to 5.5 percent of Medicaid drug spending in 2015. Medicare-Medicaid dual eligible enrollees have their drug spending reimbursed by Medicare. The share of spending by non-dual eligible Medicaid enrollees has therefore increased from roughly 6 to roughly 9 percent over this time period.
} 
Medicaid drug spending was attributed to MCOs. ${ }^{7}$ Privatization likely has little impact on negotiations with drug manufacturers: mandatory rebates from drug manufacturers to states are still based on the AMP, but plans and states remain free to negotiate additional rebates.

The ACA made two substantive changes to Medicaid drug reimbursements. First, the rebate amount for branded drugs was increased to at least 23.1 percent of AMP. Second, the rebate benefit was extended to drugs purchased by MCOs for Medicaid patients, even as MCOs remained free to negotiate supplemental rebates with drug manufacturers. As a result, privatizing pharmacy benefits became weakly more attractive than state administration of the Medicaid drug benefit post-ACA. The result was a dramatic shift of drug benefits away from states to MCOs. By 2016, 13 states had transitioned from public provision to MCO provision of Medicaid drug benefits, and over 55 percent of Medicaid drug spending was attributable to MCOs.

\subsection{Conceptual Framework and Literature}

Public Medicaid administrators face two constraints that Medicaid MCOs do not; Medicare has historically faced similar constraints. First, public Medicaid administrators are required to set point-of-sale prices for drugs using administratively determined formulas that are meant to approximate average pharmacy costs. Second, public Medicaid administrators have few tools to steer demand towards higher value drugs or pharmacies. These constraints on public provision create scope for MCOs to lower costs without lowering quality. Private firms could obtain lower point-of-sale drug prices in three key ways. First, MCOs plans can negotiate point-of-sale prices with pharmacies by threatening to steer consumers away from high-cost pharmacies or to exclude pharmacies from their networks. Anecdotally, exclusion is an important cost control mechanism (Ross [2017]). ${ }^{8}$ Second, MCOs often set binding price ceilings known as maximum allowable costs (MAC) above which they will not reimburse a pharmacy. ${ }^{9}$ Third, MCOs may shift the mix of drugs. Pharmacies have incentives to dispense profitable drugs. Under administered prices (especially those based

\footnotetext{
${ }^{7}$ Interestingly, when states first privatized their Medicaid benefits, they often carved-in pharmacy benefits. However, over time the value of the rebates that states receive for Medicaid patients increased, and this led states to move toward a carved-out model. For example, from 2007 to 2009, five states switched from a carved-in to a carved-out model. Two of these states (Indiana and Ohio) then switched back to carving-in after the 2010 policy change, whereas the other three (Connecticut, Missouri, and Wisconsin) are in the control group in our analysis. No states privatized pharmacy benefits during the 2007 to 2009 time period (The Lewin Group [2011]). We are unable to study the consequences of these earlier "carve-out" decisions because we lack carved-in pharmacy claims prior to 2010 .

${ }^{8}$ This could harm enrollee health if it reduces access or adherence; we will explore this margin in our empirical work.

${ }^{9}$ This is especially true for generic drugs. MCOs will not reimburse pharmacies for more than the MAC even in cases in which a pharmacy claims that the MAC is below their ingredient costs, leaving the pharmacy to decide between not filling the prescription or taking the MAC reimbursement.
} 
on AWP), drugs that are profitable for pharmacies to dispense may not be high-value or low cost. Alpert et al. [2013] show that this system has led to a type of "perverse competition," in which there are incentives to inflate estimated drug costs and to fill prescriptions for drugs with inflated estimated costs. Furthermore, in the case of binding MACs, pharmacies are incentivized to stock weakly cheaper drugs within a therapeutic class. Taken together, these mechanisms suggest that negotiated prices may be lower than the previously administered prices. These incentives exist despite the presence of Medicaid rebates, which we predict will remain unchanged (Scott Morton [1997]).

MCOs may also affect the utilization of drugs, either by simply skimping on the provision of drugs overall, altering the mix of drugs consumed, favoring more cost-effective drugs such as generics, or attempting to increase the consumption of "high-value" drugs or those that have large medical offsets (Starc and Town [2015]; Lavetti and Simon [2016]). Private firms will have incentives to design contracts so as to creamskim healthy enrollees - a relevant concern within our setting. Studies on both Medicare Part D (Lavetti and Simon [2016]; Carey [2017]) and the health insurance marketplaces (Geruso et al. [2016]) find evidence that screening incentives affect contract design; risk-adjustment systems can mitigate these incentives.

Our paper is related to a growing literature exploring supply-side incentives in insurance markets, with a particular focus on public programs. While a number of studies compare public and private provision in Medicare (Town and Liu [2003]; Curto et al. [2014]; Curto et al. [2017]) and Medicaid (Duggan [2004], Duggan and Hayford [2013]), researchers rarely observe details of the care received by enrollees once their care is privately provided. This makes it difficult to examine what private providers are doing differently, and to what effect. ${ }^{10}$ Other papers examine how managed care plans differ from fee-for-service health insurance for the privately insured (Cutler et al. [2000]). Our analysis provides a view inside the "black box" of managed care in an important and relatively understudied setting. A more recent literature argues that a substantial portion of the private gains from the Medicare Advantage program accrue to insurers, though the exact magnitude is a matter of debate (see Cabral et al. [2014]; Curto et al. [2014]; Duggan et al. [2016]).We focus on how MCOs affect spending and the quality of care; a full analysis of the incidence of this program is outside the scope of this paper.

\footnotetext{
${ }^{10}$ Curto et al. [2017], which compares healthcare utilization by traditional Medicare enrollees with that of Medicare Advantage enrollees contained in the Health Care Cost Institute sample of the privately insured, is a notable exception.
} 


\section{Data and Empirical Strategy}

\subsection{Drug Benefit Privatization Decisions}

State Medicaid programs can be divided into three broad categories at any given point in time: (1) non-MCO medical, non-MCO pharmacy (FFS/FFS); (2) MCO medical, non-MCO pharmacy (MCO/FFS); and (3) MCO medical, MCO pharmacy (MCO/MCO). Privatization and carving-in of pharmacy benefits are synonymous in our setting: states privatize pharmacy benefits by carving them into medical MCO contracts. For this reason, there are no instances of states categorized as having a non-MCO medical benefit but an MCO pharmacy benefit. After the implementation of the ACA, there are nine potential transitions as described in Table $1 .^{11}$

We use two main rules when categorizing states. First, Medicaid programs may differ in how care is provided in different parts of the state or to distinct eligibility groups; we categorize states with anything beyond minimal use of MCOs as MCO states. Second, we treat only risk-bearing private firms providing comprehensive medical coverage as MCOs. ${ }^{12}$

Table 1: State transition types

\begin{tabular}{|c|l|c|c|c|}
\hline \multirow{2}{*}{ (medical / pharmacy) } & \multicolumn{3}{|c|}{$\mathrm{t}=\mathrm{T}$} \\
\cline { 2 - 5 } & FFS/FFS & MCO/FFS & MCO/MCO \\
\hline \multirow{3}{*}{$\mathrm{t}=0$} & FFS/FFS & 11 & 0 & 5 \\
\cline { 2 - 5 } & MCO/FFS & 1 & 4 & 8 \\
\cline { 2 - 5 } & MCO/MCO & 0 & 0 & 22 \\
\hline
\end{tabular}

Notes: States are classified as having an MCO if the state has a significant number of enrollees in an MCO that bears risk.

In our baseline analysis, we use the 16 states that are FFS/FFS or MCO/FFS in both the pre-period and the post-period as control states, and compare them against the 13 states which transitioned to $\mathrm{MCO} / \mathrm{MCO}$ in the post-period. There were 22 states that remained MCO/MCO throughout our time period; we exclude these from our analysis. By the end of our sample period, almost all states are either FFS/FFS or MCO/MCO. Excluding prescription drugs from MCO contracts is rare in the post-period, and therefore a state's decision about whether to use an MCO for a medical benefit is likely to predict the state's decision for a pharmacy benefit.

\footnotetext{
${ }^{11}$ Table A.27 contains the identities of the states undergoing each of the nine transition types.

${ }^{12}$ Almost all state Medicaid programs contract with private firms in more limited situations, such as for administering some fee for service benefits or for providing some specific benefits (such as behavioral health). Most states without an MCO contract with private firms to provide primary care case management (PCCM), which are primary care arrangements that involve some managed care-type features, but no risk-sharing for other spending.
} 
Of the 13 states in our sample that began MCO/FFS, eight transitioned to MCO/MCO, likely reflecting a response to the ACA rule change, rather than a sudden change in preferences about drug benefit privatization. Of the 16 states that began as FFS/FFS, only five privatized their drug benefits, and all of those states did so as a part of a much larger decision to begin using MCOs for medical benefits. We argue that the drug benefits are largely incidental to the privatization decision for these states; institutional details alleviate concerns that the transition might be a function of unobservable (to the researcher) trends in drug costs. We examine the robustness of our results to alternative ways of defining treatment and control groups.

\subsection{Data}

The Medicaid State Drug Utilization Data contain information on the utilization of drugs paid for through the Medicaid program. For each National Drug Code (NDC) in each state and in each quarter, we observe the number of prescriptions filled as well as (pre-rebate) spending. ${ }^{13}$ Since the passage of the ACA, MCO drug purchases have been collected and reported separately within the same dataset: our analysis covers the second quarter of 2010 (the first quarter for which MCO drug utilization was reported), through the third quarter of 2016. Given that reimbursements and rebates rely on this data, both state and federal governments have strong incentives to ensure that the drug utilization data is complete. ${ }^{14}$

We obtain additional information from a number of sources. We compute per-enrollee Medicaid drug spending using enrollment data from the Medicaid Enrollment Reports. ${ }^{15}$ Many states expanded Medicaid as a result of the ACA; to account for the possibility that the medical needs of the average enrollee changed, we collected data on the timing of the expansions. We obtained information on the active ingredients of the drugs in the Medicaid State Drug Utilization data from current and historical versions of the Drugs @ FDA

\footnotetext{
${ }^{13}$ We also observe the total number of "units" of the drug that were dispensed. We rely upon the prescriptions rather than units for two reasons. First, prescriptions are a more easily interpreted cross-drug measure of utilization. Second, there are many possible ways in which units can be measured, and there is some evidence that units have been reported with inconsistent measurements. Many of our results do not involve either the units or prescriptions measure. To investigate the robustness of our results to this decision, we created an "average units per prescription" variable for each NDC code, and then divide units by this measure, creating a variable that provides how many "normally sized" prescriptions worth of a drug were dispensed. Medicaid suppresses data from infrequently filled NDC codes for privacy reasons. By comparing total state-year drug spending from our data to external sources, we are able to confirm that minimal spending is missing.

${ }^{14}$ The Medicaid State Drug Utilization data are an input for collecting rebates from drug manufacturers, which are split between the states and the federal government. Manufacturers pay rebates based upon these data, giving them an incentive to ensure that no additional utilization is included. CMS has the ability to withhold federal Medicaid drug funds to states that are not collecting rebate information.

${ }^{15}$ Medicare-Medicaid dual eligibles receive drug coverage from Medicare Part D, and therefore their prescription drug utilization is not included in the Medicaid State Utilization Data. When constructing Medicaid enrollee drug spending, we exclude MedicareMedicaid dual eligibles from the denominator. The exact timing of the historical reports that we were able to locate varies across years. We interpolate the enrollment data so as to make these available at the quarterly level.
} 
database and the FDA's National Drug Code (NDC) Directory, which enables us to determine whether the NDC is for a branded or generic version of the drug and its active ingredient. ${ }^{16}$

We construct a number of dependent variables: share $M C O$ provides the share of Medicaid drug spending in a state-quarter that is by MCOs, while drug spending per enrollee measures drug spending per enrollee-quarter. In order to decompose the effect of privatization, we construct prescriptions per enrollee and (point-of-sale) price per prescription, noting that drug spending per enrollee is equal to prescriptions per enrollee times price per prescription. ${ }^{17}$ Drug utilization per enrollee replaces the NDC-state-quarter point-of-sale price per prescription in the data with the average point-of-sale price per prescription for that NDC-quarter, and then recalculates spending at the new (average) prices. In order to measure the use of inexpensive generics, we created three variables: generic penetration is the share of prescriptions that are filled with a generic; generic efficiency is the share of generic prescriptions filled when a generic is available; and generic accessibility is the share of prescriptions that are for drugs for which a generic is available. Generic penetration is equal to generic efficiency times generic accessibility. To examine the effect of privatization on the mix of drugs, we create share high offset which is the share of drug spending that is for drugs that have substantial offsets as described in Chandra et al. [2010] and in Starc and Town [2015]. ${ }^{18}$

Table 2 presents summary statistics for the second quarter of 2010 as well as the differences between treatment and control states. ${ }^{1920}$ Drug spending per enrollee and drug utilization per enrollee are economically similar and statistically indistinguishable for the treatment and control states. However, there is evidence that the treatment and control states differ along several dimensions: Utilization of high offset drugs is 3.6 percentage points lower in treatment states than in control states. These differences are relatively small, but suggest slightly more room to increase these measures of efficiency in the states that privatized drug benefits. Finally, treatment states were more likely than control states to expand Medicaid under the ACA. We present all analyses both excluding and including a control for the Medicaid expansion, and find 
Table 2: Summary statistics

\begin{tabular}{lccccccc}
\hline & \multicolumn{2}{c}{ Treatment } & \multicolumn{2}{c}{ Control } & \multicolumn{2}{c}{ Difference } \\
& Mean & SD & Mean & SD & Mean & SD \\
\hline Share MCO & 0.002 & 0.005 & 0.000 & 0.000 & .002 & 0.001 \\
Drug spending per enrollee & 209 & 57 & 212 & 64 & -3 & 23 \\
Prescriptions per enrollee & 3.162 & 0.892 & 2.947 & 0.800 & .216 & 0.314 \\
Price per prescription & 66 & 8 & 73 & 15 & -6.084 & 5 \\
Price per generic prescription & 20 & 5 & 22 & 12 & -2.664 & 3 \\
Price per branded (no gen comp) prescription & 248 & 26 & 265 & 66 & -16.695 & 20 \\
Price per branded (w/ gen comp) prescription & 102 & 14 & 114 & 21 & $-11.926^{*}$ & 7 \\
Drug utilization per enrollee & 252 & 74 & 239 & 70 & 13 & 27 \\
Generic penetration & 0.661 & 0.037 & 0.668 & 0.032 & -.007 & 0.013 \\
Generic efficiency & 0.788 & 0.025 & 0.793 & 0.019 & -.005 & 0.008 \\
Generic accessibility & 0.838 & 0.028 & 0.842 & 0.023 & -.004 & 0.010 \\
Share high offset & 0.419 & 0.038 & 0.455 & 0.040 & $-.036^{* *}$ & 0.015 \\
Share with Medicaid & 0.164 & 0.054 & 0.156 & 0.043 & .008 & 0.018 \\
Share in medical MCO & 0.307 & 0.319 & 0.179 & 0.313 & .128 & 0.118 \\
Expands Medicaid? & 0.769 & 0.439 & 0.313 & 0.479 & $.457 * *$ & 0.172 \\
Share with Republican governor & 0.462 & 0.519 & 0.438 & 0.512 & .024 & 0.192 \\
Share with Republican legislature & 0.468 & 0.122 & 0.506 & 0.157 & -.038 & 0.053 \\
\hline Observations & & 13 & & 16 & & \\
\hline
\end{tabular}

Notes: Unit of observation is the state-quarter for states in the second quarter of 2010. Drug spending per enrollee, prescriptions per enrollee, and price per prescription are calculated for all spending. Price per generic prescription, price per branded (no gen comp) prescription, and price per branded (w/ gen comp) prescription are calculated for those drugs that match the FDA database. Therefore, their average does not exactly equal the average price per prescription. Differences between the treatment and control states that are statistically significant are noted as: $* 0.10 * * 0.05 * * * .01$ 
that the inclusion of this control does not affect any of the paper's results.

\subsection{Estimation}

For state $s$ in quarter $t$, let $Y_{s t}$ be one of the dependent variables of interest, $\alpha_{s}$ be a state-specific fixed effect, $\tau_{t}$ be a quarter fixed effect, priv $_{s t}$ be an indicator for whether a state has begun to privatize its Medicaid drug benefit, and $\exp _{s t}$ be an indicator for whether the state expanded Medicaid as under the ACA. Our estimating equation is given by:

$$
Y_{s t}=\alpha_{s}+\tau_{t}+\beta \operatorname{priv}_{s t}+\lambda \exp _{s t}+\varepsilon_{s t} .
$$

We also augment equation (1) by including lags and leads of the privatization indicator. We present plots of these lag/lead coefficients to illustrate both how states moved prescriptions to MCOs, and the resulting impact on drug spending. ${ }^{21}$ We weigh observations by each state's Medicaid drug spending in the second quarter of 2010, the first quarter of our analysis, and cluster standard errors by state. ${ }^{22}$ Finally, we winsorize outliers of the dependent variables in the regression analyses. ${ }^{23}$

We use equation (1) to perform a difference-in-differences (DID) analysis of the effect of privatizing some pharmacy benefits on outcomes of interest. We also refer to this as the "reduced form" analysis. When states begin privatizing some pharmacy benefits, they do not switch all pharmacy spending into MCOs. ${ }^{24}$ We therefore also create instrumental variable estimates of what the effect of privatization would be if all of a state's enrollees' pharmacy benefits were administered by MCOs. To do this, we use equation (1) to

\footnotetext{
${ }^{16}$ In analysis that rely upon the FDA data to classify drugs, we exclude drugs accounting for roughly 3 percent of revenues because they fail to match the FDA data. Many of these appear to be non-prescription drugs.

${ }^{17}$ One limitation of the Medicaid State Drug Utilization Data is that they do not account for the effect of rebates on the prices of drugs. We discuss this issue further in the robustness section.

${ }^{18}$ To ensure that this measure captures differences in utilization rather than differences in pricing, we do not use state-quarter specific prices to create spending, instead substituting in quarterly prices across all states.

${ }^{19}$ Figure A.7 presents these summary statistics in histogram form for treatment and control states.

${ }^{20}$ As the map in Figure A.6 illustrates, there is no obvious geographic clustering of our treatment and control states.

${ }^{21}$ The instrumental variable analyses substitute share $M C O$ for priv $v_{s t}$ in equation 1, and then instrument for share $M C O$ with priv $_{\text {st }}$.

${ }^{22}$ We use this weighting scheme for all state-level analysis, so as to increase comparability across specifications. Counts of prescriptions, enrollees, and measures of spending all have correlations above 0.9 , so the decision is of little empirical consequence.

${ }^{23}$ Specifically, we run a regression with state and year fixed effects on the dependent variable, and obtain predicted residuals. We then replace any residuals below the first percentile of residuals with the first percentile and any residuals above the ninety ninth percentile of residuals with the ninety ninth percentile of residuals. The winsorized version of our variable is then the predicted values from this regression plus these winsorized residuals.

${ }^{24}$ The enrollees that switch into MCOs are likely a non-random subset of enrollees. Specifically, many states move healthier enrollees into MCOs. For this reason, we do not compare spending within a state of those with MCO drug benefits relative to those with FFS drug benefits. Our estimates will represent a local average treatment effect for those switching into MCOs and therefore our results might not generalize to other groups of enrollees.
} 
estimate the "first stage" relationship between privatizing some pharmacy benefits and share MCO. The IV estimates of the effect of share $M C O$ on our outcomes of interest effectively re-scale the reduced form estimates by the first stage estimates.

\section{Results}

\subsection{First Stage}

Figure 1: Percent of Medicaid drug spending by MCOs for treatment states
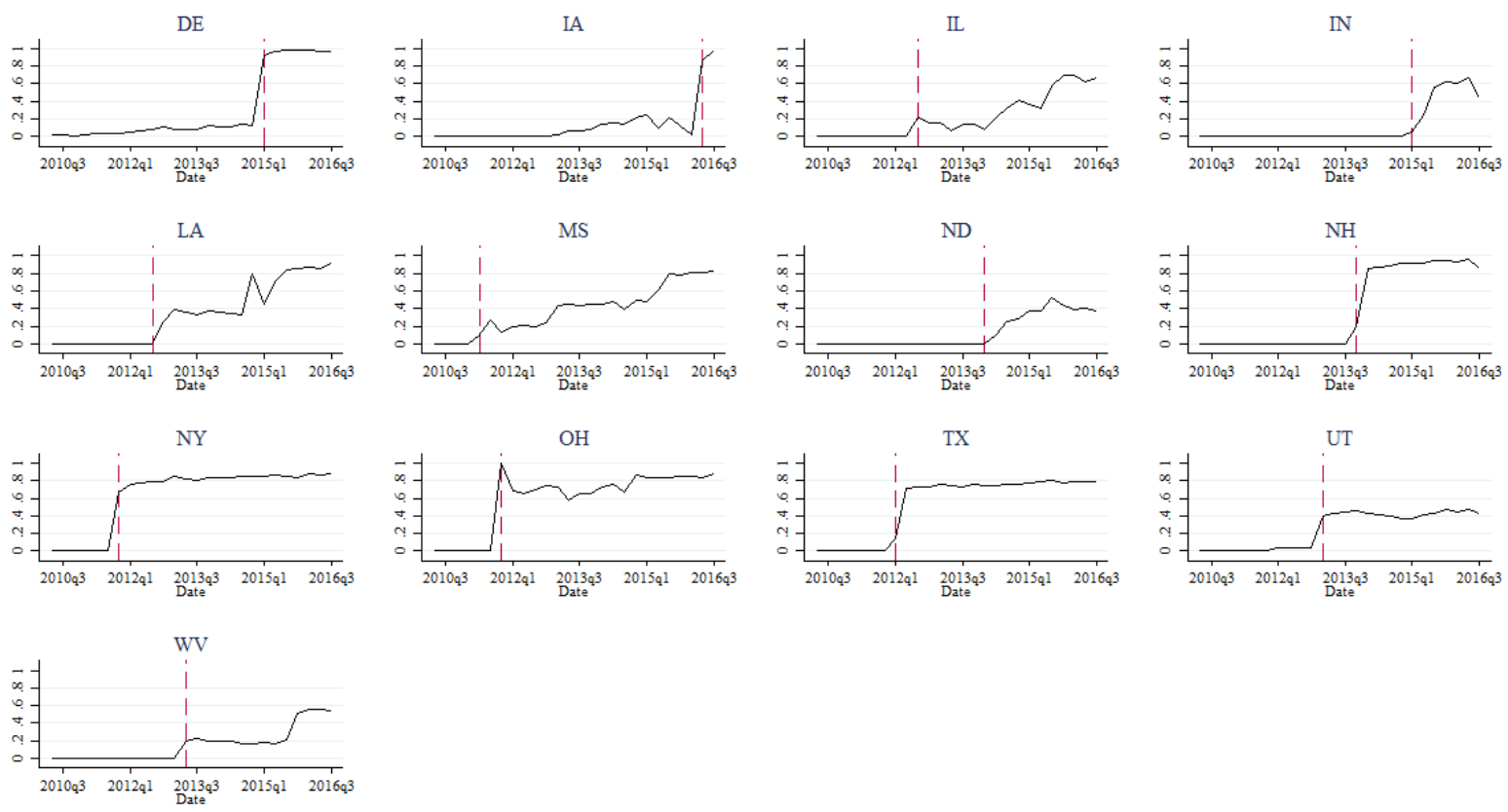

Notes: For each state, the dashed red line indicates the date upon which we record the state as beginning to privatize their prescription drug benefit. The y-axis shows the share of drug spending by MCOs.

Figure 1 plots the share of drug spending by MCOs in each of our 13 treatment states over time; the vertical dashed line denotes the privatization date. For most states, there is a relatively sharp break in the share of prescriptions to an MCO at the time of privatization. ${ }^{2526}$ Figure 2 confirms the presence of a break by

\footnotetext{
${ }^{25}$ All of these dates were confirmed by comparison to external news sources. The only date that we were unable to confirm perfectly is for the state of Illinois, which began privatizing some drug benefits for some elderly enrollees in May 2011. These enrollees are likely to be Medicare-Medicaid dual-eligible and therefore excluded from the Medicaid State Drug Utilization Data. Therefore, we instead use the third quarter of 2012, the first period for which there is private spending in our data for Illinois, as the privatization date for Illinois.

${ }^{26}$ Figure A.8 illustrates that few prescriptions are reimbursed by MCOs in control states, and that the increase in the share of prescriptions to an MCO increased much more gradually among the states that already privatized some drug benefits prior to the ACA.
} 
plotting the coefficients on lags and leads of the privatization decision using the dependent variable MCO share of prescriptions. In the first quarter after privatization begins, the share of prescriptions covered by MCOs jumps to 50 percent and reaches 70 percent within two years. ${ }^{27}$ The clear break from the flat pre-trend suggests that the DID estimates will capture a relatively stark increase in the use of MCOs. ${ }^{28}$

Panel A of Table 3 presents estimates of a regression in which we collapse the lags and leads into a prepost indicator variable. The pooled coefficient of 0.607 in column (1) indicates that the share of prescriptions written by MCOs in the privatization states rose by 60.7 percentage points. The IV estimates of the effect of MCO drug benefit provision on our outcomes of interest will effectively re-scale the reduced form DID estimates by these first stage estimates (by approximately $1 / .607=1.65$ ). In column (2) we include pre-post indicators for states that expanded Medicaid, using the appropriate timing for each state, to control for any changes in the composition of enrollees. The coefficient on Medicaid expansion is close to zero, and the coefficient on the privatization indicator is unchanged and still highly significant.

Figure 2: Lags and leads of relationship between privatization and $\mathrm{MCO}$ penetration

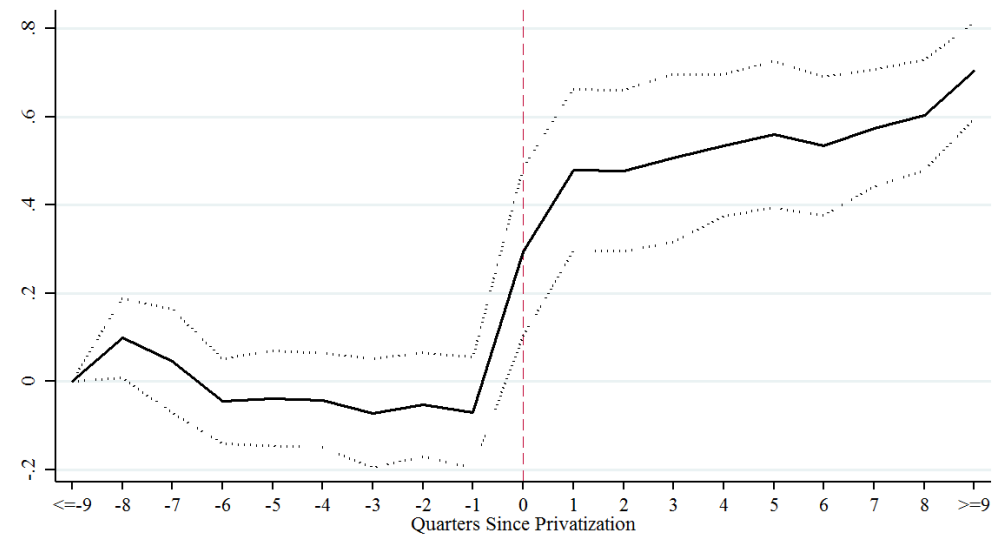

Notes: Specification is limited to treatment states that privatize pharmacy benefits and control states with no MCO pharmacy benefits. Includes state fixed effects, quarter fixed effects, and an indicator for whether the state has expanded Medicaid under the ACA. Observations are weighted by state Medicaid drug spending in the second quarter of 2010.

Point estimates for the effect of quarter pre-post privatization are presented in the dark line, and a 95 percent confidence interval for those coefficients, based upon standard errors that are clustered by state, is presented with the dotted lines.

\footnotetext{
${ }^{27}$ The estimated coefficients are all near zero prior to privatization. Note that the coefficient is not identically zero for two reasons. First, even if the MCO share of prescriptions was identically zero in the pre-period, the coefficient would not be zero because of a general time trend towards greater privatization. Second, states such as Delaware, Utah, and Iowa had very limited experiences with privatized pharmacy benefits prior to the broader adoption decision that we study.

${ }^{28}$ The existence of some pre-privatization spending by MCOs and some post-privatization spending by the state is evidence that our binary privatization decision abstracts from the nuances of state programs. Within most states, whether enrollees are enrolled in managed care and plan features (and whether enrollment in specific plans is voluntary or mandatory) can vary by geography and by reason for Medicaid eligibility.
} 


\subsection{Impact on Drug Use}

\subsubsection{Impact on drug consumption}

We first explore the effect of privatization on drug consumption, as measured by prescriptions per enrollee.

Figure 3 shows that drug consumption is basically unchanged in the post-period. Therefore, any cost savings must come for lower prices per prescription.

Figure 3: Lags and leads of relationship between privatization and logged

Prescriptions per enrollee-quarter

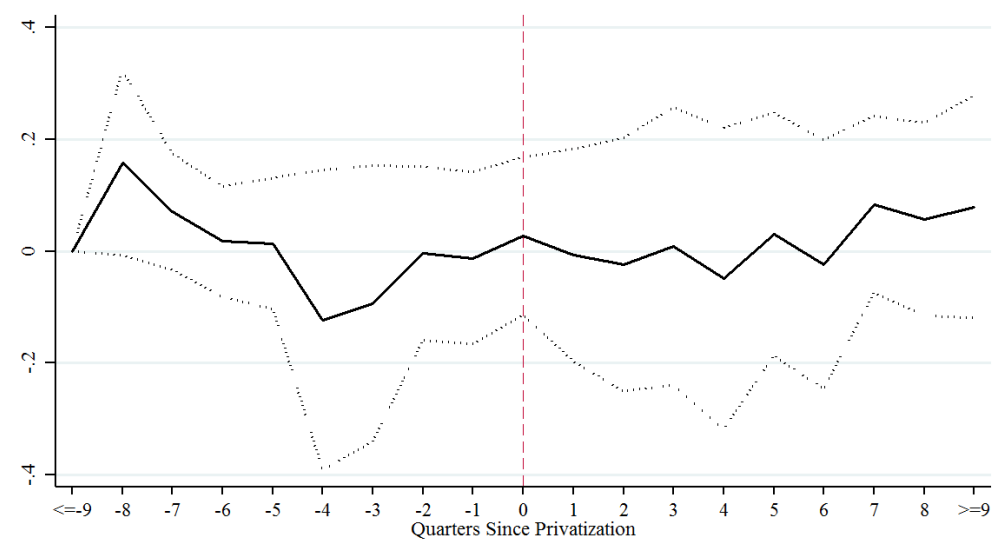

Notes: Specification is limited to treatment states that privatize pharmacy benefits and control states with no MCO pharmacy benefits. Includes state fixed effects, quarter fixed effects, and an indicator for whether the state has expanded Medicaid under the ACA. Observations are weighted by state Medicaid drug spending in the second quarter of 2010.

Point estimates for the effect of quarter pre-post privatization are presented in the dark line, and a 95 percent confidence interval for those coefficients, based upon standard errors that are clustered by state, is presented with the dotted lines.

In Figure 4, we see that the average price per prescription is flat before privatization and falls immediately following privatization. This reduction in average price could be due to lower prices for the same drugs or a shift towards less expensive drugs, or both. We will explore both mechanisms in order to decompose our results and understand the mechanisms that drive them.

\subsubsection{Impact on drug spending per enrollee}

We next present the net effect of flat drug consumption and lower drug prices on overall drug spending per enrollee. Figure 5 plots the coefficients on lags and leads of the privatization decision on the log of spending per enrollee. Spending per enrollee (in logs) fluctuates prior to privatization, but then noticeably drops following privatization. We pool the data and present regression results in Table 3. Column (1) in Panel B of Table 3 shows the reduced form estimate of the effect of privatization on logged spending, where the 
Figure 4: Lags and leads of relationship between privatization and logged price per prescription

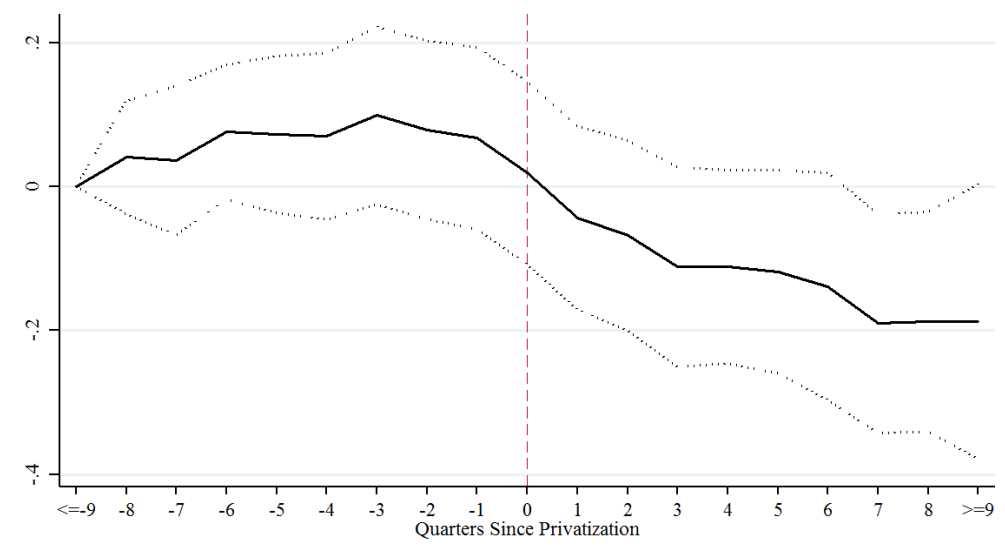

Notes: Specification is limited to treatment states that privatize pharmacy benefits and control states with no MCO pharmacy benefits. Includes state fixed effects, quarter fixed effects, and an indicator for whether the state has expanded Medicaid under the ACA. Observations are weighted by state Medicaid drug spending in the second quarter of 2010. Point estimates for the effect of quarter pre-post privatization are presented in the dark line, and a 95 percent confidence interval for those coefficients, based upon standard errors that are clustered by state, is presented with the dotted lines.

predictor variable is the privatization indicator variable, priv. Column (2) presents the IV estimate, while Columns (3) and (4) include a post-Medicaid expansion dummy as a robustness check. The estimate in our preferred specification, column (4), suggests that administering the pharmacy benefits of all Medicaid enrollees through MCOs would reduce drug spending by 22.4 percent. ${ }^{29}$

Echoing the graphical presentation above, we decompose the effect by measuring the impact of privatization on prices and quantities. Panels C, D, and E of Table 3 are structured identically to Panel B, except that the dependent variables are prescriptions per enrollee, price per prescription, and utilization per enrollee, respectively. ${ }^{30}$ Focusing on the results in column (4), Panels C and D further illustrate that the decrease in spending per enrollee is driven by a shift toward lower priced prescriptions, rather than by a decrease in the number of prescriptions per enrollee. The price per prescription decreases by a statistically significant 28 percent, more than offsetting a statistically insignificant 7.9 percent increase in the number of prescriptions per enrollee. The point estimate in Panel E implies that privatization reduces utilization per enrollee by 15.3 percent but is statistically indistinguishable from zero. We further explore the effect of privatization on point-of-sale prices in Section 4.3. Utilization per enrollee measures what spending would have been if prescriptions were re-priced to national averages: the effect of privatization on utilization per

\footnotetext{
${ }^{29}$ If the coefficient estimate in the regression is $\beta$ and the dependent variable is logged, then the administering the pharmacy benefits of all Medicaid enrollees through MCOs has a $100 \times\left(e^{\beta}-1\right)$ percent effect.

${ }^{30}$ The effect of lags and leads of the privatization decision on these variables is presented in Figure A.9.
} 
Table 3: Reduced Form and IV relationship between MCOs and per enrollee spending

\begin{tabular}{|c|c|c|c|c|}
\hline \multicolumn{5}{|c|}{ Panel A: Dep var = Share $M C O$} \\
\hline & \multicolumn{2}{|l|}{ (1) } & \multicolumn{2}{|c|}{ (2) } \\
\hline Priv & \multicolumn{2}{|c|}{0.607} & \multicolumn{2}{|c|}{0.596} \\
\hline & \multicolumn{2}{|c|}{$[0.0757]^{* * *}$} & \multicolumn{2}{|c|}{$[0.0743]^{* * *}$} \\
\hline \multirow[t]{2}{*}{ Medicaid expansion } & & & 0.03 & \\
\hline & & & {$[0.03$} & \\
\hline R-sq & 0.934 & & 0.93 & \\
\hline Kleibergen-Paap rk Wald F statistic & 36.68 & & 37.1 & \\
\hline Share $M C O$ mean & \multicolumn{4}{|c|}{$0.148(0.28)$} \\
\hline $\mathrm{N}$ & \multicolumn{2}{|l|}{741} & \multicolumn{2}{|c|}{741} \\
\hline \multicolumn{5}{|c|}{ Panel B: Dep var $=\ln ($ Spending per enrollee quarter $)$} \\
\hline & $\begin{array}{l}\text { Reduced Form } \\
\text { (1) }\end{array}$ & $\begin{array}{l}\text { IV } \\
\text { (2) }\end{array}$ & $\begin{array}{l}\text { Reduced Form } \\
\text { (3) }\end{array}$ & $\begin{array}{l}\text { IV } \\
\text { (4) }\end{array}$ \\
\hline Priv & $\begin{array}{c}-0.135 \\
{[0.0524] * *}\end{array}$ & & $\begin{array}{c}-0.151 \\
{[0.0658]^{* *}}\end{array}$ & \\
\hline Share $\mathrm{MCO}$ & & $\begin{array}{c}-0.222 \\
{[0.0896]^{* *}}\end{array}$ & & $\begin{array}{c}-0.253 \\
{[0.116]^{* *}}\end{array}$ \\
\hline Medicaid expansion & & & $\begin{array}{c}0.0551 \\
{[0.0564]}\end{array}$ & $\begin{array}{c}0.0646 \\
{[0.0637]}\end{array}$ \\
\hline R-sq & 0.801 & 0.792 & 0.803 & 0.793 \\
\hline Spending per enrollee mean & & 221.7 & $(75.62)$ & \\
\hline
\end{tabular}

\begin{tabular}{|c|c|c|c|c|}
\hline \multicolumn{5}{|c|}{ Panel C: Dep var $=\ln ($ Prescriptions per enrollee quarter $)$} \\
\hline \multirow[t]{2}{*}{ Priv } & 0.0708 & & 0.0452 & \\
\hline & [0.0411]* & & {$[0.0456]$} & \\
\hline \multirow[t]{2}{*}{ Share $M C O$} & & 0.117 & & 0.0759 \\
\hline & & {$[0.0582]^{*}$} & & {$[0.0704]$} \\
\hline \multirow[t]{2}{*}{ Medicaid expansion } & & & 0.0871 & 0.0842 \\
\hline & & & {$[0.0410]^{* *}$} & {$[0.0404]^{* *}$} \\
\hline R-sq & 0.767 & 0.778 & 0.773 & 0.781 \\
\hline \multicolumn{2}{|l|}{ Prescriptions per enrollee mean } & \multicolumn{2}{|c|}{$2.92(0.86)$} & \\
\hline \multicolumn{5}{|c|}{ Panel D: Dep var $=\ln ($ Average price per prescription $)$} \\
\hline \multirow[t]{2}{*}{ Priv } & -0.206 & & -0.196 & \\
\hline & {$[0.0470]^{* * *}$} & & {$[0.0500]^{* * *}$} & \\
\hline \multirow[t]{2}{*}{ Share $M C O$} & & -0.339 & & -0.329 \\
\hline & & {$[0.0584]^{* * *}$} & & {$[0.0693]^{* * *}$} \\
\hline \multirow[t]{2}{*}{ Medicaid expansion } & & & -0.0330 & -0.0207 \\
\hline & & & {$[0.0336]$} & {$[0.0361]$} \\
\hline R-sq & 0.819 & 0.848 & 0.821 & 0.849 \\
\hline \multicolumn{2}{|l|}{ Price per prescription mean } & \multicolumn{2}{|c|}{$76.76(18.9)$} & \\
\hline \multicolumn{5}{|c|}{ Panel E: Dep var $=\ln ($ Utilization per enrollee quarter $)$} \\
\hline \multirow[t]{2}{*}{ Priv } & -0.0830 & & -0.0988 & \\
\hline & {$[0.0540]$} & & {$[0.0680]$} & \\
\hline \multirow[t]{2}{*}{ Share $M C O$} & & -0.137 & & -0.166 \\
\hline & & {$[0.0920]$} & & [0.119] \\
\hline \multirow[t]{2}{*}{ Medicaid expansion } & & & 0.0537 & 0.0599 \\
\hline & & & {$[0.0560]$} & {$[0.0625]$} \\
\hline R-sq & 0.819 & 0.812 & 0.821 & 0.812 \\
\hline \multicolumn{2}{|l|}{ Utilization per enrollee mean } & \multicolumn{2}{|c|}{$223.23(72.89)$} & \\
\hline $\mathrm{N}$ & 741 & 741 & 741 & 741 \\
\hline
\end{tabular}

Notes: Specification is limited to treatment states that privatize pharmacy benefits and control states with no MCO pharmacy benefits. Unreported controls include state fixed effects and quarter fixed effects. The transition quarter in which a state privatizes is omitted. Observations are weighted by state Medicaid drug spending in the second quarter of 2010. Standard errors are clustered by state. Significance levels: $* 0.10 * * 0.05 * * * .01$ 
Figure 5: Lags and leads of relationship between privatization and logged quarterly spending per enrollee

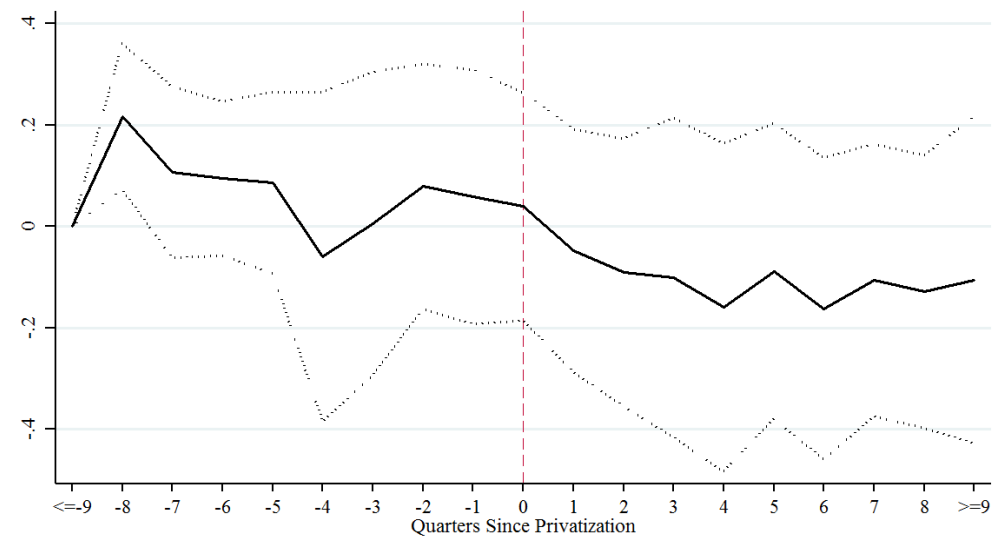

Notes: Specification is limited to treatment states that privatize pharmacy benefits and control states with no MCO pharmacy benefits. Includes state fixed effects, quarter fixed effects, and an indicator for whether the state has expanded Medicaid under the ACA. Observations are weighted by state Medicaid drug spending in the second quarter of 2010. Point estimates for the effect of quarter pre-post privatization are presented in the dark line, and a 95 percent confidence interval for those coefficients, based upon standard errors that are clustered by state, is presented with the dotted lines.

enrollee is about two thirds of the effect on spending per enrollee, suggesting that roughly 33 percent of the decrease in spending is due to price changes. ${ }^{31}$

\subsubsection{Impact on generic penetration}

Figure 6 highlights one potential driver of the decline in point-of-sale prices: substitution from branded to generic drugs. We plot the coefficients on lags and leads of the privatization decision on generic penetration. After a temporary bump in generic penetration about six quarters prior to privatization, generic penetration remains flat for the next six quarters. Generic penetration begins to increase at the time of privatization and rises steadily thereafter; two years after privatization, generic penetration has risen by roughly 5 percentage points. Panel A of Table 4 presents pooled difference-in-differences and corresponding instrumental variable estimates. The estimates in column (4) show that MCOs cause generic penetration to increase by 7.76 percentage points: an 11.7 percent increase on a base of 66 percent.

There are two distinct mechanisms through which MCOs can increase generic penetration: withinmolecule and across-molecule substitution. MCOs may provide both physicians and pharmacies with in-

\footnotetext{
${ }^{31}$ The later analysis will study the effect on prices directly and find a similar magnitude estimated with a relatively high level of precision. For simplicity in exposition, we treat both the 15.3 percent decrease and the 7.1 percent decrease as if they are precisely estimated, with the understanding that there is of course uncertainty about the actual effect of each driver of spending.
} 
Figure 6: Lags and leads of relationship between privatization and generic penetration

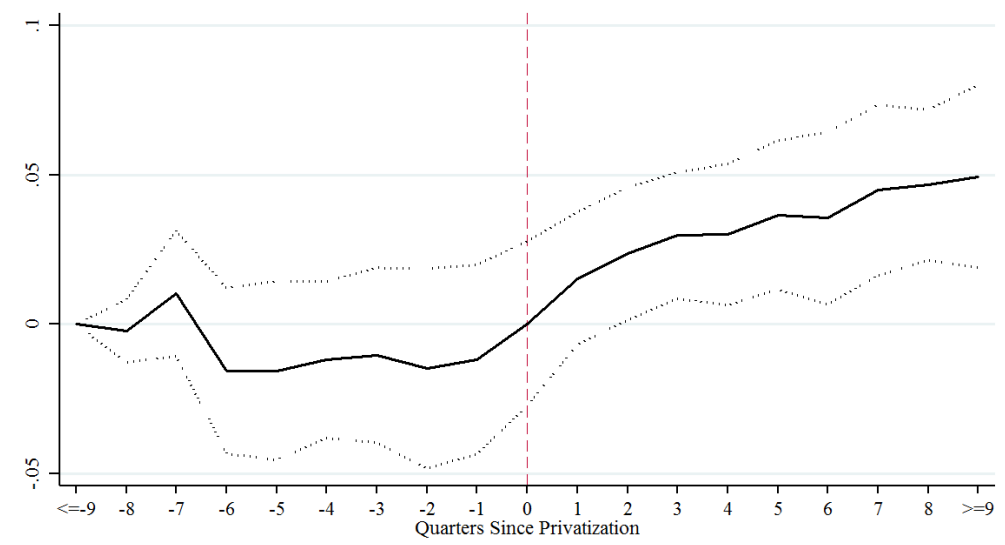

Notes: Specification is limited to treatment states that privatize pharmacy benefits and control states with no MCO pharmacy benefits. Includes state fixed effects, quarter fixed effects, and an indicator for whether the state has expanded Medicaid under the ACA. Observations are weighted by state Medicaid drug spending in the second quarter of 2010. Point estimates for the effect of quarter pre-post privatization are presented in the dark line, and a 95 percent confidence interval for those coefficients, based upon standard errors that are clustered by state, is presented with the dotted lines.

centives to prescribe more generics. Physicians may respond directly by prescribing more generics (both within and across molecules). Pharmacists cannot normally switch prescriptions from one molecule to another without the physician's consent, but they can often unilaterally substitute a bio-equivalent generic version in place of the branded drug. Many pharmacies have software that flags costly branded drugs, and pharmacists may contact physicians to request generics.

Panel B of Table 4 presents estimates from a model with generic efficiency (share of generic prescriptions when a generic is available) as the dependent variable, while Panel $\mathrm{C}$ of Table 4 presents estimates from a model with generic accessibility (share of prescriptions that are for drugs for which a generic is available) as the dependent variable. ${ }^{32}$ The coefficients in column (4) for generic efficiency and generic accessibility are both statistically significant, meaning that both within- and across-molecule substitution contribute to the increase in generic penetration. The coefficient on generic accessibility is 0.0526 , meaning prescriptions filled for molecules for which no generic is available fell by 5.26 percentage points, or 29 percent (on a pre privatization mean of 18.6 percent). We also estimate a 4.18 percentage point increase in the share of prescriptions that are generic among molecules for which a generic is available. Our results imply that roughly two thirds of the increase in generic penetration results from across-molecule shifts and roughly one third is a result of within-molecule shifts from branded to generic. ${ }^{33}$

\footnotetext{
${ }^{32}$ In the interests of space, the reduced form relationships for these two variables are presented in Figure A.10 and Figure A.11.

${ }^{33}$ Our estimates imply that the share of prescriptions that are for branded drugs with no generic equivalent available decreased
} 
Table 4: Effect of MCOs on generic penetration

\begin{tabular}{|c|c|c|c|c|}
\hline \multicolumn{5}{|c|}{ Panel A: Dep var = Generic penetration } \\
\hline & $\begin{array}{l}\text { Reduced Form } \\
\text { (1) }\end{array}$ & $\begin{array}{l}\text { IV } \\
(2)\end{array}$ & $\begin{array}{l}\text { Reduced Form } \\
\text { (3) }\end{array}$ & $\begin{array}{l}\text { IV } \\
\text { (4) }\end{array}$ \\
\hline Priv & $\begin{array}{c}0.0531 \\
{[0.0191]^{* * *}}\end{array}$ & & $\begin{array}{c}0.0463 \\
{[0.0168]^{* *}}\end{array}$ & \\
\hline Share $M C O$ & & $\begin{array}{c}0.0874 \\
{[0.0260]^{* * *}}\end{array}$ & & $\begin{array}{c}0.0776 \\
{[0.0246]^{* * *}}\end{array}$ \\
\hline Medicaid expansion & & & $\begin{array}{c}0.0232 \\
{[0.0102]^{* *}}\end{array}$ & $\begin{array}{c}0.0203 \\
{[0.00990]^{* *}}\end{array}$ \\
\hline R-sq & 0.893 & 0.907 & 0.903 & 0.914 \\
\hline Generic penetration mean & & 0.733 & $0.046)$ & \\
\hline
\end{tabular}

Panel B: Dep var = Generic efficiency

\begin{tabular}{|c|c|c|c|c|}
\hline Priv & $\begin{array}{c}0.0309 \\
{[0.0106]^{* * * *}}\end{array}$ & & $\begin{array}{c}0.0249 \\
{[0.0101]^{* *}}\end{array}$ & \\
\hline Share $M C O$ & & $\begin{array}{c}0.0508 \\
{[0.0154]^{* * *}}\end{array}$ & & $\begin{array}{c}0.0418 \\
{[0.0160]^{* *}}\end{array}$ \\
\hline Medicaid expansion & & & $\begin{array}{c}0.0202 \\
{[0.00703]^{* * *}}\end{array}$ & $\begin{array}{c}0.0187 \\
{[0.00760]^{* *}}\end{array}$ \\
\hline R-sq & 0.825 & 0.838 & 0.851 & 0.861 \\
\hline Generic efficiency mean & \multicolumn{4}{|c|}{$0.823(0.026)$} \\
\hline
\end{tabular}

Panel C: Dep var $=$ Generic accessibility

\begin{tabular}{|c|c|c|c|c|}
\hline Priv & $\begin{array}{c}0.0333 \\
{[0.0143]^{* *}}\end{array}$ & & $\begin{array}{c}0.0314 \\
{[0.0120]^{* *}}\end{array}$ & \\
\hline Share $M C O$ & & $\begin{array}{c}0.0548 \\
{[0.0191]^{* * *}}\end{array}$ & & $\begin{array}{c}0.0526 \\
{[0.0165]^{* * *}}\end{array}$ \\
\hline Medicaid expansion & & & $\begin{array}{c}0.00641 \\
{[0.00826]}\end{array}$ & $\begin{array}{c}0.00444 \\
{[0.00732]}\end{array}$ \\
\hline R-sq & 0.892 & 0.906 & 0.894 & 0.907 \\
\hline Generic accessibility mean & \multicolumn{4}{|c|}{$0.889(0.035)$} \\
\hline $\mathrm{N}$ & 741 & 741 & 741 & 741 \\
\hline
\end{tabular}

Notes: Specification is limited to treatment states that privatize pharmacy benefits and control states with no MCO pharmacy benefits. Unreported controls include state fixed effects and quarter fixed effects. The transition quarter in which a state privatizes is omitted. Observations are weighted by state Medicaid drug spending in the second quarter of 2010. Standard errors are clustered by state. Significance levels: * $0.10 * * 0.05 * * * .01$ 
We performed a back of the envelope calculation, which suggests that increased use of generic and generic accessible drugs decrease drug spending by 8.9 percent. ${ }^{34}$ We calculate a 7.5 percent decrease in drug spending from reduced use of branded drugs for which no generic is available, a 3.6 percent decrease from eliminating prescriptions for branded drugs for which generic drugs are available, and a 2.2 percent increase from replacing all of these prescriptions with prescriptions for generics. We conclude that much of the remaining decrease in spending (not attributable to lower point-of-sale prices) can be explained by increased use of generics. ${ }^{35}$

The generic accessibility result could be driven by patent expiration, rather than molecular substitution: differences across states in the types of drugs used by Medicaid patients combined with patent expiration could lead to changes in generic accessibility. We rule out this concern directly by creating a simulated generic accessibility measure that calculates how generic accessibility would have changed over time (as a result of patent expiration) if drug utilization patterns had remained fixed at the second quarter of 2010 levels. Figure A.12 presents the relationship between that measure and lags and leads of the privatization decision. There is no break from trend in this variable at the time of privatization.

\subsubsection{Impact on use of high offset drugs}

MCOs reduce drug utilization; however, if this reduction is attributable to high-value drugs that offset other spending, overall medical costs could increase. We examine the effect of privatization on consumption of high offset drugs in Figure 7, which plots the coefficients on lags and leads of the privatization decision on the variable share high offset. There is an immediate jump of roughly 3 percent in the share of spending for high offset drugs post-privatization. ${ }^{36}$ In Panel C of Table 5, we present pooled versions of this analysis;

by 5.26 percentage points. The share of prescriptions that are for generics increased by 7.76 percentage points. It therefore follows that the share of prescriptions that are for branded drugs for which a generic is available increased by 2.50 percentage points.

${ }^{34}$ This back-of-the-envelope calculation is described in Table A.9. The calculation assumes that shifts in demand are for average priced drugs within three groups of drugs: (i) branded drugs with no generic equivalents, (ii) branded drugs with a generic equivalent, and (iii) generic drugs. Increased use of generics has such a large effect on spending because of the very large price differentials between branded drugs and generic drugs. As a result, these numbers are relatively sensitive to assumptions about the prices of the branded drugs that are being shifted to generic. We therefore assume in our preferred calculation that all of the shifting from branded to generic drugs is away from branded drugs that are priced like branded drugs for which a generic is available.

${ }^{35}$ Within the same molecule, spending decreases from increased generic utilization are unlikely to have any potential adverse consequences, but also have only a limited impact on spending. While beyond the scope of our paper, a deeper investigation into the potential health consequences of cross-molecule substitution among Medicaid enrollees is an important direction for future public health research. Table A.29 presents an alternative decomposition of the ways in which MCOs decrease prices per prescription. It illustrates that while a number of channels contribute to the decrease, that the two more important are price decreases for identical 9 digit NDCs and across-molecule but within drug class substitution of branded drugs for generics.

${ }^{36}$ There is a marked increase in the share of spending that is high offset at least two years prior to privatization in states that eventually privatize their medical benefit. After that, states that privatize do not have a different trend in the share of spending that 
we find that MCOs cause the share of utilization for high offset drugs to increase by 5.26 percentage points. Prior to privatization of drug benefits, MCOs had incentives to promote the use of high offset drugs and would have been relatively indifferent about the use of low offset drugs. Privatization might enhance the MCO's ability to promote high offset drugs while discouraging use of low-value drugs. Panels A and B of Table 5 illustrate that there is no evidence of a change in the per enrollee utilization of high offset drugs after privatization. Instead, the result is driven by decreased utilization of all other drugs. ${ }^{37}$ Lower utilization - which holds prices constant - of non-high offset drugs decreased spending by roughly 13.4 percent. $^{38}$ Additional decompositions are available in Table A.10. ${ }^{39}$

We note that MCOs have particularly good incentives to keep enrollees using high offset drugs. In Table A.28 we also find more muted changes for drugs in Medicare's six protected drug classes. This provides some additional evidence to assuage concerns that MCOs may not be providing sufficient coverage of drugs deemed to be clinically valuable. ${ }^{40}$

\subsection{Point-of-sale Drug Prices}

State Medicaid programs reimburse pharmacies based on a measure of acquisition cost, while MCOs can negotiate different point-of-sale prices with pharmacies. In this section, we estimate the effect of privatization on drug pricing to explore the extent to which MCOs pay lower prices for identical drugs. We construct a price per prescription for each NDC 9 code-state-quarter. The point-of-sale price measures the actual reimbursements made to pharmacies, but does not fully capture payer costs or drug manufacturer revenues because they do not account for rebates.

For NDC $d$ in state $s$ in quarter $t$, let $Y_{d s t}$ be the logged price per prescription. Let $\alpha_{d s}$ be an NDC9-statespecific fixed effect, $\tau_{d t}$ be an NDC9-quarter fixed effect, priv $v_{s t}$ be an indicator for whether a state has begun to privatize its Medicaid drug benefit, and $\exp _{s t}$ be an indicator for whether the state expanded Medicaid as a result of the ACA. Our estimating equation is given by:

is for high offset drugs up until privatization occurs.

${ }^{37}$ In the interest of space, we relegate the figures with the effect of lags and leads of the adoption decision on these utilization variables to Figure A.13 and Figure A.14.

${ }^{38}$ Privatization decreases utilization for non-high offset drugs by 22.7 percent. Non-high offset drugs are roughly 60 percent of spending, suggesting that the lower utilization on non-high offset drugs lowers overall spending by roughly 13.4 percent. Utilization of high offset drugs does not decrease, meaning lower prices for identical drugs decreased spending by the remaining 8 percent.

${ }^{39}$ The results are also presented graphically in Figure A.15 and Figure A.16.

${ }^{40}$ In unreported results, there is evidence of substitution towards generics and therefore spending decreases for three of the six protected classes (antidepressants, antipsychotics, and immunosuppressants). By contrast, there is no evidence of changes for the other three protected classes. Antidepressants, antipsychotics, and immunosuppressants have been flagged as the three protected classes for which protected status may no longer be appropriate. 
Table 5: Effect of MCOs on use of high offset drugs

\begin{tabular}{|c|c|c|c|c|}
\hline \multicolumn{5}{|c|}{ Panel A: Dep var $=\ln ($ Utilization per enrollee quarter, high offset drugs $)$} \\
\hline & $\begin{array}{l}\text { Reduced Form } \\
\text { (1) }\end{array}$ & $\begin{array}{l}\text { IV } \\
(2)\end{array}$ & $\begin{array}{l}\text { Reduced Form } \\
\text { (3) }\end{array}$ & $\begin{array}{l}\text { IV } \\
\text { (4) }\end{array}$ \\
\hline Priv & $\begin{array}{l}-0.0224 \\
{[0.0544]}\end{array}$ & & $\begin{array}{l}-0.0116 \\
{[0.0642]}\end{array}$ & \\
\hline Share $M C O$ & & $\begin{array}{l}-0.0369 \\
{[0.0905]}\end{array}$ & & $\begin{array}{c}-0.0195 \\
{[0.108]}\end{array}$ \\
\hline Medicaid expansion & & & $\begin{array}{l}-0.0368 \\
{[0.0542]}\end{array}$ & $\begin{array}{l}-0.0361 \\
{[0.0577]}\end{array}$ \\
\hline R-sq & 0.847 & 0.845 & 0.848 & 0.847 \\
\hline \multicolumn{5}{|c|}{ Panel B: Dep var $=\ln ($ Utilization per enrollee quarter, not high offset drugs) } \\
\hline Priv & $\begin{array}{c}-0.126 \\
{[0.0606]^{* *}}\end{array}$ & & $\begin{array}{c}-0.153 \\
{[0.0751]^{*}}\end{array}$ & \\
\hline Share $M C O$ & & $\begin{array}{c}-0.208 \\
{[0.102]^{* *}}\end{array}$ & & $\begin{array}{c}-0.257 \\
{[0.131]^{*}}\end{array}$ \\
\hline Medicaid expansion & & & $\begin{array}{c}0.0912 \\
{[0.0564]}\end{array}$ & $\begin{array}{c}0.101 \\
{[0.0647]}\end{array}$ \\
\hline R-sq & 0.820 & 0.810 & 0.825 & 0.812 \\
\hline \multicolumn{5}{|c|}{ Panel C: Dep var = Share of spending on high offset drugs } \\
\hline Priv & $\begin{array}{c}0.0237 \\
{[0.00676]^{* * *}}\end{array}$ & & $\begin{array}{c}0.0314 \\
{[0.00657]^{* * *}}\end{array}$ & \\
\hline Share $\mathrm{MCO}$ & & $\begin{array}{c}0.0391 \\
{[0.00869]^{* * *}}\end{array}$ & & $\begin{array}{c}0.0526 \\
{[0.00823]^{* * *}}\end{array}$ \\
\hline Medicaid expansion & & & $\begin{array}{c}-0.0261 \\
{[0.00408]^{* * *}}\end{array}$ & $\begin{array}{c}-0.0281 \\
{[0.00444]^{* * *}}\end{array}$ \\
\hline R-sq & 0.936 & 0.939 & 0.950 & 0.954 \\
\hline $\mathrm{N}$ & 741 & 741 & 741 & 741 \\
\hline
\end{tabular}

Notes: Specification is limited to treatment states that privatize pharmacy benefits and control states with no MCO pharmacy benefits. Unreported controls include state fixed effects and quarter fixed effects. The transition quarter in which a state privatizes is omitted. Observations are weighted by state Medicaid drug spending in the second quarter of 2010. Standard errors are clustered by state. Significance levels: $* 0.10 * * 0.05 * * * .01$ 
Figure 7: Reduced form effect of privatization on the share of utilization on high offset drugs

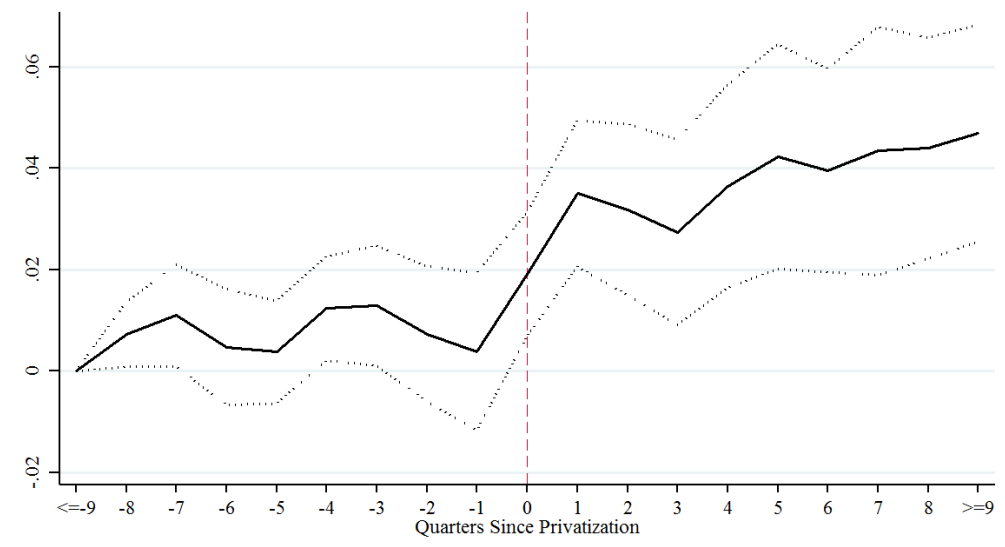

Notes: Specification is limited to treatment states that privatize pharmacy benefits and control states with no MCO pharmacy benefits. Includes state fixed effects, quarter fixed effects, and an indicator for whether the state has expanded Medicaid under the ACA. Observations are weighted by state Medicaid drug spending in the second quarter of 2010. Point estimates for the effect of quarter pre-post privatization are presented in the dark line, and a 95 percent confidence interval for those coefficients, based upon standard errors that are clustered by state, is presented with the dotted lines.

$$
Y_{d s t}=\alpha_{d s}+\tau_{d t}+\beta \operatorname{priv}_{s t}+\lambda \exp _{s t}+\varepsilon_{d s t}
$$

The inclusion of drug and time fixed effects implies that we are controlling for pricing differentials at a very granular level. ${ }^{41}$

Figure 8 presents leads and lags showing the movement of prices before and after privatization: prices are relatively flat until privatization and then drop by 5.4 percent after privatization, consistent with our previous results. Analogous regressions are presented in Table 6; the IV regression indicates that full provision of drug benefits by MCOs would decrease point-of-sale prices paid by 8.9 percent. ${ }^{42}$ Consistent with previous results, these estimates imply that roughly 40 percent of the overall decrease in spending per enrollee could be driven by lower reimbursements to pharmacies. Since we lack drug-specific rebate data, these results represent a lower bound on the potential savings by private firms. In addition, we observe realized prices, rather than price schedules: we cannot account for any variation across consumers or pharmacies in the price for a specific NDC code. In Section A.1, we break prices into two components - Medicaid's per prescription reimbursement to pharmacies and enrollee coinsurance - and examine heterogeneity in point-

\footnotetext{
${ }^{41}$ We also estimate versions with lags and leads of the decision to privatize, so as to check for pre-trends.

${ }^{42}$ This is similar but not identical to the 7.1 percent decrease in spending from price changes in Section 4.2.2. Factors such as differences in weighting, the level of aggregation, and the controls included likely contribute to the (small) difference.
} 
of-sale price changes across different kinds of drugs. We find that price decreases are driven by lower prices to pharmacies, while consumer cost sharing remains similar. Furthermore, we find that pharmacy reimbursements from Medicaid are decreasing substantially for drugs that are neither generics nor high offset, while reimbursements for generics remain similar. ${ }^{43}$

Figure 8: Lags and leads of relationship between privatization and logged price per prescription

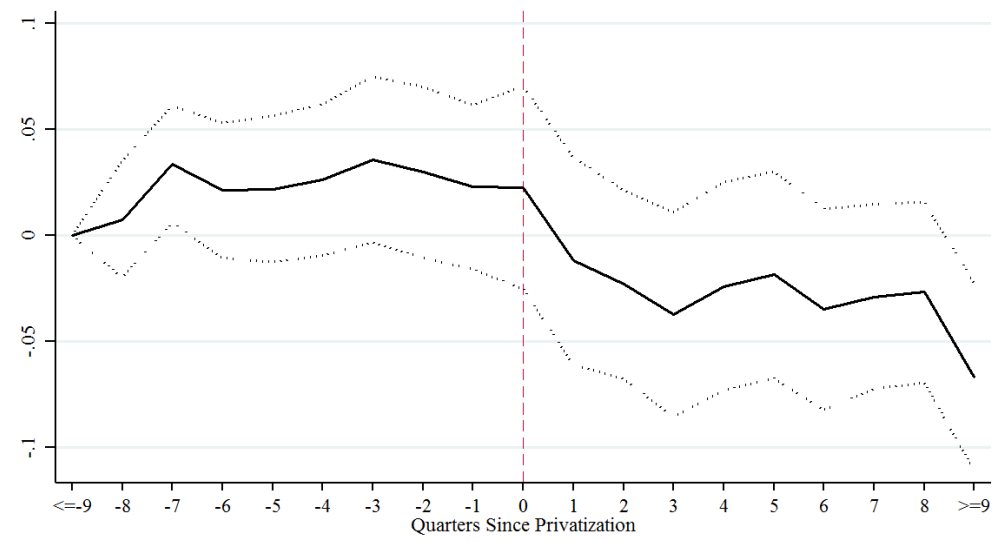

Notes: Specification is limited to treatment states that privatize pharmacy benefits and control states with no MCO pharmacy benefits. Unit of observation is the NDC9-state-quarter. Includes NDC9-state fixed effects, NDC9-quarter fixed effects, and an indicator for whether the state has expanded Medicaid under the ACA. Observations are weighted by drug spending for each NDC9-state combination in the first quarter in which it appears in the data. Point estimates for the effect of quarter pre-post privatization are presented in the dark line, and a 95 percent confidence interval for those coefficients, based upon standard errors that are clustered by state, is presented with the dotted lines.

Table 6: Effect of MCOs on privatization and logged Pharmacy prices

\begin{tabular}{lcccc}
\hline & Reduced Form & IV & Reduced Form & IV \\
& $(1)$ & $(2)$ & $(3)$ & $(4)$ \\
\hline Priv & -0.0532 & & -0.0555 \\
& {$[0.0141]^{* * *}$} & & {$[0.0140]^{* * *}$} & \\
Share MCO & & -0.0879 & & -0.0929 \\
& & {$[0.0286]^{* * *}$} & & {$[0.0317]^{* * *}$} \\
Medicaid expansion & & & 0.00886 & 0.0120 \\
& & & {$[0.0132]$} & {$[0.0177]$} \\
R-sq & 0.992 & 0.992 & 0.992 & 0.992 \\
\hline $\mathrm{N}$ & 3220610 & 3220610 & 3220610 & 3220610 \\
\hline
\end{tabular}

Notes: Specification is limited to treatment states that privatize pharmacy benefits and control states with no MCO pharmacy benefits. Unit of observation is the NDC9-state-quarter. Unreported controls includes NDC9-state fixed effects, and NDC9-quarter fixed effects. The transition quarter in which a state privatizes is omitted. Observations are weighted by drug spending for each NDC9-state combination in the first quarter in which it appears in the data. Standard errors are clustered by state. Significance levels: * $0.10 * * 0.05 * * * .01$

\footnotetext{
${ }^{43}$ The effect of privatization on the prices of non-generic drugs that are high offset is more mixed.
} 


\subsubsection{Rebates}

One potential concern with the analyses of point-of-sale drug prices is that the data do not capture drug rebates. Section A.2 examines whether privatization affect the drug rebates that states receive. Note that in our sample of states in 2010, roughly 92 percent of rebates were federally mandated, rather than any supplemental negotiated rebates. It is, therefore, perhaps unsurprising that we find no evidence that privatization affects rebates.

\subsection{Alternative hypotheses}

In this section, we explore two alternative hypotheses. First, MCOs may cream-skim profitable patients. Second, our results may be driven by an effort to reduce the deadweight loss associated with moral hazard, as in Einav et al. [2016].

Our results show that privatization leads to lower point-of-sale prices, to a shift in spending to high offset drugs, and to the increased use of generics. These changes are more naturally explained by attempts by private firms to control spending rather than by attempts to cream-skim. In addition, we do not find evidence that the pattern in our results is systematically stronger in those states that do not risk adjust Medicaid payments based upon enrollee health, or that the results are systematically different in markets that include some of the largest Medicaid MCOs. ${ }^{44}$ We conclude that cream-skimming is unlikely to explain our pattern of results.

Private MCOs may be better equipped to reduce the deadweight loss associated with moral hazard. In Section A.5, we explore additional heterogeneity in our effect across drugs. This analysis, which uses elasticities estimated in Einav et al. [2016], does not find evidence that decreased utilization is concentrated among drugs that are more price elastic. We also examine whether cost sharing increases more for more price elastic drugs. Consistent with the very limited cost sharing that is allowed in Medicaid, we find no evidence to suggest that MCOs increase coinsurance on drugs for which demand is more price elastic. We conclude that the mechanisms underlying our results and previous studies exploring demand-side cost-sharing are likely different.

\footnotetext{
${ }^{44}$ These results are presented in Table A.12. In unreported regressions, we also find that the results are qualitatively similar across markets with greater degrees of insurer concentration, as measured by HHIs of Part D carriers.
} 


\section{Robustness and Extensions}

\subsection{Heterogeneity}

In this section, we examine three potential sources of heterogeneity in the effect of privatization. First, we collect data from the Medicaid Drug Utilization Review (MDUR) to determining whether MCOs are required to use the state's formulary or whether the MCO has some leeway in creating its own formulary. ${ }^{45}$ If the formulary is an important tool for steering consumers, we anticipate larger effects in the states in which MCOs have some control over formularies. Second, we consider whether a state risk adjusts based upon enrollee health. ${ }^{46}$ Without perfect risk-adjustment, MCOs may have an incentive to under-provide coverage that will be particularly attractive for sick enrollees, which could in turn affect utilization. ${ }^{47}$ Finally, we separate treated states based on whether they privatized both the medical and prescription drug benefit at the same time. We replicate our central analysis, adding interactions between privatization and indicators for simultaneous MCO privatization, formulary requirements, and risk-adjustment. ${ }^{48}$ The results of these analyses are presented in Table 7. In Panel A, we interact the privatization dummy and the three indicators. In Panel B, we perform an IV specification in which we interact share $M C O$ and the three indicators. In the IV specifications, we instrument for the endogenous variables with interactions between priv and the three binary variables. We focus on results including all three categorizations in Table $7 .{ }^{49}{ }^{50}$ Column (1) of Panel A presents the effect of the privatization when interacted with the three categorizations on the share of drug spending by MCOs. ${ }^{51}$

\footnotetext{
${ }^{45}$ We follow the coding in the 2015 MDUR on whether MCOs had to adopt the state's Preferred Drug List (i.e., formulary) for all states except Iowa, which did not have a carved-in benefit at that time. We determined based on more recent information from the Kaiser Family Foundation that Iowa requires MCOs to follow the state formulary. MCOs that are not required to use a state's formulary may still face some oversight in how they design their formulary.

${ }^{46}$ We construct this based upon whether a state is listed as risk adjusting MCO payments based upon enrollee health status using responses in Gifford et al. [2011]. For the states that privatized medical benefits after 2010, we performed additional interest searches to determine whether they risk adjust based upon health. We found evidence that all of the states moving to Medicaid managed care since the publication of Gifford et al. [2011] are risk-adjusting based on health.

${ }^{47}$ We note that while this is an important concern for states, cream-skimming incentives are unlikely to affect utilization of generics or a shift toward use of higher offset drugs.

${ }^{48}$ Table A.13 presents each states categorization for each of the binary variables.

${ }^{49}$ The coefficients in these analyses remain similar when we add the three interactions one at a time, rather than all together. Doing so leads to a very large number of coefficients, so these specifications are presented in Tables A.14 - A.21.

${ }^{50}$ Given the very large number of coefficients in these analyses, we do not systematically present specifications that include lags and leads of the privatization decision. However, Figure A.17 presents lags and leads of the privatization decision separating states based on whether MCOs have flexibility in designing PDLs. These specifications confirm breaks in trend following privatization for states with this flexibility, but not for states that lack it.

${ }^{51}$ We relegate the first stages for the four endogenous variables to Table A.22. We can, however, draw the same insights from Table 7, panel A, column (1). In particular, privatization in the states that do not risk adjust based upon health led to a much smaller increase in the share of spending by MCOs (i.e., the point estimate is 0.28 rather than 0.68 ). Furthermore, because the coefficient on the interaction between privatization and not risk adjusting is very different from zero, the IV effect of priv $^{*} 1$ (no risk adj) in the first
} 


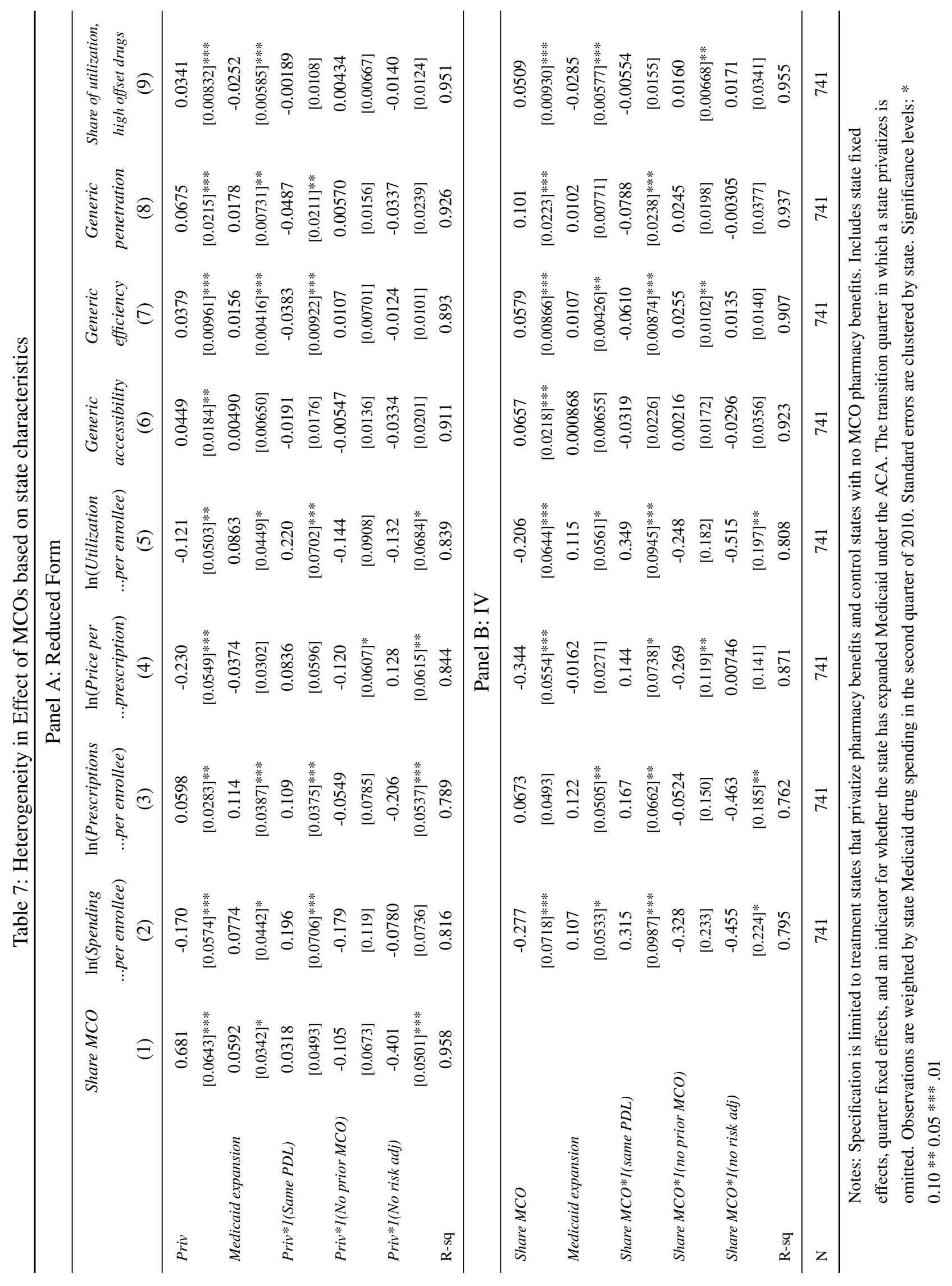


In Panel $\mathrm{B}$, the coefficient on share $M C O^{*} 1($ Same $P D L)$ often has the opposite sign of the effect of share MCO in many of the columns, implying that the privatization effect is stronger in states that allow their MCOs to design their own formularies. This suggests that MCO interactions with physicians, absent changes in formulary design, are not sufficient to drive the same reductions in spending. Column (2) reveals that the effect of MCOs on spending per enrollee is effectively zero in states in which MCOs cannot design their own formulary. Columns (3) and (4) show that point-of-sale pharmacy prices went down by less in places where MCOs must use the state's formulary. Columns (6) through (8) show that the shift towards generics is weaker in places where the MCO must use the state's formulary. Even in the states in which the MCOs must use the state's formulary, MCOs shifted utilization to higher offset drugs (Column (9)) and to substitution of non-bioequivalent generics for branded drugs; such shifts could not be achieved through formulary design alone.

We next examine heterogeneity in our main effect across the five states that privatized medical and pharmacy benefits concurrently relative to the effect of MCOs for the eight states that carved pharmacy benefits into existing MCO contracts. We do not find statistically significant differences across the two groups of treated states. Finally, we examine the coefficient on share $M C O * 1$ (no risk adj), which gives the differential effect of MCOs for the three states that do not employ health based risk-adjustment. In these states, we observe slightly larger decreases in spending per enrollee, driven by decreases in the number of prescriptions being written per enrollee. ${ }^{52}$ Overall, the results of this section suggest that formulary design is an important tool with which MCOs affect prescription drug spending.

\subsection{Robustness}

Beginning with Table A.23, we estimate specifications analogous to those in Sections 4.2.2, 4.2.3, and 4.2.4 for different samples. To facilitate comparison, column (1) presents the paper's central estimates. In column (2), we report estimates from specifications that exclude control states, so that we rely on other treatment states to serve as controls. In column (3), we use the sample of 16 states that begin without medical MCOs, 11 of which serve as control states and 5 of which convert both medical and drug spending to MCOs. In

stage relationships will be capturing both the effect of much lower levels of spending by MCOs and that there is no health-based risk-adjustment. We therefore focus further discussion on Panel B which presents the IV estimates, but note that the effect of MCOs in states with no risk-adjustment should be interpreted with additional caution.

${ }^{52}$ In Table A.26, we determine that the increased relative prices for generics relative to those for branded drugs are not concentrated among the states that allow MCOs to design their own formularies. This provides some evidence against the hypothesis that the shifting relative prices for generics versus branded drugs are driving the increased use of generics. 
column (4), we repeat the analysis for the sample of 13 states that begin with MCOs for medical but carved out drug benefits, five of which serve as controls and eight of which begin to carve in drug spending to MCOs. Column (5) of Table A.23 excludes the two states in our treatment sample (Indiana and North Dakota) that privatized drug benefits and expanded Medicaid at the same time. The timing of privatization decisions does not appear to be coincident with large changes in enrollment more broadly. ${ }^{53}$ In columns (6) and (7), we split the sample based upon whether a state expanded Medicaid. Across these specifications, many of the results remain quite similar. One exception is that when we restrict the analyses to only those states that did not expand Medicaid (Mississippi, Texas, and Utah are the only states that privatized drug benefits but did not expand Medicaid), we no longer find any evidence of overall per enrollee spending decreases from privatization. In these states, there is still evidence of price decreases, increases in the use of generics, and a shift towards high offset drugs. However, there are increases in the number of prescriptions per enrollee that negate these sources of savings.

Table A.24 illustrates the robustness of our results to excluding individual states from the central analyses from Sections 4.2.2, 4.2.3, and 4.2.4. The results remain very similar when individual treatment states are excluded. ${ }^{54}$ Finally, we replicate the central analyses utilizing variation across all states and replacing the privatization variable with the share of pharmacy spending by MCOs (lagged by one quarter). ${ }^{55}$ We present these results in Table A.25. The results remain quite similar to the baseline results.

\subsection{Medicare Falsification Exercise}

We next show that changes in prescription drug usage are not driven by contemporaneous state level factors that are correlated with Medicaid pharmacy benefit privatization. We re-perform our central analyses using Medicare (Part D) prescription drug usage to serve as a placebo test. More specifically, we began with a 10 percent sample of Medicare beneficiaries for 2010 through 2014. We then restricted the sample to beneficiaries that are greater than 65 and that never receive low income part D subsidies. We recalculate each of our central measures for this sample of patients. ${ }^{56}$ For additional details on the structure of and

\footnotetext{
${ }^{53}$ We examine the relationship between enrollment and drug benefit privatization in Figure A.18.

${ }^{54}$ When New York state is excluded, the effect of privatization on spending per enrollee falls by about 20 percent and becomes statistically insignificant. All of the estimates remain similar when New York state is excluded.

${ }^{55}$ We exclude DC, RI, HI, KS, and the second quarter of 2014 for VA. These states all have implausible data patterns.

${ }^{56}$ Whereas the Medicaid data gives the number of prescriptions filled, the Medicare data we used contains the number of days of pills filled. The measures in this analysis are therefore slightly different, although such differences should not affect the results. We also create the dependent variable Simulated generic accessibility for Medicare, which gives the change in generic accessibility due to patent expiration but holding drug usage fixed at the levels of the second quarter of 2010. We illustrated in Figure A.12 that
} 
utilization in the Part D program, please see Einav et al. [2015, 2016], Duggan and Scott Morton [2010], Starc and Town [2015], Abaluck et al. [2015], Dalton et al. [2015].

Figure 9: Lags and leads of relationship between Medicaid privatization and Medicare prescription drug usage
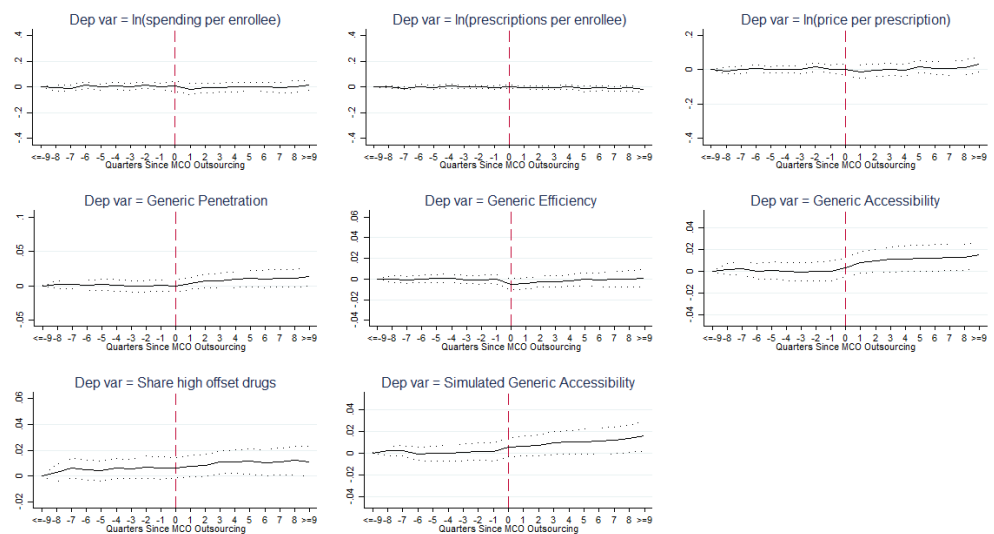

Notes: Specifications are limited to treatment states that privatize pharmacy benefits and control states with no MCO pharmacy benefits. Unreported controls include state fixed effects, quarter fixed effects, and an indicator for whether the state has expanded Medicaid under the ACA. The transition quarter in which a state privatizes is omitted. Observations are weighted by state Medicaid drug spending the second quarter of 2010. Standard errors are clustered by state. Spending is computed for Medicare enrollees 65+ years old who never receive a low income subsidy during the years we have data. Data covers the second quarter of 2010 through the fourth quarter of 2014 . Significance levels: *0.10 $* * 0.05 * * * 0.01$

Figure 9 presents the relationship between lags and leads of the Medicaid privatization decision and Medicare Part D prescription drug usage. Table 8 presents pooled versions of this relationship. There is no evidence of any relationship between Medicaid privatization and spending per enrollees, days supply per enrollee (the analog of prescriptions per enrollee), price per days supply (the analog of price per prescription), utilization per enrollee or generic efficiency for Medicare Part D enrollees. The pooled estimate for share high offset is statistically significant, but small. Inspection of the lags and leads of the effect illustrate that the break occurs long before privatization. For generic accessibility (and therefore also generic penetration), there is a noticeable break from trend at the time of privatization. The pooled estimate is statistically significant with a magnitudes that is roughly $1 / 4$ th as large as for the Medicaid prescription drug sample. However, the point estimate for the variable simulated generic accessibility is nearly identical to the generic accessibility point estimation, implying that the increased use of generics in the Medicare Part D sample is driven exclusively by patent expiration. ${ }^{57}$ Overall, the falsification exercise does not provide any evidence privatization did not affect this variable for Medicaid patients.

${ }^{57}$ We previously ruled out this explanation for the Medicaid sample. For example, the entry of generic Lipitor - used heavily in 
Table 8: Relationship between Medicaid privatization and Medicare prescription drug spending (falsification)

\begin{tabular}{lc}
\hline Dependent Variable & \\
\hline $\ln$ (Spending per enrollee) & -0.00882 \\
& {$[0.0164]$} \\
$\ln$ (Days supply per enrollee) & -0.00815 \\
& {$[0.00639]$} \\
$\ln$ (Price per days supply) & -0.000882 \\
& {$[0.0132]$} \\
$\ln ($ Utilization per enrollee $)$ & -0.0144 \\
& {$[0.0138]$} \\
Generic accessibility & 0.0110 \\
& {$[0.00493]^{* *}$} \\
Simulated generic accessibility & 0.00944 \\
& {$[0.00431]^{* *}$} \\
Generic efficiency & -0.00127 \\
& {$[0.00134]$} \\
Generic penetration & 0.00843 \\
& {$[0.00432]^{*}$} \\
Share high offset & 0.00409 \\
& {$[0.00192]^{* *}$}
\end{tabular}

Notes: Specifications are limited to treatment states that privatize pharmacy benefits and control states with no MCO pharmacy benefits. Unreported controls include state fixed effects, quarter fixed effects, and an indicator for whether the state has expanded Medicaid under the ACA. The transition quarter in which a state privatizes is omitted. Observations are weighted by state Medicaid drug spending the second quarter of 2010. Standard errors are clustered by state. Spending is computed for Medicare enrollees 65+ years old who never receive a low income subsidy during the years we have data. Data covers the second quarter of 2010 through the fourth quarter of 2014 . Significance levels: $* 0.10$ $* * 0.05 * * * 0.01$ 
to suggest that our central results are driven by contemporaneous factors that are unrelated to Medicaid drug benefit privatization.

\subsection{Extensions}

Privatization may affect other dependent variables of interest. Section A.3 examines the effect of privatization on total state spending on Medicaid, which depends on both drug spending and any spillover effects on other types of spending, as well as on how MCOs and states split any surplus that MCOs create. There is no evidence that privatization affected total per enrollee spending by the state Medicaid program, although the results are quite imprecise. Section A.4 looks for any spillover effects of drug benefit privatization on Emergency Department use by Medicaid patients. We were only able to obtain data for four states that privatized drug benefits and eight control states. There is no evidence that privatization affected Emergency Department use by Medicaid patients, although again the estimates are imprecise.

\section{Conclusions}

State and federal officials have proposed a range of policies to combat rising drug prices. Some policies including price controls and caps on consumer expenditure - are likely to have serious unintended consequences. By contrast, the policy change we study could save billions of dollars without reducing overall drug utilization; the sheer ability of MCOs to control access leads to major reductions in price per prescription. Furthermore, beyond calls for "Medicare-for-all," many advocate for direct price negotiation between the Medicare program and drug manufacturers. This debate overlooks the fact that private MCOs administer a large percentage of both Medicare and Medicaid drug benefits; it is important to know whether outsourcing to MCOs has been successful.

Several prior studies compare the performance of government versus MCO-administered Medicaid health benefits (Duggan and Hayford [2013], Duggan [2004]). Our approach allows us to go inside the "black box" to break out the sources of observed performance differences. In this paper, we examine the impact of a plausibly exogenous rule change that made it weakly preferable for states to use MCOs to administer Medicaid drug benefits. Based on our preferred specification, if states "carved in" 100 percent of the Medicaid drug benefit, drug spending would fall by 22.4 percent.

the Medicare population but not the Medicaid population of interest - explains a substantial share of increased generic accessibility among Medicare Part D patients. 
We use highly granular data to identify the sources of these savings and consider possible harmful consequences. Our results suggest that MCOs achieve these spending cuts with a scalpel rather than a hatchet. MCOs negotiate lower point-of-sale prices with pharmacies, accounting for approximately one third of the savings. MCOs also shift utilization to generic drugs, explaining between one third and two thirds of the reduction, depending on assumptions. We find that patients in MCOs use a higher share of utilization on drugs with high medical offsets, a result driven by a decrease in utilization for drugs that do not have high medical offsets, with little change in utilization for high offset drugs.

It is unlikely that reducing point of sale pricing and increasing generic utilization would harm patients. While we did find evidence of lower overall drug usage, the reduction did not apply to high offset drugs, whose usage tends to lead to reduced spending elsewhere in the health system. This suggests, if not conclusively, that MCOs are not shortchanging the use of drugs with large health benefits. Cream-skimming does not appear to explain our pattern of results.

Taken together, our findings suggest that the carving-in of drug benefits has reduced drug spending without harming enrollee health. However, an alternative interpretation of our results is that policymakers could focus on giving states greater latitude to design formularies and negotiate prices with pharmacies. The Medicare and Medicaid programs increasingly rely on private MCOs to administer health benefits, and our findings suggest that this trend could help to control costs. The U.S. model will likely continue

to entail a public/private partnership, where the government provides insurance but private MCOs procure services. This may even entail allowing enrollees to choose among competing MCOs - the current practice in Medicare and an essential component of the health insurance exchanges under Obamacare. Understanding insurer behavior in these settings and how privatization affects costs and quality is therefore critical to the health policy debate.

\section{Bibliography}

\section{References}

Jason Abaluck, Jonathan Gruber, and Ashley Swanson. Prescription Drug Use under Medicare Part D: A Linear Model of Nonlinear Budget Sets. NBER Working Paper No. 20976, 2015. 
Abby Alpert, Mark Duggan, and Judith K Hellerstein. Perverse Reverse Price Competition: Average Wholesale Prices and Medicaid Pharmaceutical Spending. Journal of Public Economics, 108:44-62, 2013.

Marika Cabral, Michael Geruso, and Neale Mahoney. Do Larger Health Insurance Subsidies Benefit Patients or Producers? Evidence from Medicare Advantage. NBER Working Paper No. 20470, 2014.

Colleen Carey. Technological Change and Risk Adjustment: Benefit Design Incentives in Medicare Part D. American Economic Journal: Economic Policy, 9(1):38-73, 2017.

Centers for Medicare and Medicaid Services. May 2017 Medicaid and Chip Application, Eligibility Determination, and Enrollment Report. Issue Brief, available online at https://www.medicaid.gov, 2017.

Amitabh Chandra, Jonathan Gruber, and Robin McKnight. Patient Cost-Sharing and Hospitalization Offsets in the Elderly. The American Economic Review, 100(1):193-213, 2010.

Vilsa Curto, Liran Einav, Jonathan Levin, and Jay Bhattacharya. Can Health Insurance Competition Work? Evidence from Medicare Advantage. NBER Working Paper No. 20818, 2014.

Vilsa Curto, Liran Einav, Amy Finkelstein, Jonathan D Levin, and Jay Bhattacharya. Healthcare Spending and Utilization in Public and Private Medicare. NBER Working Paper No. 23090, 2017.

D. Cutler, M. McClellan, and J. Newhouse. How Does Managed Care Do It? RAND Journal of Economics, 31(3):526-548, 2000.

Christina M. Dalton, Gautam Gowrisankaran, and Robert Town. Salience, Myopia, and Complex Dynamic Incentives: Evidence from Medicare Part D. NBER Working Paper No. 21104, 2015.

Mark Duggan. Does Contracting Out Increase the Efficiency of Government Programs? Evidence from Medicaid HMOs. Journal of Public Economics, 88(12):2549-2572, 2004.

Mark Duggan and Tamara Hayford. Has the Shift to Managed Care Reduced Medicaid Expenditures? Evidence from State and Local-Level Mandates. Journal of Policy Analysis and Management, 32(3): 505-535, 2013.

Mark Duggan and Fiona Scott Morton. The Effect of Medicare Part D on Pharmaceutical Prices and Utilization. American Economic Review, 100(1):590-607, 2010. 
Mark Duggan, Amanda Starc, and Boris Vabson. Who Benefits when the Government Pays More? PassThrough in the Medicare Advantage Program. Journal of Public Economics, 141:50-67, 2016.

Liran Einav, Amy Finkelstein, and Paul Schrimpf. The Response of Drug Expenditures to Non-Linear Contract Design: Evidence from Medicare Part D. Quarterly Journal of Economics, 130(2):841-899, 2015.

Liran Einav, Amy Finkelstein, and Maria Polyakova. Private Provision of Social Insurance: Drug-Specific Price Elasticities and Cost Sharing in Medicare Part D. NBER Working Paper No. 22277, 2016.

Michael Geruso, Timothy J. Layton, and Daniel Prinz. Screening in Contract Design: Evidence from the ACA Health Insurance Exchanges. NBER Working Paper No. 22832, 2016.

Kathy Gifford, Julia Paradise, Vernon Smith, and Dyke Snipes. A Profile of Medicaid Managed Care Programs in 2010: Findings From a 50-State Survey. Issue Brief, The Henry J. Kaiser Family Foundation, available online at http://www.kff.org, 2011.

S. P. Keehan, D. A. Stone, J. A. Poisal, G. A. Cuckler, A. M. Sisko, S. D. Smith, and J. M. Lizonitz. National Health Expenditure Projections, 201625: Price Increases, Aging Push Sector to 20 Percent of Economy. Health Affairs, 36(3):553-563, 2017.

Kurt Lavetti and Kosali Simon. Strategic Formulary Design in Medicare Part D Plans. NBER Working Paper No. 22338, 2016.

Medicaid and CHIP Payment and Access Commission. Medicaid Payment for Outpatient Prescription Drugs. Issue Brief, available online at https://www.macpac.gov, 2017.

Jim Ross. Small Pharmacies Fight to Stay in Medicaid. Ocala Star-Banner, available online at http://www.ocala.com/news/20170402/small-pharmacies-fight-to-stay-in-medicaid, 2017.

Fiona Scott Morton. The Strategic Response by Pharmaceutical Firms to the Medicaid Most-FavoredCustomer Rules. RAND Journal of Economics, 28(2), 1997.

Mark Shepard. Hospital Network Competition and Adverse Selection: Evidence from the Massachusetts Health Insurance Exchange. NBER Working Paper No. 22600, 2016. 
Amanda Starc and Robert J Town. Internalizing Behavioral Externalities: Benefit Integration in Health Insurance. NBER Working Paper No. 21783, 2015.

The Lewin Group. Projected Impacts of Adopting a Pharmacy Carve-In Approach Within Medicaid Capitation Programs. Issue brief, available online at http://www.lewin.com, 2011.

Robert Town and Su Liu. The Welfare Impact of Medicare HMOs. RAND Journal of Economics, pages 719-736, 2003.

Katherine Young, Rachel Garfield, Musumeci MaryBeth, Lisa Clemens-Cope, and Emily Lawton. Medicaid's Role for Dual Eligible Beneficiaries. Issue Brief, The Henry J. Kaiser Family Foundation, available online at http://www.kff.org, 2013. 


\section{A Appendices (For Online Publication Only)}

\section{A.1 Point-of-Sale Drug Prices}

We first estimate a variant of the regression in equation 2, including interactions between privatization and whether the NDC was high offset, generic, or neither. We plot the coefficients from these regressions in Figure A.1. Panels A and C plot coefficients from the same regression in which Medicaid's price per prescription was the dependent variable. Panel B and D plot the coefficients from the same regression in which coinsurance per prescription is the dependent variable. In Panel A, the red line plots out the coefficients on lags and leads of the privatization decision interacted with a drug being a generic, whereas the black line plots out the coefficients on lags and leads of the privatization decision interacted with a drug being neither a generic nor a high offset drug. In Panel C, the red line plots out the coefficients on lags and leads of the privatization interacted with a drug being high offset, whereas the black line plots out the coefficients on lags and leads of the privatization decision interacted with a drug being neither a generic nor a high offset drug. Thus, the black lines in Panel A and Panel C are identical. Based on Panel A, pharmacy reimbursements from Medicaid are decreasing substantially for drugs that are neither generics nor high offset. By contrast, reimbursements for generics remain similar. Based upon Panel C, the drop in Medicaid per prescription reimbursements is smaller for high offset drugs than for drugs that are neither generic nor high offset.

We present a pooled versions of this analysis in Table A.1. We present the differential effect for generics and the differential effect for high offset drugs. The pooled results confirm that the decrease in prices to pharmacies is $\$ 6$ less for generics than for other drugs. ${ }^{58}$ When pooled, there is no evidence of differential pharmacy prices post-privatization for high offset drugs. ${ }^{59}$

\footnotetext{
${ }^{58} \mathrm{~A}$ back of the envelope calculation suggests that paying an additional $\$ 6$ for all generic prescriptions (i.e., both the marginal and infra-marginal prescriptions) in return for increasing generic penetration by 7.68 percentage points would be profitable for the MCO.

${ }^{59}$ There are at least two possible reasons for this pattern in results. First, it could be that MCOs are choosing this pricing structure, so as to provide pharmacies with stronger incentives to steer consumers towards generics. Perhaps pharmacies have fewer tools to push consumers to use high offset drugs, and therefore MCOs have little reason to provide pharmacies with incentives to steer consumers towards these drugs. Alternatively, this pattern of results may simply reflect differences in where pharmacies extract their rents from MCOs versus states, but may not be tied to shifting demand.
} 
Table A.1: Reduced Form relationship between privatization and Pharmacy prices

\begin{tabular}{|c|c|c|c|c|}
\hline \multicolumn{5}{|c|}{ Panel A: Dep var = Medicaid price per prescription } \\
\hline & (1) & (2) & (3) & (4) \\
\hline \multirow[t]{2}{*}{ Priv } & -3.986 & -4.127 & -7.737 & -8.070 \\
\hline & {$[0.904]^{* * *}$} & {$[0.923]^{* * *}$} & {$[1.705]^{* * *}$} & {$[1.748]^{* * *}$} \\
\hline \multirow[t]{2}{*}{ Medicaid expansion } & & 0.483 & & 1.272 \\
\hline & & [0.766] & & [1.827] \\
\hline \multirow[t]{2}{*}{ Priv $* 1$ (High offset $)$} & & & -0.921 & -0.770 \\
\hline & & & {$[1.770]$} & [1.848] \\
\hline \multirow[t]{2}{*}{ Priv*1(Generic) } & & & 5.965 & 6.215 \\
\hline & & & {$[1.975]^{* * *}$} & {$[2.018] * * *$} \\
\hline \multirow[t]{2}{*}{ (Medicaid expansion $) * 1$ (High offset) } & & & & -0.531 \\
\hline & & & & [1.589] \\
\hline \multirow[t]{2}{*}{$($ Medicaid expansion $) * 1($ Generic $)$} & & & & -0.986 \\
\hline & & & & [1.902] \\
\hline R-sq & 0.999 & 0.999 & 0.999 & 0.999 \\
\hline \multicolumn{5}{|c|}{ Panel B: Dep var $=$ Cost sharing per prescription } \\
\hline \multirow[t]{2}{*}{ Priv } & 0.488 & 0.386 & 1.046 & 0.764 \\
\hline & {$[0.348]$} & [0.359] & [0.956] & [0.977] \\
\hline \multirow[t]{2}{*}{ Medicaid expansion } & & 0.352 & & 1.094 \\
\hline & & [0.299] & & [0.874] \\
\hline \multirow[t]{2}{*}{ Priv*1(High offset $)$} & & & 0.140 & 0.174 \\
\hline & & & {$[0.749]$} & [0.784] \\
\hline \multirow[t]{2}{*}{ Priv*l(Generic) } & & & -0.889 & -0.632 \\
\hline & & & [0.975] & [1.002] \\
\hline \multirow[t]{2}{*}{ (Medicaid expansion $) * 1($ High offset $)$} & & & & -0.130 \\
\hline & & & & {$[0.578]$} \\
\hline \multirow[t]{2}{*}{$($ Medicaid expansion $) * 1($ Generic $)$} & & & & -1.003 \\
\hline & & & & [0.839] \\
\hline R-sq & 0.992 & 0.992 & 0.992 & 0.992 \\
\hline $\mathrm{N}$ & 3220610 & 3220610 & 3220610 & 3220610 \\
\hline
\end{tabular}

Notes: Specification is limited to treatment states that privatize pharmacy benefits and control states with no MCO pharmacy benefits. Unit of observation is the NDC9-state-quarter. Unreported controls include NDC9-state fixed effects and NDC9-quarter fixed effects. The transition quarter in which a state privatizes is omitted. Observations are weighted by drug spending for each NDC9-state combination in the first quarter in which it appears in the data. Standard errors are clustered by state. $* 0.10 * * 0.05 * * * .01$ 
Figure A.1: Lags and leads of relationship between privatization and Medicaid's price
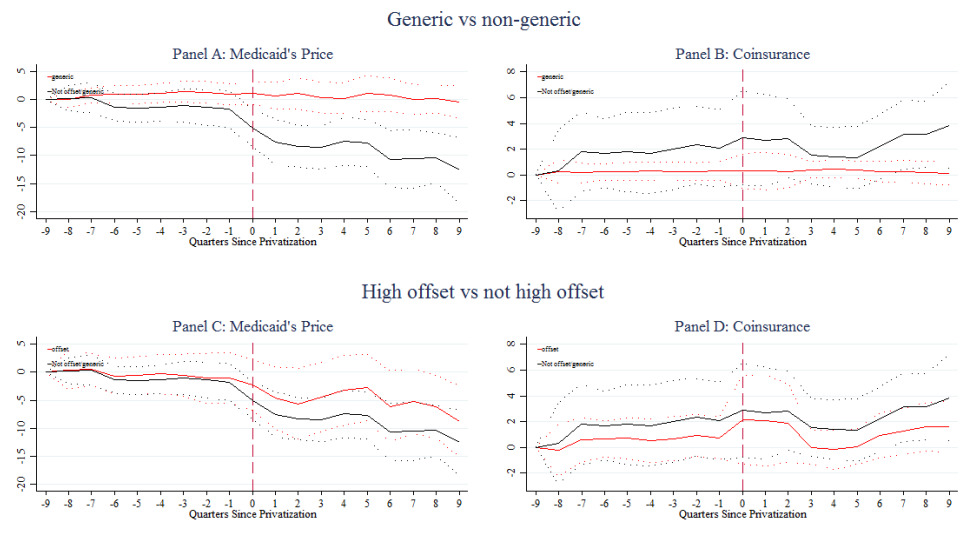

Notes: Specification is limited to treatment states that privatize pharmacy benefits and control states with no MCO pharmacy benefits. Unit of observation is the NDC9-state-quarter. Includes NDC9-state fixed effects, NDC9-quarter fixed effects, and an indicator for whether the state has expanded Medicaid under the ACA. Observations are weighted by drug spending for each NDC9-state combination in the first quarter in which it appears in the data. Point estimates for the effect of quarter pre-post privatization is presented in the dark line and a 95 percent confidence interval for those coefficients, based upon standard errors that are clustered by state, is presented with the dotted lines.

\section{A.2 Rebates}

The preceding analysis ignores the existence of drug rebates paid by drug manufacturers to states. To examine the importance of this limitation, we collected supplemental data from the Medicaid Financial Management Report. These reports provide state-year level summary information on all Medicaid expenditures. We construct rebate share as the share of prescription drug spending that is returned in rebates. The rebate data in the numerator is constructed from the Medicaid Financial Management Reports, while the denominator is constructed from the Medicaid State Drug Utilization Data. On average, rebates reduce drug spending by fifty percent.

We replicate our central analyses using rebate share as the dependent variable to explore whether privatization affected rebates. The reduced form of this analysis is presented in Figure A.2 and in Table A.2. ${ }^{60}$ We find no evidence that rebates change as a result of privatization. Perhaps, this should be unsurprising. Prior to the ACA, the absence of MCOs offering drug coverage suggests that they were unable to obtain rebates as generous as states. For example, roughly 92 percent of rebates in our samples states were the federally mandated rebates in our sample states in 2010. Given that there is no relationship between aggregate state level rebates and the decision to privatize drug benefits, and that we lack any information on rebates for spe-

\footnotetext{
${ }^{60}$ Note that the Medicaid State Drug Utilization data is only reported at the annual level, so the regressions that use it are also at the annual level)
} 
cific drugs, we do not attempt to adjust drug prices or drug spending for rebates. Proportional adjustments would not affect any of our analyses in which the dependent variable is in logs rather than levels.

Figure A.2: Lags and leads of relationship between privatization and rebates as a share of gross drug spending

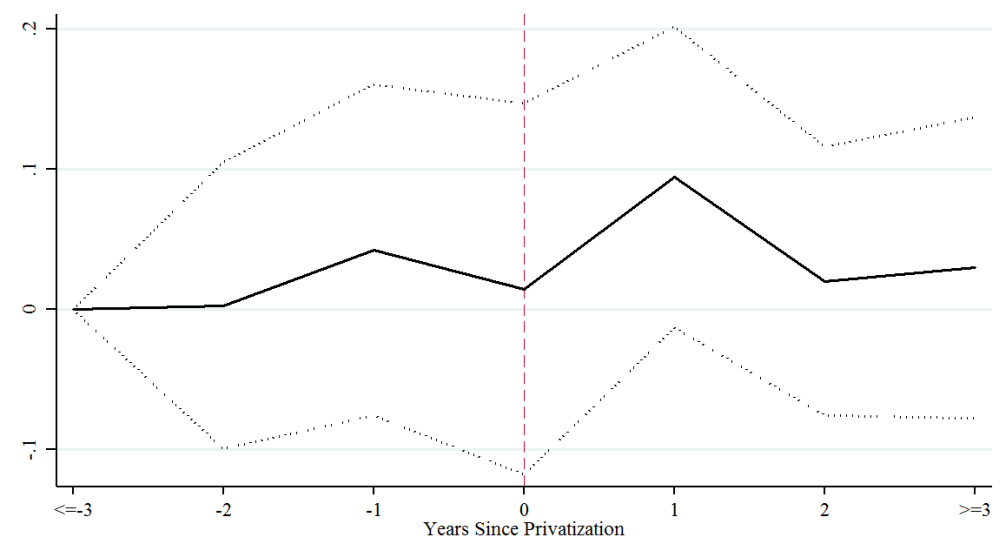

Notes: Specification is limited to treatment states that privatize pharmacy benefits and control states with no MCO pharmacy benefits. Includes state fixed effects, year fixed effects, and an indicator for whether the state has expanded Medicaid under the ACA. Observations are weighted by state Medicaid drug spending in quarter 2 through 4 of 2010. Point estimates for the effect of quarter pre-post privatization is presented in the dark line and a 95 percent confidence interval for those coefficients, based upon standard errors that are clustered by state, is presented with the dotted lines.

\section{A.3 Impact on overall state spending on Medicaid}

Figure A.3 presents the relationship between privatization and total spending per enrollee. There is an increase in spending at least two years prior to privatization, followed by spending levels that are relatively flat, with no noticeable break around the time of privatization. Unsurprisingly, given that prescription drug spending is only a small share of overall Medicaid spending and the aggregated nature of our data, we are unable to rule out very economically large total spending increases or total spending decreases. Table A.3 confirms this fact.

\section{A.4 Impact on Emergency Department use}

To investigate whether there were any spillover effects of drug privatization on enrollee health or non-drug spending, we investigated whether there was any effect of privatization on Emergency Department usage using data downloaded from HCUP on Emergency Department Utilization by Medicaid enrollees. This data is only available for a limited part of our time period (i.e., the data ends at the end of 2015) and only 
Table A.2: Effect of MCOs on rebates as share of gross drug spending

\begin{tabular}{lcccc}
\hline & $\begin{array}{c}\text { Reduced Form } \\
(1)\end{array}$ & $\begin{array}{c}\text { IV } \\
(2)\end{array}$ & $\begin{array}{c}\text { Reduced Form } \\
(3)\end{array}$ & $\begin{array}{c}\text { IV } \\
(4)\end{array}$ \\
\hline Priv & -0.0108 & & 0.0118 \\
& {$[0.0506]$} & & {$[0.0356]$} & \\
Share MCO & & -0.0177 & & 0.0194 \\
& & {$[0.0845]$} & & {$[0.0568]$} \\
Medicaid expansion & & & -0.117 & -0.118 \\
& & & {$[0.0386]^{* * *}$} & {$[0.0378]^{* * *}$} \\
R-sq & 0.502 & 0.501 & 0.573 & 0.575 \\
\hline $\mathrm{N}$ & 151 & 151 & 151 & 151 \\
\hline
\end{tabular}

Notes: Specification is limited to treatment states that privatize pharmacy benefits and control states with no MCO pharmacy benefits. Unreported controls include state fixed effects and year fixed effects. The transition year in which a state privatizes is omitted. Observations are weighted by state Medicaid drug spending in quarter 2 through 4 of 2010. Standard errors are clustered by state. Significance levels: * $0.10 * * 0.05 * * * .01$

Table A.3: Effect of MCOs on logged total spending per enrollee

\begin{tabular}{lcccc}
\hline & $\begin{array}{c}\text { Reduced Form } \\
(1)\end{array}$ & $\begin{array}{c}\text { IV } \\
(2)\end{array}$ & $\begin{array}{c}\text { Reduced Form } \\
\text { (3) }\end{array}$ & $\begin{array}{c}\text { IV } \\
(4)\end{array}$ \\
\hline Priv & -0.0351 & & -0.0217 & \\
Share MCO & {$[0.0387]$} & & {$[0.0329]$} & \\
& & -0.0575 & & -0.0357 \\
Medicaid expansion & & {$[0.0616]$} & & {$[0.0533]$} \\
& & & -0.0696 & -0.0690 \\
R-sq & 0.935 & 0.934 & 0.940 & 0.940 \\
\hline $\mathrm{N}$ & 151 & 151 & 151 & 151 \\
\hline
\end{tabular}

Notes: Specification is limited to treatment states that privatize pharmacy benefits and control states with no MCO pharmacy benefits. Includes state fixed effects, year fixed effects, and an indicator for whether the state has expanded Medicaid under the ACA. The transition year in which a state privatizes is omitted. Observations are weighted by state Medicaid drug spending in quarter 2 through 4 of 2010. Standard errors are clustered by state. Significance levels: * $0.10 * * 0.05 * * * .01$ 
Figure A.3: Lags and leads of relationship between privatization and logged total spending per enrollee

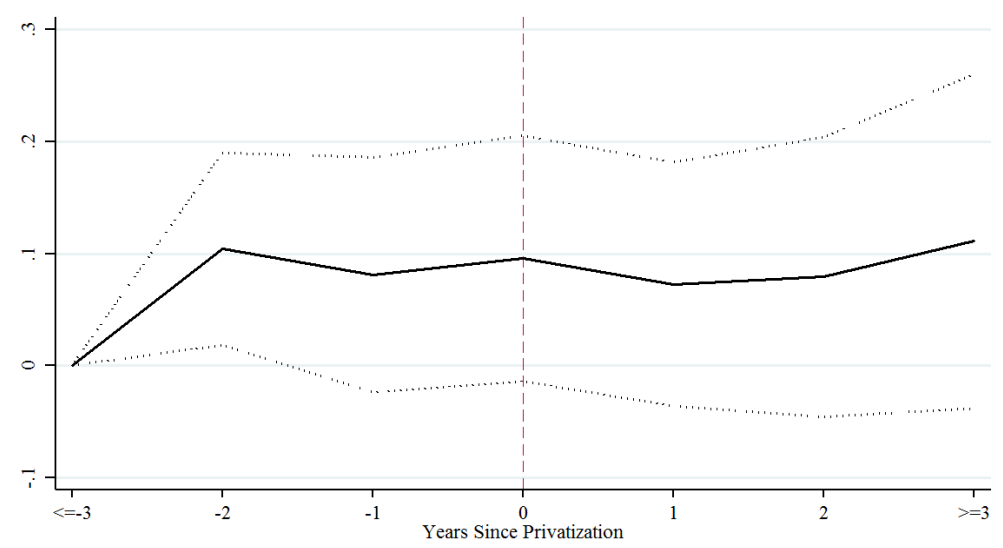

Notes: Specification is limited to treatment states that privatize pharmacy benefits and control states with no MCO pharmacy benefits. Includes state fixed effects, year fixed effects, and an indicator for whether the state has expanded Medicaid under the ACA. Observations are weighted by drug spending for the second to fourth quarters of 2010. Point estimates for the effect of quarter pre-post privatization is presented in the dark line and a 95 percent confidence interval for those coefficients, based upon standard errors that are clustered by state, is presented with the dotted lines.

covers four treatment states (IL,NY, ND, UT) and eight control states (ME, MO, NC, NE, SD, TN, VT, WI). ${ }^{61}$ Given the more limited sample and time frame, we view this analysis with an additional degree of caution. Nonetheless, we examine whether there were changes in Medicaid Emergency Department utilization, finding no evidence to suggest that there were increases after privatization. Figure A.4 presents lags and leads of the privatization decision on Medicaid ED utilization. There is a downward trend that precedes the policy change and that shows no sign of a break. The pooled point estimate, presented in Table A.4, is negative, marginally statistically significant, driven by the existence of a pre-trend, and the magnitude of the point estimate is economically somewhat sensitive to controlling for the Medicaid expansion. The mean of ED visits per enrollee is 0.185 in our sample, suggesting we can rule out large increases in ED use from privatization.

\footnotetext{
${ }^{61}$ HCUP reports more limited data from a number of other states that we exclude. We excluded IN and IA, both of which are treatment states but are treated after the end of the data. We also excluded AR, MT, and WY, all of which are control states and only had data available for very limited time periods. Finally, we exclude NY prior to the first quarter of 2011 because of a change in how Medicaid managed care enrollees are coded. Other than excluding the coding changes in NY, these restrictions have little impact on the analysis.
} 
Table A.4: Effect of Privatization on ED usage for Medicaid enrollees

\begin{tabular}{lcc} 
& $(1)$ & $(2)$ \\
\hline Priv & -0.000416 & -0.00803 \\
& {$[0.00417]$} & {$[0.00418]^{*}$} \\
Medicaid expansion & & 0.0191 \\
& & {$[0.0128]$} \\
R-sq & 0.934 & 0.941 \\
\hline $\mathrm{N}$ & 254 & 254
\end{tabular}

Notes: Unit of observation is the state $\mathrm{x}$ quarter. Specification is restricted to the four treatment states (IL, NY, ND, UT) and eight control states (ME, MO, NC, NE, SD, TN, VT, WI) for which ED data was available. Unreported controls includes state fixed effects and quarter fixed effects. The transition quarter in which a state privatizes is omitted. Observations are weighted by state Medicaid drug spending in the second quarter of 2010. Standard errors are clustered by state. Significance levels: * $0.10 * * 0.05 * * * .01$

Figure A.4: Lags and leads of relationship between privatization and Medicaid ED visits per enrollee

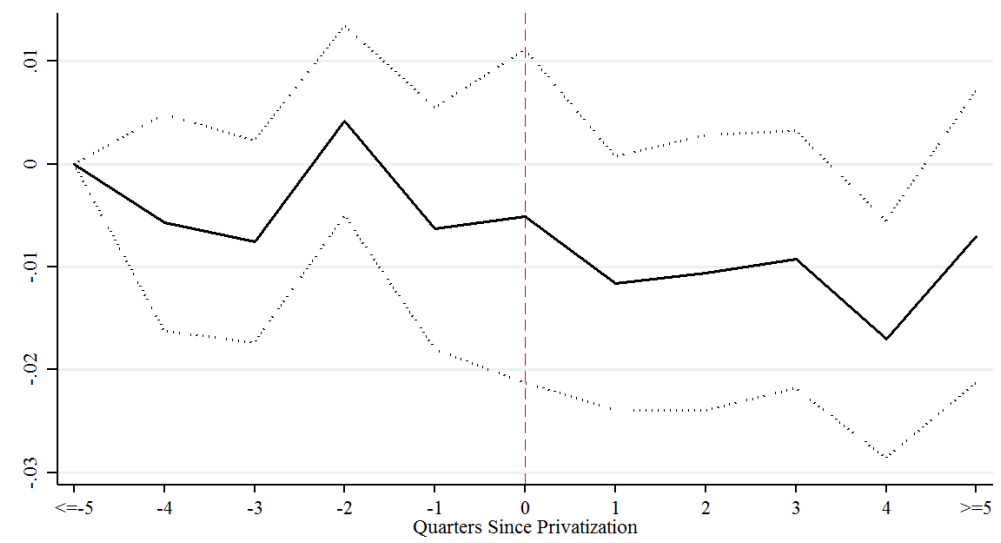

Notes: Unit of observation is the state $\mathrm{x}$ quarter. Specification is restricted to the four treatment states (IL, NY, ND, UT) and eight control states (ME, MO, NC, NE, SD, TN, VT, WI) for which ED data was available. Includes state fixed effects and quarter fixed effects, and an indicator for whether the state has expanded Medicaid under the ACA. Point estimates for the effect of quarter pre-post privatization is presented in the dark line and a 95 percent confidence interval for those coefficients, based upon standard errors that are clustered by state, is presented with the dotted lines.

\section{A.5 Moral Hazard}

We obtained data on 160 molecule-generic combinations for which Einav, Finkelstein, and Polykova published their price elasticities. We created a sample where the unit of observation is the state-molecule-generic status-quarter for these drugs. Drug utilization patterns are quite different for Medicare and Medicaid patients. For example, within the sample of 160 drugs, Atorvastatin Calcium (a statin) is roughly 10 percent of Medicare spending, but only 1 percent of Medicaid spending. By contrast, Quetiapine Fumarate (an an- 
tipsychotic) is nearly 9 percent of Medicaid spending within this sample, but is only 1 percent of Medicare spending. The correlation in spending shares is under 0.06 , and only roughly a quarter of Medicaid spending is on these drugs. As a result, the results on this subsample of Medicaid spending will not perfectly match our central results. Furthermore, if demand patterns are very different across these two populations, demand elasticities may be quite different as well. We proceed nonetheless.

We split drugs into a "more elastic" sample and a "less elastic" sample by the revenue weighted median of these drugs (the results are similar when we use a continuous measure of elasticity). For each observation, we calculated the number of prescriptions per Medicaid enrollee, the Medicaid price per prescription, and cost sharing per prescription. We examined the effect of privatization on each of these dependent variables. We also included interactions between privatization and four drug categories: (i) whether the drug is a generic, (ii) whether the drug is relatively price elastic, (iii) whether it is a maintenance drug, and (iv) whether the drug treats a chronic condition.

Tables A.5-A.7 present results from this analysis. Table A.5 presents additional evidence that Medicaid price per prescription decreases after privatization, but that prices for generics do not decrease. More elastic drugs have slightly larger price decreases. One possible explanation for this result might be that pharmacies have stronger incentives to reduce prices for drugs for which demand is price elastic (if this in some way filters through to consumer prices). The result may also be coincidental or due to some omitted variable bias. There is little heterogeneity in the effect of privatization on Medicaid price per prescription for the remaining drug categories.

Turning to Table A.6, there is no evidence of relationship between privatization and cost sharing per prescription, either on average or for any of these specific drug types. In particular, it does not appear that Medicaid MCOs are raising cost sharing on drugs for which demand is particularly price elastic. Given the limited role of cost sharing, this is perhaps unsurprising. In Table A.7, we examine the relationship between privatization and logged prescriptions per enrollee for each of these drugs. The interaction term between privatization and being elastic is near zero and statistically insignificant. There is some evidence (although no longer statistically significant) that use of generics increases after privatization. Furthermore, there is marginally statistically significant evidence that use of maintenance drugs (which likely overlap with our high offset sample) increases after privatization.

Overall, we conclude that the mechanism they identify is not driving our results. 
Table A.5: Reduced Form relationship between prices and quantities and privatization and Einav, Finkelstein, Polykova's drug elasticities

\begin{tabular}{|c|c|c|c|c|}
\hline \multicolumn{5}{|c|}{ Dep var $=$ Medicaid price per prescription } \\
\hline & (1) & (2) & (3) & (4) \\
\hline \multirow[t]{2}{*}{ Priv } & -5.305 & -4.998 & -10.21 & -9.642 \\
\hline & {$[0.955]^{* * *}$} & {$[1.016]^{* * *}$} & {$[2.327]^{* * *}$} & {$[2.774]^{* * *}$} \\
\hline \multirow[t]{2}{*}{ Medicaid expansion } & & -0.924 & & -2.160 \\
\hline & & [0.811] & & [2.608] \\
\hline \multirow[t]{2}{*}{ Priv*1(Generic) } & & & 9.634 & 9.136 \\
\hline & & & {$[2.260]^{* * *}$} & {$[2.667]^{* * *}$} \\
\hline \multirow[t]{2}{*}{ Priv*1(Elastic) } & & & -3.427 & -3.222 \\
\hline & & & {$[1.398]^{* *}$} & {$[1.378]^{* *}$} \\
\hline \multirow[t]{2}{*}{ Priv*1(Maintenance) } & & & -2.423 & -2.207 \\
\hline & & & {$[1.701]$} & {$[1.821]$} \\
\hline \multirow[t]{2}{*}{ Priv $* 1$ (Chronic) } & & & 2.535 & 1.873 \\
\hline & & & {$[2.078]$} & [2.382] \\
\hline \multirow[t]{2}{*}{$($ Medicaid expansion $) * 1($ Generic $)$} & & & & 1.930 \\
\hline & & & & [2.395] \\
\hline \multirow[t]{2}{*}{$($ Medicaid expansion $) * 1($ Elastic $)$} & & & & -0.601 \\
\hline & & & & {$[1.584]$} \\
\hline \multirow[t]{2}{*}{$($ Medicaid expansion $) * 1$ (Maintenance) } & & & & -0.594 \\
\hline & & & & [1.489] \\
\hline \multirow[t]{2}{*}{$($ Medicaid expansion $) * 1($ Chronic $)$} & & & & 1.967 \\
\hline & & & & [1.979] \\
\hline R-sq & 0.994 & 0.994 & 0.994 & 0.994 \\
\hline $\mathrm{N}$ & 67545 & 67545 & 67545 & 67545 \\
\hline
\end{tabular}

Notes: Specification is limited to treatment states that privatize pharmacy benefits and control states with no MCO pharmacy benefits. Unit of observation is the NDC9-state-quarter. Unreported controls include NDC9-state fixed effects and NDC9-quarter fixed effects. The transition quarter in which a state privatizes is omitted. Observations are weighted by drug spending for each NDC9-state combination in the first quarter in which it appears in the data. Standard errors are clustered by state. Significance levels: $* 0.10 * * 0.05 * * * .01$ 
Table A.6: Reduced Form relationship between prices and quantities and privatization and Einav, Finkelstein, Polykova's drug elasticities

\begin{tabular}{|c|c|c|c|c|}
\hline \multicolumn{5}{|c|}{ Dep var $=$ Cost sharing per prescription } \\
\hline & (1) & (2) & (3) & (4) \\
\hline \multirow[t]{2}{*}{ Priv } & 0.490 & 0.443 & 1.027 & 0.891 \\
\hline & {$[0.245]^{* *}$} & {$[0.247]^{*}$} & {$[0.704]$} & [0.723] \\
\hline \multirow[t]{2}{*}{ Medicaid expansion } & & 0.140 & & 0.529 \\
\hline & & [0.181] & & [0.576] \\
\hline \multirow[t]{2}{*}{ Priv*l(Generic) } & & & -0.848 & -0.652 \\
\hline & & & {$[0.761]$} & [0.760] \\
\hline \multirow[t]{2}{*}{ Priv*1(Elastic) } & & & -0.0639 & -0.166 \\
\hline & & & [0.249] & [0.226] \\
\hline \multirow[t]{2}{*}{ Priv $* 1($ Maintenance $)$} & & & 0.152 & 0.115 \\
\hline & & & {$[0.460]$} & [0.465] \\
\hline \multirow[t]{2}{*}{ Priv $* 1$ (Chronic) } & & & 0.193 & 0.209 \\
\hline & & & {$[0.617]$} & {$[0.650]$} \\
\hline \multirow[t]{2}{*}{$($ Medicaid expansion $) * 1($ Generic $)$} & & & & -0.707 \\
\hline & & & & [0.613] \\
\hline \multirow[t]{2}{*}{$($ Medicaid expansion $) * 1($ Elastic) } & & & & 0.304 \\
\hline & & & & [0.231] \\
\hline \multirow[t]{2}{*}{ (Medicaid expansion)*1(Maintenance) } & & & & 0.108 \\
\hline & & & & [0.252] \\
\hline \multirow[t]{2}{*}{$($ Medicaid expansion $) * 1($ Chronic $)$} & & & & -0.0367 \\
\hline & & & & [0.481] \\
\hline R-sq & 0.891 & 0.891 & 0.892 & 0.892 \\
\hline $\mathrm{N}$ & 67545 & 67545 & 67545 & 67545 \\
\hline
\end{tabular}

Notes: Specification is limited to treatment states that privatize pharmacy benefits and control states with no MCO pharmacy benefits. Unit of observation is the NDC9-state-quarter. Unreported controls include NDC9-state fixed effects and NDC9-quarter fixed effects. The transition quarter in which a state privatizes is omitted. Observations are weighted by drug spending for each NDC9-state combination in the first quarter in which it appears in the data. Standard errors are clustered by state. Significance levels: $* 0.10 * * 0.05 * * * .01$ 
Table A.7: Reduced Form relationship between prices and quantities and privatization and Einav, Finkelstein, Polykova's drug elasticities

\begin{tabular}{|c|c|c|c|c|}
\hline \multicolumn{5}{|c|}{ Dep var $=\ln ($ Prescriptions per enrollee $)$} \\
\hline & (1) & (2) & (3) & (4) \\
\hline \multirow[t]{2}{*}{ Priv } & 0.104 & 0.0889 & -0.123 & -0.0572 \\
\hline & {$[0.0312]^{* * *}$} & {$[0.0330]^{* * *}$} & {$[0.0894]$} & {$[0.0973]$} \\
\hline \multirow[t]{2}{*}{ Medicaid expansion } & & 0.0465 & & -0.215 \\
\hline & & {$[0.0316]$} & & {$[0.0817]^{* * *}$} \\
\hline \multirow[t]{2}{*}{ Priv*l(Generic) } & & & 0.178 & 0.0873 \\
\hline & & & {$[0.0883]^{* *}$} & [0.0943] \\
\hline \multirow[t]{2}{*}{ Priv*1(Elastic) } & & & 0.0153 & 0.00966 \\
\hline & & & {$[0.0304]$} & {$[0.0306]$} \\
\hline \multirow[t]{2}{*}{ Priv*1(Maintenance) } & & & 0.111 & 0.101 \\
\hline & & & {$[0.0539]^{* *}$} & {$[0.0597]^{*}$} \\
\hline \multirow[t]{2}{*}{ Priv*l(Chronic) } & & & 0.116 & 0.0540 \\
\hline & & & {$[0.0741]$} & {$[0.0837]$} \\
\hline \multirow[t]{2}{*}{$($ Medicaid expansion $) * 1($ Generic $)$} & & & & 0.285 \\
\hline & & & & {$[0.0736]^{* * *}$} \\
\hline \multirow[t]{2}{*}{$($ Medicaid expansion $) * 1$ (Elastic) } & & & & 0.0195 \\
\hline & & & & {$[0.0379]$} \\
\hline \multirow[t]{2}{*}{ (Medicaid expansion)*1(Maintenance) } & & & & 0.0271 \\
\hline & & & & {$[0.0545]$} \\
\hline \multirow[t]{2}{*}{$($ Medicaid expansion $) * 1($ Chronic $)$} & & & & 0.175 \\
\hline & & & & {$[0.0745]^{* *}$} \\
\hline R-sq & 0.968 & 0.968 & 0.968 & 0.969 \\
\hline $\mathrm{N}$ & 67545 & 67545 & 67545 & 67545 \\
\hline
\end{tabular}

Notes: Specification is limited to treatment states that privatize pharmacy benefits and control states with no MCO pharmacy benefits. Unit of observation is the NDC9-state-quarter. Unreported controls include NDC9-state fixed effects and NDC9-quarter fixed effects. The transition quarter in which a state privatizes is omitted. Observations are weighted by drug spending for each NDC9-state combination in the first quarter in which it appears in the data. Standard errors are clustered by state. Significance levels: $* 0.10 * * 0.05 * * * .01$ 


\section{A.6 Impact of rebate law change on states that had already privatized pharmacy benefits}

Only four states (AZ, GA, MD, and PA) had relatively extensive privatization of their drug programs prior to the ACA and had relatively stable levels of privatization after the ACA (most other states privatized benefits for large numbers of additional beneficiaries after the ACA). We use these four states as a sample that should have been affected by the ACA by providing states with rebates for existing MCO enrollees that they were not previously receiving. ${ }^{62}$ We compare these four states with the sample of control states in our main analysis, states that did not have privatized drug benefits. Because we lack Medicaid state utilization data prior to the ACA, this analysis relies upon annual variables from the Medicaid Financial Management Report data. In particular, we construct four dependent variables: rebates per enrollee (both logged and unlogged), MCO premiums per enrollee (which includes premiums for both pharmacy and medical) and logged spending per enrollee. We include separate time trends $\left(\tau_{t e}\right.$ and $\left.\tau_{t-e}\right)$ for states depending upon whether they already privatized most pharmacy benefits. Thus, our estimation equation is:

$$
Y_{s t}=\alpha_{s}+\tau_{t e}+\tau_{t-e}+\lambda \exp _{s t}+\varepsilon_{s t}
$$

In Figure A.5, we plot the year coefficients. Coefficients for states that always had privatized drug benefits are plotted in red, whereas the coefficients for states that never had privatized drug benefits are plotted in black. There is clear evidence of a break from trend in rebates in states that always had privatized benefits relative to rebates in states that never had privatized benefits in 2011. For MCO premiums per enrollee and logged spending per enrollee, there is no clear evidence of a break from trend. We examined versions of these regressions where we pool the years 2011 and later in Table A.8. To attempt to improve the precision of our estimates, we also scaled the intensity of any effect of the policy change across the four states by their share of prescription drugs that were privatized in the second quarter of 2010 (the first quarter for which we have data), recognizing that doing so may introduce some endogeneity concerns. Across these specifications, we find evidence that state governments captured more in rebates in these four states than in states with no privatized drug benefits after the ACA. However, our estimates are too imprecise to distinguish whether these were fully offset by premium changes from MCOs, and as we noted earlier, it is difficult to rule out other possible reasons for premium changes.

\footnotetext{
${ }^{62}$ Michigan had also privatized pharmacy benefits for many enrollees. However, we exclude Michigan because of systematic errors in Medicaid's reporting of enrollment for the state.
} 
Table A.8: Effect of ACA change allowing collection of MCO rebates on states already outsourcing pharmacy benefits

\begin{tabular}{|c|c|c|c|c|}
\hline \multicolumn{5}{|c|}{ Panel A: Dep var $=\ln ($ Rebate per enrollee $)$} \\
\hline & (1) & $(2)$ & (3) & (4) \\
\hline Early adopts*(Year>2010) & $\begin{array}{c}0.513 \\
{[0.277]^{*}}\end{array}$ & $\begin{array}{c}0.507 \\
{[0.283]^{*}}\end{array}$ & & \\
\hline Ehare MCO $2010 Q 2 *($ Year>2010) & & & $\begin{array}{c}1.486 \\
{[0.110]^{* * *}}\end{array}$ & $\begin{array}{c}1.486 \\
{[0.128]^{* * *}}\end{array}$ \\
\hline Medicaid expansion & & $\begin{array}{l}0.0562 \\
{[0.120]}\end{array}$ & & $\begin{array}{c}0.00147 \\
{[0.104]}\end{array}$ \\
\hline R-sq & 0.879 & 0.879 & 0.921 & 0.921 \\
\hline \multicolumn{5}{|c|}{ Panel B: Dep var $=\ln ($ Spend per enrollee $)$} \\
\hline Early adopts $*($ Year $>2010)$ & $\begin{array}{l}-0.0566 \\
{[0.0550]}\end{array}$ & $\begin{array}{l}-0.0490 \\
{[0.0573]}\end{array}$ & & \\
\hline Share MCO $2010 Q 2 *($ Year $>2010)$ & & & $\begin{array}{c}-0.0735 \\
{[0.112]}\end{array}$ & $\begin{array}{c}-0.0545 \\
{[0.115]}\end{array}$ \\
\hline Medicaid expansion & & $\begin{array}{l}-0.0514 \\
{[0.0528]}\end{array}$ & & $\begin{array}{l}-0.0527 \\
{[0.0536]}\end{array}$ \\
\hline R-sq & 0.914 & 0.916 & 0.912 & 0.914 \\
\hline \multicolumn{5}{|c|}{ Panel C: Dep var = Rebate per enrollee } \\
\hline Early adopts*(Year>2010) & $\begin{array}{l}43.95 \\
{[53.21]}\end{array}$ & $\begin{array}{l}45.01 \\
{[57.43]}\end{array}$ & & \\
\hline Share MCO $2010 Q 2 *($ Year $>2010)$ & & & $\begin{array}{c}130.1 \\
{[79.91]}\end{array}$ & $\begin{array}{c}137.4 \\
{[84.12]}\end{array}$ \\
\hline Medicaid expansion & & $\begin{array}{l}-7.161 \\
{[37.48]}\end{array}$ & & $\begin{array}{l}-19.97 \\
{[34.54]}\end{array}$ \\
\hline R-sq & 0.850 & 0.850 & 0.861 & 0.862 \\
\hline
\end{tabular}

Panel D: Dep var = MCO premiums per enrollee

\begin{tabular}{lcccc}
\hline Early adopts*(Year>2010) & 103.1 & 181.9 & & \\
& {$[505.7]$} & {$[497.1]$} & 160.8 & 360.3 \\
Share MCO $2010 Q 2 *($ Year $>2010)$ & & & {$[1128.9]$} & {$[1086.6]$} \\
& & & -552.3 \\
Medicaid expansion & & -531.8 & & {$[293.8]^{*}$} \\
& & {$[314.7]$} & 0.934 & 0.937 \\
\hline $\mathrm{R}$-sq & 0.934 & 0.937 & 160 & 160 \\
\hline
\end{tabular}

Notes: Specification is limited to states which had already privatized a substantial share of pharmacy benefits prior ot 2010 and to control states with no MCO pharmacy benefits. Includes state fixed effects and year fixed effects. Excludes 2010. Observations are weighted by 2007 Medicaid enrollment. Standard errors are clustered by state. Significance levels: * $0.10 * * 0.05 * * * .01$ 
Figure A.5: Effect of rebate law change on states already privatizing drug benefits
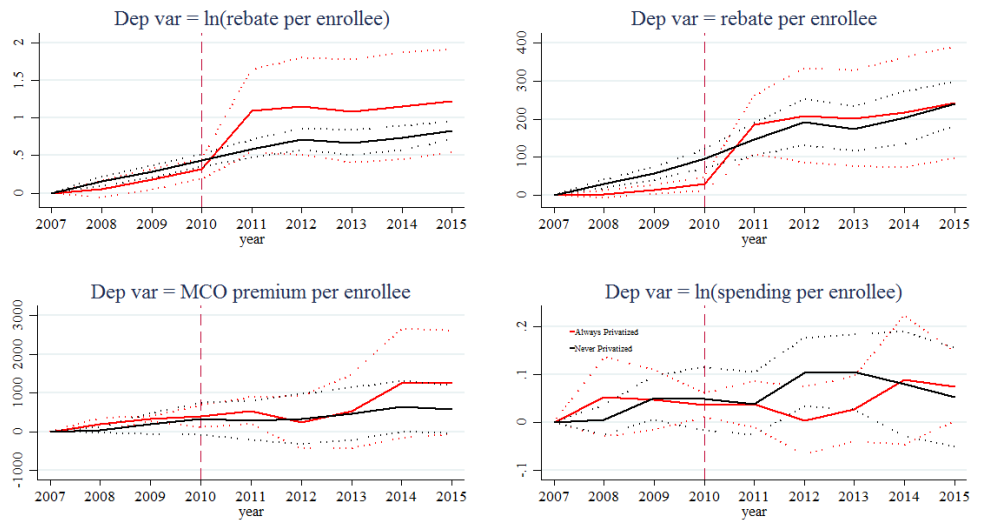

Notes: Specification is limited to states which had already privatized a substantial share of pharmacy benefits prior ot 2010 and to control states with no MCO pharmacy benefits. Includes state fixed effects and year fixed effects, and an indicator for whether the state has expanded Medicaid under the ACA. Observations are weighted by 2007 Medicaid enrollment.Point estimates for the time varying effect of each year for treatment and control states are presented in the dark line and a 95 percent confidence interval for those coefficients, based upon standard errors that are clustered by state, are presented with the dotted lines.

\section{A.7 Appendix Exhibits}

Figure A.6: Map of states by Medicaid drug MCO status, 2010-2016

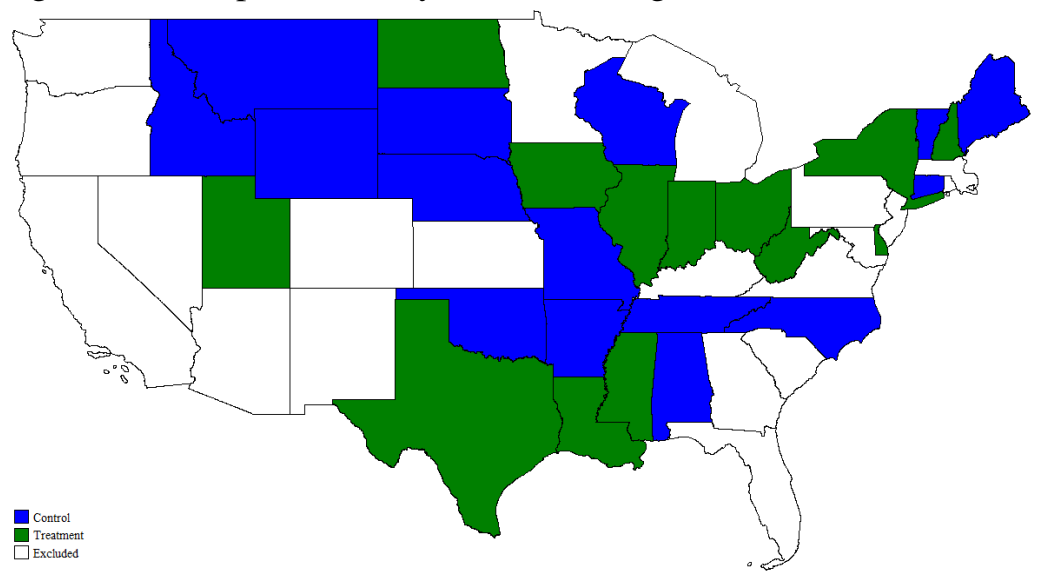

Notes: Excludes Alaska (no MCO) and Hawaii (carve-in). 


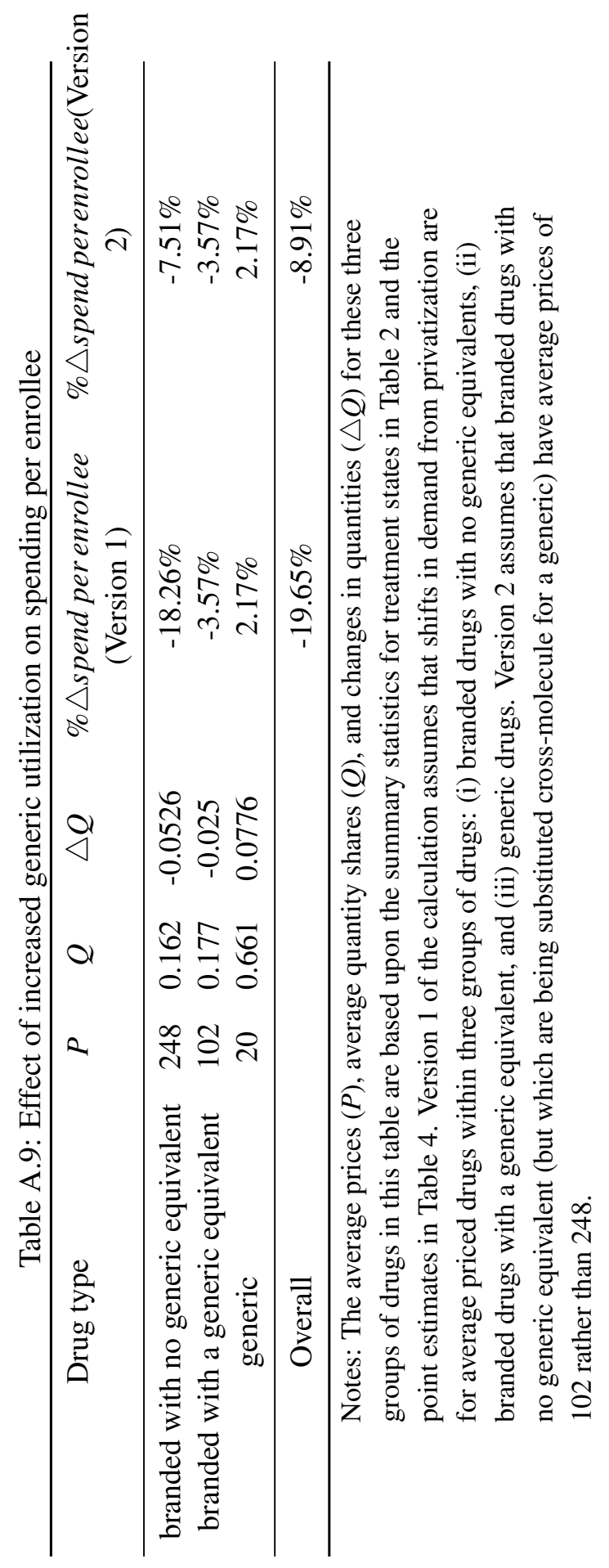


Table A.10: Heterogeneity in IV estimates of effect of MCOs on high offset vs non-high offset drugs

\begin{tabular}{lcc}
\hline & Non-high offset & High offset \\
Dependent Variable & $(1)$ & $(2)$ \\
\hline $\ln ($ Spending per enrollee $)$ & -0.321 & -0.138 \\
& {$[0.129]^{* *}$} & {$[0.101]$} \\
$\ln ($ Prescriptions per enrollee $)$ & 0.0529 & 0.143 \\
& {$[0.0733]$} & {$[0.0732]^{*}$} \\
$\ln ($ Price per prescription $)$ & -0.376 & -0.283 \\
& {$[0.0838]^{* * *}$} & {$[0.0559]^{* * *}$} \\
$\ln ($ Utilization per enrollee $)$ & -0.257 & -0.0195 \\
& {$[0.131]^{*}$} & {$[0.108]$} \\
Generic accessibility & 0.0591 & 0.0483 \\
& {$[0.0245]^{* *}$} & {$[0.0120]^{* * *}$} \\
Generic efficiency & 0.0517 & 0.0191 \\
& {$[0.0189]^{* *}$} & {$[0.0141]$} \\
Generic penetration & 0.0919 & 0.0557 \\
& {$[0.0338]^{* *}$} & {$[0.0118]^{* * *}$} \\
\hline
\end{tabular}

Notes: Specifications are limited to treatment states that privatize pharmacy benefits and control states with no MCO pharmacy benefits. Unreported controls includes state fixed effects, quarter fixed effects, and an indicator for whether the state has expanded Medicaid under the ACA. The transition quarter in which a state privatizes is omitted.

Observations are weighted by state Medicaid drug spending in the second quarter of 2010. Standard errors are clustered by state. Significance levels: * $0.10 * * 0.05 * * * .01$

Table A.11: State characteristics for heterogeneity in Centene + Molina presence

\begin{tabular}{cc}
\hline State & Has Centene + Has Molina \\
\hline DE & 0 \\
IA & 0 \\
IL & 1 \\
IN & 1 \\
LA & 1 \\
MS & 1 \\
ND & 0 \\
NH & 1 \\
NY & 1 \\
OH & 2 \\
TX & 2 \\
UT & 1 \\
WV & 0 \\
\hline
\end{tabular}

Notes: States with Centene and Molina are determined by examining company annual reports. 


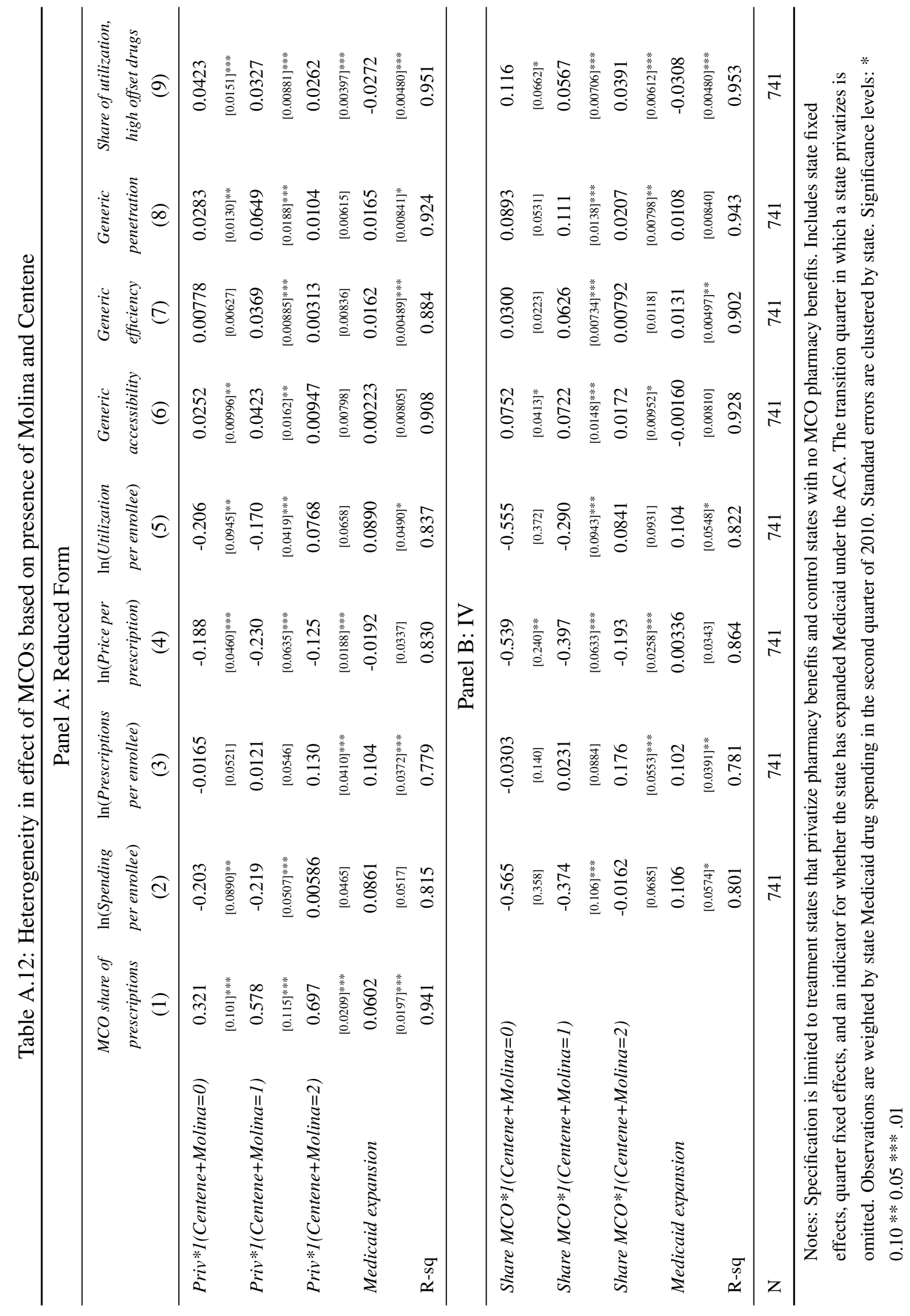


Table A.13: State characteristics for heterogeneity analysis

\begin{tabular}{lccc}
\hline State & No prior MCO? & Same PDL? & No risk adj? \\
\hline IN & No & No & No \\
OH & No & No & No \\
UT & No & No & No \\
NY & No & No & No \\
IL & No & No & Yes \\
DE & No & Yes & No \\
TX & No & Yes & No \\
WV & No & Yes & Yes \\
LA & Yes & No & No \\
ND & Yes & No & No \\
NH & Yes & Yes & No \\
IA & Yes & Yes & No \\
MS & Yes & Yes & Yes \\
\hline
\end{tabular}

Notes: Same PDL is an indicator for whether MCOs are required to use the state's formulary or whether the MCO has some leeway in creating its own formulary is from the Medicaid Drug Utilization Review (MDUR). No prior $M C O$ is an indicator for whether a state concurrently privatized medical and pharmacy benefits or already had privatized medical benefits prior to privatizing pharmacy benefits. No risk adj is an indicator for whether a state risk adjusts MCO payments based upon enrollee health status is based using responses in Gifford et al. [2011]. For the states that privatized medical benefits after 2010, we performed additional internet searches to determine whether they risk adjust based upon health.

Figure A.7: Histogram of summary statistics
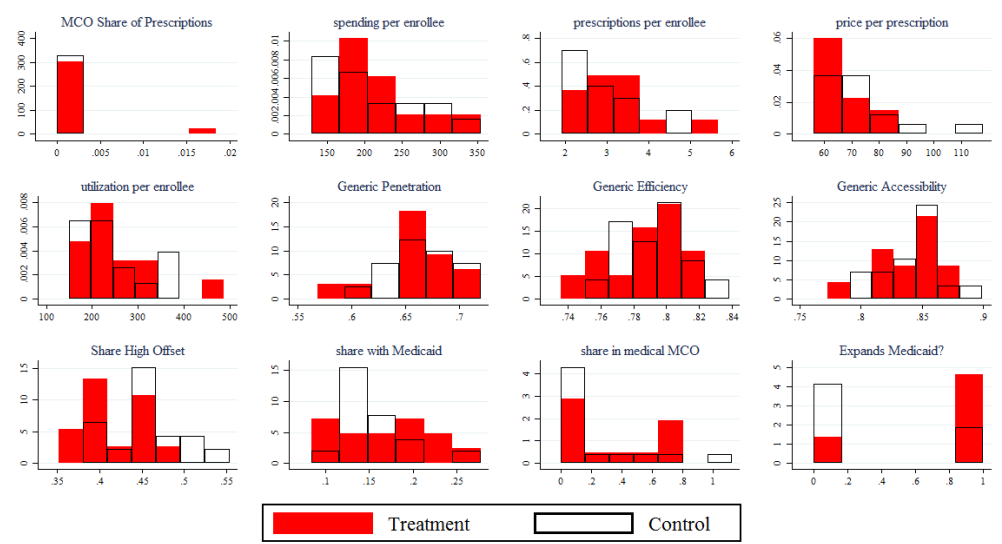

Notes: Unit of observation is the state-quarter for states in the second quarter of 2010. 
Table A.14: Heterogeneity in effect of privatization across states on per enrollee spending

\begin{tabular}{|c|c|c|c|c|c|}
\hline \multicolumn{6}{|c|}{ Panel A: Dep var = MCO share of prescriptions } \\
\hline & (1) & (2) & (3) & (4) & $(5)$ \\
\hline \multirow[t]{2}{*}{ Priv } & 0.596 & 0.589 & 0.609 & 0.675 & 0.681 \\
\hline & {$[0.0743]^{* * *}$} & {$[0.101]^{* * *}$} & {$[0.0855]^{* * *}$} & {$[0.0488]^{* * *}$} & {$[0.0643]^{* * *}$} \\
\hline \multirow[t]{2}{*}{ Medicaid expansion } & 0.0374 & 0.0410 & 0.0300 & 0.0626 & 0.0592 \\
\hline & {$[0.0306]$} & {$[0.0301]$} & {$[0.0307]$} & {$[0.0314]^{*}$} & {$[0.0342]^{*}$} \\
\hline \multirow[t]{2}{*}{ Priv*1(Same PDL) } & & 0.0216 & & & 0.0318 \\
\hline & & [0.134] & & & [0.0493] \\
\hline \multirow[t]{2}{*}{ Priv $* 1($ No prior $M C O)$} & & & -0.0879 & & -0.105 \\
\hline & & & {$[0.0921]$} & & {$[0.0673]$} \\
\hline \multirow[t]{2}{*}{ Priv $* 1$ (No risk adj) } & & & & -0.396 & -0.401 \\
\hline & & & & {$[0.0496]^{* * *}$} & {$[0.0501]^{* * *}$} \\
\hline R-sq & 0.935 & 0.935 & 0.935 & 0.957 & 0.958 \\
\hline \multicolumn{6}{|c|}{ Panel B: Dep var $=\ln ($ Spending per enrollee $)($ Reduced Form $)$} \\
\hline \multirow[t]{2}{*}{ Priv } & -0.151 & -0.213 & -0.123 & -0.138 & -0.170 \\
\hline & {$[0.0658]^{* *}$} & {$[0.0537]^{* * *}$} & {$[0.0635]^{*}$} & {$[0.0748]^{*}$} & {$[0.0574]^{* * *}$} \\
\hline \multirow[t]{2}{*}{ Medicaid expansion } & 0.0551 & 0.0878 & 0.0395 & 0.0593 & 0.0774 \\
\hline & {$[0.0564]$} & {$[0.0530]$} & {$[0.0478]$} & [0.0539] & {$[0.0442]^{*}$} \\
\hline \multirow[t]{2}{*}{ Priv*1(Same PDL) } & & 0.197 & & & 0.196 \\
\hline & & {$[0.0864]^{* *}$} & & & {$[0.0706]^{* * *}$} \\
\hline \multirow[t]{2}{*}{ Priv $* 1($ No prior $M C O)$} & & & -0.185 & & -0.179 \\
\hline & & & [0.149] & & {$[0.119]$} \\
\hline \multirow[t]{2}{*}{ Priv $* 1$ (No risk adj) } & & & & -0.0654 & -0.0780 \\
\hline & & & & {$[0.0828]$} & {$[0.0736]$} \\
\hline R-sq & 0.803 & 0.811 & 0.807 & 0.804 & 0.816 \\
\hline \multicolumn{6}{|c|}{ Panel C: Dep var $=\ln ($ Spending per enrollee $)(\mathrm{IV})$} \\
\hline \multirow[t]{2}{*}{ Share $M C O$} & -0.253 & -0.359 & -0.207 & -0.215 & -0.277 \\
\hline & {$[0.116]^{* *}$} & {$[0.102]^{* * *}$} & {$[0.105]^{*}$} & {$[0.110]^{*}$} & {$[0.0718]^{* * *}$} \\
\hline \multirow[t]{2}{*}{ Medicaid expansion } & 0.0646 & 0.111 & 0.0422 & 0.0799 & 0.107 \\
\hline & {$[0.0637]$} & {$[0.0581]^{*}$} & {$[0.0517]$} & {$[0.0662]$} & {$[0.0533]^{*}$} \\
\hline \multirow[t]{2}{*}{ Share $M C O^{*} 1($ Same PDL) } & & 0.312 & & & 0.315 \\
\hline & & {$[0.151]^{* *}$} & & & {$[0.0987]^{* * *}$} \\
\hline \multirow[t]{2}{*}{ Share $M C O * 1($ No prior $M C O)$} & & & -0.358 & & -0.328 \\
\hline & & & {$[0.251]$} & & {$[0.233]$} \\
\hline \multirow[t]{2}{*}{ Share $M C O * 1$ (No risk adj) } & & & & -0.431 & -0.455 \\
\hline & & & & {$[0.227]^{*}$} & {$[0.224]^{*}$} \\
\hline R-sq & 0.793 & 0.799 & 0.805 & 0.778 & 0.795 \\
\hline $\mathrm{N}$ & 741 & 741 & 741 & 741 & 741 \\
\hline
\end{tabular}

Notes: Specification is limited to treatment states that privatize pharmacy benefits and control states with no MCO pharmacy benefits. Includes state fixed effects and quarter fixed effects. The transition quarter in which a state privatizes is omitted. Observations are weighted by state Medicaid drug spending in the second quarter of 2010. Standard errors are clustered by state. Significance levels: $* 0.10 * * 0.05 * * * .01$ 
Table A.15: Heterogeneity in effect of privatization across states on prescriptions per enrollee

\begin{tabular}{|c|c|c|c|c|c|}
\hline \multicolumn{6}{|c|}{ Panel A: Dep var $=\ln ($ Prescriptions per enrollee $)($ Reduced Form $)$} \\
\hline & (1) & (2) & (3) & (4) & $(5)$ \\
\hline \multirow[t]{2}{*}{ Priv } & 0.0452 & 0.0124 & 0.0528 & 0.0849 & 0.0598 \\
\hline & {$[0.0456]$} & {$[0.0489]$} & {$[0.0513]$} & {$[0.0338]^{* *}$} & {$[0.0283]^{* *}$} \\
\hline \multirow[t]{2}{*}{ Medicaid expansion } & 0.0871 & 0.104 & 0.0828 & 0.0998 & 0.114 \\
\hline & {$[0.0410]^{* *}$} & {$[0.0375]^{* * *}$} & {$[0.0409]^{*}$} & {$[0.0402]^{* *}$} & {$[0.0387]^{* * *}$} \\
\hline \multirow[t]{2}{*}{ Priv*1(Same PDL) } & & 0.104 & & & 0.109 \\
\hline & & [0.0704] & & & {$[0.0375]^{* * *}$} \\
\hline \multirow[t]{2}{*}{ Priv $* 1($ No prior $M C O)$} & & & -0.0503 & & -0.0549 \\
\hline & & & {$[0.0771]$} & & {$[0.0785]$} \\
\hline \multirow[t]{2}{*}{ Priv $* 1($ No risk adj $)$} & & & & -0.200 & -0.206 \\
\hline & & & & {$[0.0694]^{* * *}$} & {$[0.0537]^{* * *}$} \\
\hline R-sq & 0.773 & 0.777 & 0.774 & 0.785 & 0.789 \\
\hline \multicolumn{6}{|c|}{ Panel B: Dep var $=\ln ($ Prescriptions per enrollee $)(\mathrm{IV})$} \\
\hline \multirow[t]{2}{*}{ Share $M C O$} & 0.0759 & 0.0228 & 0.0857 & 0.115 & 0.0673 \\
\hline & {$[0.0704]$} & {$[0.0788]$} & [0.0748] & {$[0.0496]^{* *}$} & {$[0.0493]$} \\
\hline \multirow[t]{2}{*}{ Medicaid expansion } & 0.0842 & 0.108 & 0.0795 & 0.0999 & 0.122 \\
\hline & {$[0.0404]^{* *}$} & {$[0.0376] * * *$} & {$[0.0403]^{*}$} & {$[0.0476]^{* *}$} & {$[0.0505]^{* *}$} \\
\hline \multirow[t]{2}{*}{ Share $M C O * 1($ Same PDL) } & & 0.157 & & & 0.167 \\
\hline & & {$[0.0962]$} & & & {$[0.0662]^{* *}$} \\
\hline \multirow[t]{2}{*}{ Share $M C O * 1($ No prior $M C O)$} & & & -0.0756 & & -0.0524 \\
\hline & & & {$[0.123]$} & & {$[0.150]$} \\
\hline \multirow[t]{2}{*}{ Share $M C O * 1($ No risk adj $)$} & & & & -0.442 & -0.463 \\
\hline & & & & {$[0.211]^{* *}$} & {$[0.185]^{* *}$} \\
\hline R-sq & 0.781 & 0.780 & 0.784 & 0.762 & 0.762 \\
\hline $\mathrm{N}$ & 741 & 741 & 741 & 741 & 741 \\
\hline
\end{tabular}

Notes: Specification is limited to treatment states that privatize pharmacy benefits and control states with no MCO pharmacy benefits. Includes state fixed effects and quarter fixed effects. The transition quarter in which a state privatizes is omitted. Observations are weighted by state Medicaid drug spending in the second quarter of 2010. Standard errors are clustered by state. Significance levels: $* 0.10 * * 0.05 * * * .01$ 
Table A.16: Heterogeneity in effect of privatization across states on price per prescription

\begin{tabular}{|c|c|c|c|c|c|}
\hline \multicolumn{6}{|c|}{ Panel A: Dep var = $\ln ($ Price per prescription $)($ Reduced Form $)$} \\
\hline & (1) & (2) & (3) & (4) & $(5)$ \\
\hline \multirow[t]{2}{*}{ Priv } & -0.196 & -0.225 & -0.177 & -0.223 & -0.230 \\
\hline & {$[0.0500]^{* * *}$} & {$[0.0634]^{* * *}$} & {$[0.0513]^{* * *}$} & {$[0.0500]^{* * *}$} & {$[0.0549]^{* * *}$} \\
\hline \multirow[t]{2}{*}{ Medicaid expansion } & -0.0330 & -0.0180 & -0.0440 & -0.0415 & -0.0374 \\
\hline & {$[0.0336]$} & {$[0.0356]$} & {$[0.0246]^{*}$} & {$[0.0336]$} & {$[0.0302]$} \\
\hline \multirow[t]{2}{*}{ Priv*1(Same PDL) } & & 0.0906 & & & 0.0836 \\
\hline & & [0.0676] & & & [0.0596] \\
\hline \multirow[t]{2}{*}{ Priv $* 1($ No prior $M C O)$} & & & -0.130 & & -0.120 \\
\hline & & & {$[0.101]$} & & {$[0.0607]^{*}$} \\
\hline \multirow[t]{2}{*}{ Priv $* 1$ (No risk adj) } & & & & 0.135 & 0.128 \\
\hline & & & & {$[0.0568]^{* *}$} & {$[0.0615]^{* *}$} \\
\hline R-sq & 0.821 & 0.828 & 0.828 & 0.833 & 0.844 \\
\hline \multicolumn{6}{|c|}{ Panel B: Dep var $=\ln ($ Price per prescription $)(\mathrm{IV})$} \\
\hline \multirow[t]{2}{*}{ Share $M C O$} & -0.329 & -0.380 & -0.293 & -0.330 & -0.344 \\
\hline & {$[0.0693]^{* * *}$} & {$[0.0704]^{* * *}$} & {$[0.0582]^{* * *}$} & {$[0.0702]^{* * *}$} & {$[0.0554]^{* * *}$} \\
\hline \multirow[t]{2}{*}{ Medicaid expansion } & -0.0207 & 0.00179 & -0.0379 & -0.0211 & -0.0162 \\
\hline & {$[0.0361]$} & {$[0.0380]$} & {$[0.0246]$} & {$[0.0360]$} & {$[0.0271]$} \\
\hline \multirow[t]{2}{*}{ Share $M C O * 1($ Same PDL $)$} & & 0.150 & & & 0.144 \\
\hline & & [0.0912] & & & {$[0.0738]^{*}$} \\
\hline \multirow[t]{2}{*}{ Share $M C O * 1($ No prior $M C O)$} & & & -0.276 & & -0.269 \\
\hline & & & {$[0.161]^{*}$} & & {$[0.119]^{* *}$} \\
\hline \multirow[t]{2}{*}{ Share $M C O * 1($ No risk adj) } & & & & 0.0107 & 0.00746 \\
\hline & & & & {$[0.123]$} & {$[0.141]$} \\
\hline $\mathrm{R}-\mathrm{sq}$ & 0.849 & 0.862 & 0.858 & 0.849 & 0.871 \\
\hline $\mathrm{N}$ & 741 & 741 & 741 & 741 & 741 \\
\hline
\end{tabular}

Notes: Specification is limited to treatment states that privatize pharmacy benefits and control states with no MCO pharmacy benefits. Includes state fixed effects and quarter fixed effects. The transition quarter in which a state privatizes is omitted. Observations are weighted by state Medicaid drug spending in the second quarter of 2010. Standard errors are clustered by state. Significance levels: $* 0.10 * * 0.05 * * * .01$ 
Table A.17: Heterogeneity in effect of privatization across states on utilization per enrollee

\section{Panel A: Dep var $=\ln ($ Utilization per enrollee $)($ Reduced Form $)$}

\begin{tabular}{|c|c|c|c|c|c|}
\hline & (1) & (2) & (3) & (4) & (5) \\
\hline \multirow[t]{2}{*}{ Priv } & -0.0988 & -0.168 & -0.0765 & -0.0752 & -0.121 \\
\hline & {$[0.0680]$} & {$[0.0441]^{* * *}$} & {$[0.0713]$} & {$[0.0761]$} & {$[0.0503]^{* *}$} \\
\hline \multirow[t]{2}{*}{ Medicaid expansion } & 0.0537 & 0.0900 & 0.0412 & 0.0613 & 0.0863 \\
\hline & {$[0.0560]$} & {$[0.0508]^{*}$} & [0.0523] & {$[0.0526]$} & {$[0.0449]^{*}$} \\
\hline \multirow[t]{2}{*}{ Priv*1(Same PDL) } & & 0.219 & & & 0.220 \\
\hline & & {$[0.0961]^{* *}$} & & & {$[0.0702]^{* * *}$} \\
\hline \multirow[t]{2}{*}{ Priv $* 1($ No prior $M C O)$} & & & -0.148 & & -0.144 \\
\hline & & & {$[0.123]$} & & {$[0.0908]$} \\
\hline \multirow[t]{2}{*}{ Priv*1(No risk adj) } & & & & -0.119 & -0.132 \\
\hline & & & & {$[0.0772]$} & {$[0.0684]^{*}$} \\
\hline $\mathrm{R}$-sq & 0.821 & 0.833 & 0.824 & 0.824 & 0.839 \\
\hline \multicolumn{6}{|c|}{ Panel B: Dep var $=\ln ($ Utilization per enrollee $)(\mathrm{IV})$} \\
\hline \multirow[t]{2}{*}{ Share $M C O$} & -0.166 & -0.281 & -0.129 & -0.123 & -0.206 \\
\hline & {$[0.119]$} & {$[0.0884]^{* * *}$} & {$[0.118]$} & [0.111] & {$[0.0644]^{* * *}$} \\
\hline \multirow[t]{2}{*}{ Medicaid expansion } & 0.0599 & 0.111 & 0.0423 & 0.0769 & 0.115 \\
\hline & {$[0.0625]$} & {$[0.0552]^{*}$} & [0.0563] & {$[0.0650]$} & {$[0.0561]^{*}$} \\
\hline \multirow[t]{2}{*}{ Share $M C O^{*} 1($ Same PDL) } & & 0.343 & & & 0.349 \\
\hline & & {$[0.155]^{* *}$} & & & {$[0.0945]^{* * *}$} \\
\hline \multirow[t]{2}{*}{ Share $M C O * 1($ No prior $M C O)$} & & & -0.282 & & -0.248 \\
\hline & & & {$[0.205]$} & & [0.182] \\
\hline \multirow[t]{2}{*}{ Share $M C O * 1$ (No risk adj) } & & & & -0.480 & -0.515 \\
\hline & & & & {$[0.202]^{* *}$} & {$[0.197]^{* *}$} \\
\hline R-sq & 0.812 & 0.819 & 0.821 & 0.793 & 0.808 \\
\hline $\mathrm{N}$ & 741 & 741 & 741 & 741 & 741 \\
\hline
\end{tabular}

Notes: Specification is limited to treatment states that privatize pharmacy benefits and control states with no MCO pharmacy benefits. Includes state fixed effects and quarter fixed effects. The transition quarter in which a state privatizes is omitted. Observations are weighted by state Medicaid drug spending in the second quarter of 2010. Standard errors are clustered by state. Significance levels: $* 0.10 * * 0.05 * * * .01$ 
Table A.18: Heterogeneity in effect of privatization across states on generic accessibility

\begin{tabular}{|c|c|c|c|c|c|}
\hline \multicolumn{6}{|c|}{ Panel A: Dep var = Generic accessibility (Reduced Form) } \\
\hline & (1) & (2) & (3) & (4) & $(5)$ \\
\hline \multirow[t]{2}{*}{ Priv } & 0.0314 & 0.0377 & 0.0318 & 0.0381 & 0.0449 \\
\hline & {$[0.0120]^{* *}$} & {$[0.0165]^{* *}$} & {$[0.0142]^{* *}$} & {$[0.0141]^{* *}$} & {$[0.0184]^{* *}$} \\
\hline \multirow[t]{2}{*}{ Medicaid expansion } & 0.00641 & 0.00309 & 0.00615 & 0.00857 & 0.00490 \\
\hline & {$[0.00826]$} & {$[0.00722]$} & {$[0.00702]$} & {$[0.00745]$} & {$[0.00650]$} \\
\hline \multirow[t]{2}{*}{ Priv*1(Same PDL) } & & -0.0200 & & & -0.0191 \\
\hline & & [0.0185] & & & {$[0.0176]$} \\
\hline \multirow[t]{2}{*}{ Priv $^{*} 1($ No prior $M C O)$} & & & -0.00302 & & -0.00547 \\
\hline & & & {$[0.0185]$} & & {$[0.0136]$} \\
\hline \multirow[t]{2}{*}{ Priv $* 1$ (No risk adj) } & & & & -0.0340 & -0.0334 \\
\hline & & & & {$[0.0195]^{*}$} & [0.0201] \\
\hline R-sq & 0.894 & 0.899 & 0.894 & 0.906 & 0.911 \\
\hline \multicolumn{6}{|c|}{ Panel B: Dep var = Generic acessibility (IV) } \\
\hline \multirow[t]{2}{*}{ Share $M C O$} & 0.0526 & 0.0636 & 0.0523 & 0.0556 & 0.0657 \\
\hline & {$[0.0165]^{* * *}$} & {$[0.0192]^{* * *}$} & {$[0.0186]^{* * *}$} & {$[0.0182] * * *$} & {$[0.0218]^{* * *}$} \\
\hline \multirow[t]{2}{*}{ Medicaid expansion } & 0.00444 & -0.000426 & 0.00462 & 0.00565 & 0.000868 \\
\hline & {$[0.00732]$} & {$[0.00726]$} & [0.00627] & [0.00680] & {$[0.00655]$} \\
\hline \multirow[t]{2}{*}{ Share $M C O^{*} 1($ Same PDL) } & & -0.0326 & & & -0.0319 \\
\hline & & {$[0.0225]$} & & & {$[0.0226]$} \\
\hline \multirow[t]{2}{*}{ Share $M C O * 1($ No prior $M C O)$} & & & 0.00279 & & 0.00216 \\
\hline & & & [0.0267] & & {$[0.0172]$} \\
\hline \multirow[t]{2}{*}{ Share $M C O^{*} 1($ No risk adj $)$} & & & & -0.0340 & -0.0296 \\
\hline & & & & {$[0.0348]$} & {$[0.0356]$} \\
\hline R-sq & 0.907 & 0.915 & 0.907 & 0.915 & 0.923 \\
\hline $\mathrm{N}$ & 741 & 741 & 741 & 741 & 741 \\
\hline
\end{tabular}

Notes: Specification is limited to treatment states that privatize pharmacy benefits and control states with no MCO pharmacy benefits. Includes state fixed effects and quarter fixed effects. The transition quarter in which a state privatizes is omitted. Observations are weighted by state Medicaid drug spending in the second quarter of 2010. Standard errors are clustered by state. Significance levels: $* 0.10 * * 0.05 * * * .01$ 
Table A.19: Heterogeneity in effect of privatization across states on generic efficiency

\begin{tabular}{|c|c|c|c|c|c|}
\hline \multicolumn{6}{|c|}{ Panel A: Dep var = Generic efficiency (Reduced Form) } \\
\hline & (1) & (2) & (3) & (4) & $(5)$ \\
\hline \multirow[t]{2}{*}{ Priv } & 0.0249 & 0.0372 & 0.0230 & 0.0277 & 0.0379 \\
\hline & {$[0.0101]^{* *}$} & {$[0.00863]^{* * *}$} & {$[0.0114]^{*}$} & {$[0.0122]^{* *}$} & {$[0.00961]^{* * *}$} \\
\hline \multirow[t]{2}{*}{ Medicaid expansion } & 0.0202 & 0.0138 & 0.0213 & 0.0211 & 0.0156 \\
\hline & {$[0.00703]^{* * *}$} & {$[0.00473]^{* * *}$} & {$[0.00617]^{* * *}$} & {$[0.00693]^{* * *}$} & {$[0.00416]^{* * *}$} \\
\hline \multirow[t]{2}{*}{ Priv*1(Same PDL) } & & -0.0389 & & & -0.0383 \\
\hline & & {$[0.00960] * * *$} & & & {$[0.00922]^{* * *}$} \\
\hline \multirow[t]{2}{*}{ Priv $* 1($ No prior $M C O)$} & & & 0.0130 & & 0.0107 \\
\hline & & & [0.0173] & & {$[0.00701]$} \\
\hline \multirow[t]{2}{*}{ Priv* 1 (No risk adj) } & & & & -0.0142 & -0.0124 \\
\hline & & & & {$[0.0127]$} & {$[0.0101]$} \\
\hline R-sq & 0.851 & 0.888 & 0.853 & 0.855 & 0.893 \\
\hline \multicolumn{6}{|c|}{ Panel B: Dep var = Generic efficiency (IV) } \\
\hline \multirow[t]{2}{*}{ Share $M C O$} & 0.0418 & 0.0625 & 0.0381 & 0.0413 & 0.0579 \\
\hline & {$[0.0160]^{* *}$} & {$[0.00823] * * *$} & {$[0.0167]^{* *}$} & {$[0.0169]^{* *}$} & {$[0.00866]^{* * *}$} \\
\hline \multirow[t]{2}{*}{ Medicaid expansion } & 0.0187 & 0.00952 & 0.0205 & 0.0185 & 0.0107 \\
\hline & {$[0.00760]^{* *}$} & {$[0.00478]^{*}$} & {$[0.00665]^{* * *}$} & {$[0.00775]^{* *}$} & {$[0.00426]^{* *}$} \\
\hline \multirow[t]{2}{*}{ Share $M C O * 1($ Same PDL) } & & -0.0613 & & & -0.0610 \\
\hline & & {$[0.0104]^{* * *}$} & & & {$[0.00874]^{* * *}$} \\
\hline \multirow[t]{2}{*}{ Share $M C O * 1$ (No prior $M C O)$} & & & 0.0289 & & 0.0255 \\
\hline & & & {$[0.0279]$} & & {$[0.0102]^{* *}$} \\
\hline \multirow[t]{2}{*}{ Share $M C O^{*} 1($ No risk adj $)$} & & & & 0.00627 & 0.0135 \\
\hline & & & & {$[0.0191]$} & {$[0.0140]$} \\
\hline R-sq & 0.861 & 0.907 & 0.864 & 0.860 & 0.907 \\
\hline $\mathrm{N}$ & 741 & 741 & 741 & 741 & 741 \\
\hline
\end{tabular}

Notes: Specification is limited to treatment states that privatize pharmacy benefits and control states with no MCO pharmacy benefits. Includes state fixed effects and quarter fixed effects. The transition quarter in which a state privatizes is omitted. Observations are weighted by state Medicaid drug spending in the second quarter of 2010. Standard errors are clustered by state. Significance levels: $* 0.10 * * 0.05 * * * .01$ 
Table A.20: Heterogeneity in effect of privatization across states on generic penetration

\begin{tabular}{|c|c|c|c|c|c|}
\hline \multicolumn{6}{|c|}{ Panel A: Dep var = Generic penetration $($ Reduced Form $)$} \\
\hline & (1) & (2) & (3) & (4) & $(5)$ \\
\hline \multirow[t]{2}{*}{ Priv } & 0.0463 & 0.0621 & 0.0448 & 0.0533 & 0.0675 \\
\hline & {$[0.0168]^{* *}$} & {$[0.0189]^{* * *}$} & {$[0.0195]^{* *}$} & {$[0.0204]^{* *}$} & {$[0.0215]^{* * *}$} \\
\hline \multirow[t]{2}{*}{ Medicaid expansion } & 0.0232 & 0.0149 & 0.0240 & 0.0255 & 0.0178 \\
\hline & {$[0.0102]^{* *}$} & {$[0.00833]^{*}$} & {$[0.00826]^{* * *}$} & {$[0.00977]^{* *}$} & {$[0.00731]^{* *}$} \\
\hline \multirow[t]{2}{*}{ Priv*1(Same PDL) } & & -0.0499 & & & -0.0487 \\
\hline & & {$[0.0216]^{* *}$} & & & {$[0.0211]^{* *}$} \\
\hline \multirow[t]{2}{*}{ Priv $* 1($ No prior $M C O)$} & & & 0.00954 & & 0.00570 \\
\hline & & & {$[0.0280]$} & & {$[0.0156]$} \\
\hline \multirow[t]{2}{*}{ Priv $* 1$ (No risk adj) } & & & & -0.0357 & -0.0337 \\
\hline & & & & [0.0243] & [0.0239] \\
\hline R-sq & 0.903 & 0.919 & 0.903 & 0.910 & 0.926 \\
\hline \multicolumn{6}{|c|}{ Panel B: Dep var = Generic penetration (IV) } \\
\hline \multirow[t]{2}{*}{ Share $M C O$} & 0.0776 & 0.104 & 0.0739 & 0.0787 & 0.101 \\
\hline & {$[0.0246]^{* * *}$} & {$[0.0187]^{* * *}$} & {$[0.0268]^{* *}$} & {$[0.0270]^{* * *}$} & {$[0.0223]^{* * *}$} \\
\hline \multirow[t]{2}{*}{ Medicaid expansion } & 0.0203 & 0.00844 & 0.0221 & 0.0208 & 0.0102 \\
\hline & {$[0.00990]^{* *}$} & [0.00858] & {$[0.00819]^{* *}$} & {$[0.0102]^{*}$} & {$[0.00771]$} \\
\hline \multirow[t]{2}{*}{ Share $M C O * 1($ Same PDL) } & & -0.0794 & & & -0.0788 \\
\hline & & {$[0.0245]^{* * *}$} & & & {$[0.0238]^{* * *}$} \\
\hline \multirow[t]{2}{*}{ Share $M C O * 1$ (No prior $M C O)$} & & & 0.0284 & & 0.0245 \\
\hline & & & {$[0.0432]$} & & {$[0.0198]$} \\
\hline \multirow[t]{2}{*}{ Share $M C O * 1($ No risk adj) } & & & & -0.0129 & -0.00305 \\
\hline & & & & {$[0.0375]$} & {$[0.0377]$} \\
\hline R-sq & 0.914 & 0.936 & 0.914 & 0.916 & 0.937 \\
\hline $\mathrm{N}$ & 741 & 741 & 741 & 741 & 741 \\
\hline
\end{tabular}

Notes: Specification is limited to treatment states that privatize pharmacy benefits and control states with no MCO pharmacy benefits. Includes state fixed effects and quarter fixed effects. The transition quarter in which a state privatizes is omitted. Observations are weighted by state Medicaid drug spending in the second quarter of 2010. Standard errors are clustered by state. Significance levels: $* 0.10 * * 0.05 * * * .01$ 
Table A.21: Heterogeneity in effect of privatization across states on use of high offset drugs

\begin{tabular}{|c|c|c|c|c|c|}
\hline \multicolumn{6}{|c|}{ Panel A: Dep var = Share of utilization to high offset drugs $($ Reduced Form $)$} \\
\hline & (1) & (2) & (3) & (4) & $(5)$ \\
\hline \multirow[t]{2}{*}{ Priv } & 0.0314 & 0.0322 & 0.0306 & 0.0342 & 0.0341 \\
\hline & {$[0.00657]^{* * *}$} & {$[0.00864]^{* * *}$} & {$[0.00751]^{* * *}$} & {$[0.00621]^{* * *}$} & {$[0.00832]^{* * *}$} \\
\hline \multirow[t]{2}{*}{ Medicaid expansion } & -0.0261 & -0.0265 & -0.0257 & -0.0252 & -0.0252 \\
\hline & {$[0.00408]^{* * *}$} & {$[0.00525]^{* * *}$} & {$[0.00435]^{* * *}$} & {$[0.00424] * * *$} & {$[0.00585]^{* * *}$} \\
\hline \multirow[t]{2}{*}{ Priv*1(Same PDL) } & & -0.00244 & & & -0.00189 \\
\hline & & {$[0.0103]$} & & & {$[0.0108]$} \\
\hline \multirow[t]{2}{*}{ Priv*1(No prior $M C O)$} & & & 0.00508 & & 0.00434 \\
\hline & & & {$[0.00693]$} & & {$[0.00667]$} \\
\hline \multirow[t]{2}{*}{ Priv* 1 (No risk adj) } & & & & -0.0142 & -0.0140 \\
\hline & & & & {$[0.0123]$} & {$[0.0124]$} \\
\hline R-sq & 0.950 & 0.950 & 0.950 & 0.951 & 0.951 \\
\hline \multicolumn{6}{|c|}{ Panel B: Dep var = Share of utilization to high offset drugs (IV) } \\
\hline \multirow[t]{2}{*}{ Share $M C O$} & 0.0526 & 0.0545 & 0.0505 & 0.0511 & 0.0509 \\
\hline & {$[0.00823]^{* * *}$} & {$[0.00799]^{* * *}$} & {$[0.00873]^{* * *}$} & {$[0.00792]^{* * *}$} & {$[0.00930]^{* * *}$} \\
\hline \multirow[t]{2}{*}{ Medicaid expansion } & -0.0281 & -0.0289 & -0.0270 & -0.0287 & -0.0285 \\
\hline & {$[0.00444]^{* * *}$} & {$[0.00598]^{* * *}$} & {$[0.00459]^{* * *}$} & {$[0.00399]^{* * *}$} & {$[0.00577]^{* * *}$} \\
\hline \multirow[t]{2}{*}{ Share $M C O * 1($ Same PDL) } & & -0.00551 & & & -0.00554 \\
\hline & & {$[0.0175]$} & & & {$[0.0155]$} \\
\hline \multirow[t]{2}{*}{ Share $M C O * 1$ (No prior $M C O)$} & & & 0.0168 & & 0.0160 \\
\hline & & & {$[0.00697]^{* *}$} & & {$[0.00668]^{* *}$} \\
\hline \multirow[t]{2}{*}{ Share $M C O^{*} 1($ No risk adj $)$} & & & & 0.0174 & 0.0171 \\
\hline & & & & {$[0.0338]$} & {$[0.0341]$} \\
\hline R-sq & 0.954 & 0.954 & 0.955 & 0.954 & 0.955 \\
\hline $\mathrm{N}$ & 741 & 741 & 741 & 741 & 741 \\
\hline
\end{tabular}

Notes: Specification is limited to treatment states that privatize pharmacy benefits and control states with no MCO pharmacy benefits. Includes state fixed effects and quarter fixed effects. The transition quarter in which a state privatizes is omitted. Observations are weighted by state Medicaid drug spending in the second quarter of 2010. Standard errors are clustered by state. Significance levels: $* 0.10 * * 0.05 * * * .01$ 
Table A.22: First Stage relationship for analysis on heterogeneity in effect of MCOs across states

$\begin{array}{cccc}\text { Share MCO } & \text { Share } M C O & \text { Share } M C O & \text { Share } M C O \\ & * 1(\text { Same } P D L) & * 1(\text { No prior } M C O) & * 1(\text { No risk adj })\end{array}$

(1) (2) (3) (4)

\begin{tabular}{lcccc}
\hline Priv & 0.681 & 0.0180 & -0.00654 & -0.0228 \\
& {$[0.0643]^{* * *}$} & {$[0.0186]$} & {$[0.00958]$} & {$[0.0205]$} \\
Priv $^{*}$ l(Same PDL) & 0.0318 & 0.660 & 0.00237 & 0.00647 \\
& {$[0.0493]$} & {$[0.0606]^{* * *}$} & {$[0.0176]$} & {$[0.0181]$} \\
Priv*l(No prior MCO) & -0.105 & -0.0326 & 0.565 & 0.0276 \\
& {$[0.0673]$} & {$[0.0339]$} & {$[0.0352]^{* * *}$} & {$[0.0201]$} \\
Priv*l(No risk adj) & -0.401 & -0.104 & -0.00951 & 0.350 \\
& {$[0.0501]^{* * *}$} & {$[0.0814]$} & {$[0.0122]$} & {$[0.0165]^{* * *}$} \\
Medicaid expansion & 0.0592 & -0.0236 & -0.00900 & 0.0200 \\
& {$[0.0342]^{*}$} & {$[0.0171]$} & {$[0.0179]$} & {$[0.0334]$} \\
\hline R-sq & 0.958 & 0.966 & 0.849 & 0.753 \\
$\mathrm{~N}$ & 741 & 741 & 741 & 741 \\
\hline
\end{tabular}

Notes: Specification is limited to treatment states that privatize pharmacy benefits and control states with no MCO pharmacy benefits. Includes state fixed effects and quarter fixed effects. The transition quarter in which a state privatizes is omitted. Observations are weighted by state Medicaid drug spending in the second quarter of 2010. Standard errors are clustered by state. Significance levels: $* 0.10 * * 0.05 * * * .01$

Figure A.8: Share MCO by state type
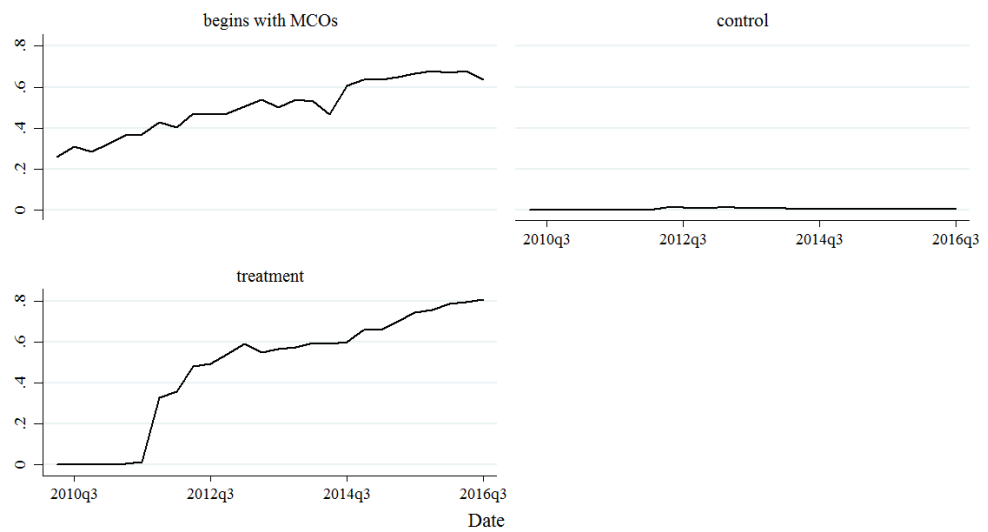

Notes: This Figure excludes DC, MA, and RI because of data limitations. 


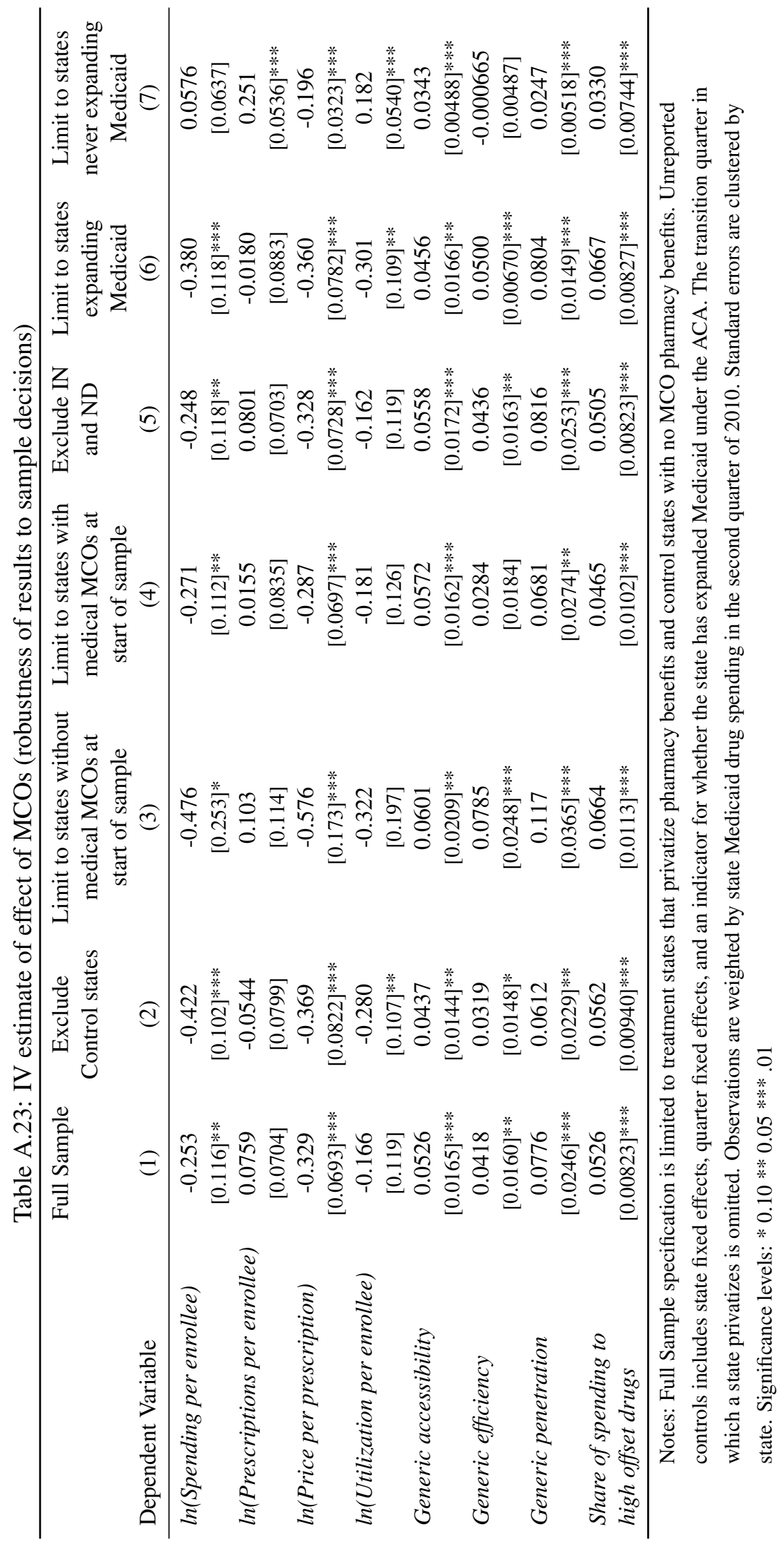




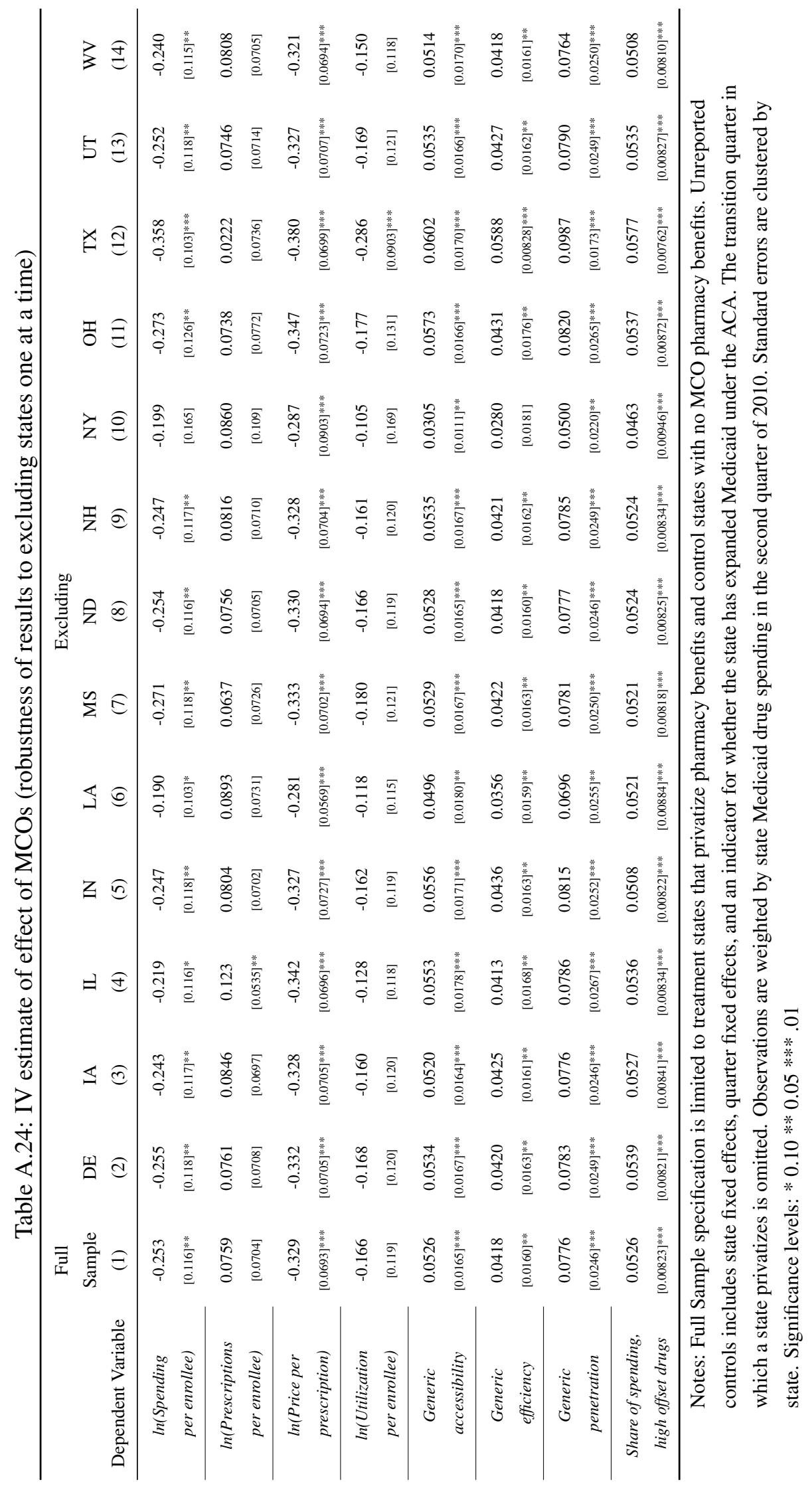




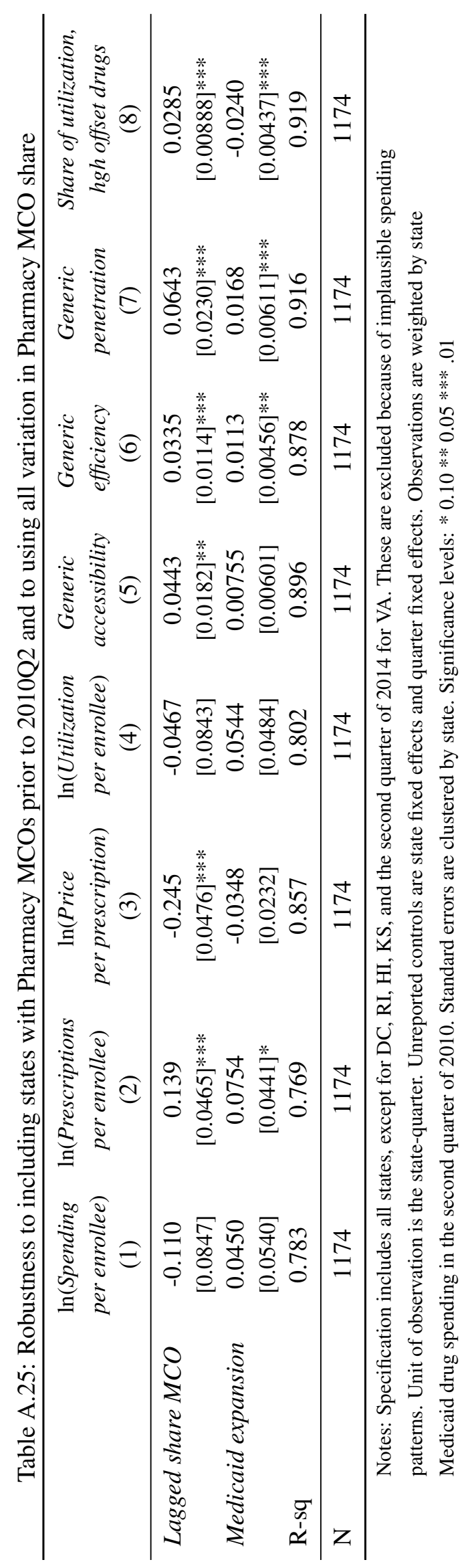


Table A.26: Reduced Form relationship between privatization and Pharmacy prices (heterogeneity by whether MCOs must use state PDL)

\begin{tabular}{|c|c|c|}
\hline & $\begin{array}{c}\text { Dep var }= \\
\text { Medicaid price per prescription } \\
\text { (1) }\end{array}$ & $\begin{array}{c}\text { Dep var }= \\
\text { Cost sharing per prescription } \\
\text { (2) }\end{array}$ \\
\hline \multirow[t]{2}{*}{ Priv } & -7.623 & 1.952 \\
\hline & {$[1.944]^{* * *}$} & {$[1.044]^{*}$} \\
\hline \multirow[t]{2}{*}{ Priv*1(High offset) } & -0.547 & 0.285 \\
\hline & [2.118] & {$[0.866]$} \\
\hline \multirow[t]{2}{*}{ Priv*l(Generic) } & 6.397 & -1.733 \\
\hline & {$[2.333]^{* * *}$} & [1.081] \\
\hline \multirow[t]{2}{*}{ Medicaid expansion } & 1.041 & 0.500 \\
\hline & [1.617] & [0.789] \\
\hline \multirow[t]{2}{*}{$($ Medicaid expansion $) * 1$ (High offset $)$} & -0.624 & -0.187 \\
\hline & [1.381] & [0.547] \\
\hline \multirow[t]{2}{*}{$($ Medicaid expansion $) * 1($ Generic $)$} & -1.044 & -0.446 \\
\hline & [1.688] & {$[0.768]$} \\
\hline \multirow[t]{2}{*}{ Priv*1(Same PDL) } & -1.427 & -3.859 \\
\hline & {$[3.752]$} & {$[0.845] * * *$} \\
\hline \multirow[t]{2}{*}{ Priv $* 1($ Same PDL $) * 1($ High offset $)$} & -0.935 & -0.577 \\
\hline & [3.527] & {$[0.773]$} \\
\hline \multirow[t]{2}{*}{$\operatorname{Priv}^{*} 1($ Same PDL $) * 1($ Generic $)$} & -0.504 & 3.646 \\
\hline & [4.019] & {$[0.906]^{* * *}$} \\
\hline R-sq & 0.999 & 0.992 \\
\hline $\mathrm{N}$ & 3220610 & 3220610 \\
\hline
\end{tabular}

Notes: Specification is limited to treatment states that privatize pharmacy benefits and control states with no MCO pharmacy benefits. Unit of observation is the NDC9-state-quarter. Includes NDC9-state fixed effects, NDC9-quarter fixed effects, and an indicator for whether the state has expanded Medicaid under the ACA. The transition quarter in which a state privatizes is omitted. Observations are weighted by drug spending for each NDC9-state combination in the first quarter in which it appears in the data. Standard errors are clustered by state. Significance levels: * $0.10 * * 0.05$ $* * * .01$ 
Table A.27: State identities by transition type

\begin{tabular}{|c|c|c|c|c|}
\hline \multirow{2}{*}{ (medical / pharmacy) } & \multicolumn{3}{|c|}{$\mathrm{t}=\mathrm{T}$} \\
\cline { 3 - 5 } & FFS/FFS & FFS/FFS & MCO/FFS & MCO/MCO \\
\hline \multirow{2}{*}{$\mathrm{t}=0$} & $\begin{array}{c}\text { MT, NC, OK, SD, VT, } \\
\text { WY }\end{array}$ & - & IA, LA, MS, NH, ND \\
\cline { 2 - 5 } & MCO/FFS & CT & NE, MO, WI, TN & IL, UT, TX, WV, NY, IN, \\
& MCO/MCO & - & - & DE, OH \\
\cline { 2 - 5 } & & & & AZ, CA, CO, DC, FL, \\
& & & GA, HI, KS, KY, MA, \\
& & & NV, OR, PA, RI, SC, VA, \\
& & & WA \\
\hline
\end{tabular}

Notes: States are classified as having an MCO if the state has a significant number of enrollees in an MCO that bears risk. We list VT in the FFS/FFS category, although VT Medicaid enrollees are in an MCO because the MCO is a unique, state run MCO.

Table A.28: Heterogeneity in Effect of MCOs on Medicare's 6 protected class vs other drugs

\begin{tabular}{lcc}
\hline & Any protected class & Not protected class \\
Dependent Variable & $(1)$ & $(2)$ \\
\hline $\ln ($ spending per enrollee $)$ & -0.0469 & -0.335 \\
& {$[0.101]$} & {$[0.124]^{* *}$} \\
$\ln$ (prescriptions per enrollee) & 0.122 & 0.0719 \\
& {$[0.0791]$} & {$[0.0723]$} \\
$\ln ($ price per prescription) & -0.171 & -0.407 \\
& {$[0.0640]^{* *}$} & {$[0.0797]^{* * *}$} \\
$\ln ($ utilization per enrollee $)$ & 0.00989 & -0.236 \\
& {$[0.105]$} & {$[0.126]^{*}$} \\
Generic Accessibility & 0.0531 & 0.0560 \\
Generic Efficiency & {$[0.0178]^{* * *}$} & {$[0.0157]^{* * *}$} \\
& 0.0332 & 0.0441 \\
Generic Penetration & {$[0.0134]^{* *}$} & {$[0.0167]^{* *}$} \\
& 0.0674 & 0.0828 \\
& {$[0.0206]^{* * *}$} & {$[0.0245]^{* * *}$} \\
\hline
\end{tabular}

Notes: Specification is limited to treatment states that privatize pharmacy benefits and control states with no MCO pharmacy benefits. Unreported controls includes state fixed effects and quarter fixed effects. The transition quarter in which a state privatizes is omitted. Observations are weighted by state Medicaid drug spending in the second quarter of 2010. Standard errors are clustered by state. $* 0.10 * * 0.05 * * * .01$ 
Table A.29: Decomposition of source of decreases in price per prescription

\begin{tabular}{ccccccc}
\hline & NDC 9 & molecule-generic & molecule & VA class-generic & VA class & All prescriptions \\
& $(1)$ & $(2)$ & $(3)$ & $(4)$ & $(5)$ & $(6)$ \\
\hline Share $\mathrm{MCO}$ & -0.0878 & -0.0182 & -0.0265 & -0.0390 & -0.109 & -0.0535 \\
& {$[0.0238]^{* * *}$} & {$[0.0104]^{*}$} & {$[0.0174]$} & {$[0.0367]$} & {$[0.0507]^{* *}$} & {$[0.0291]^{*}$} \\
\hline
\end{tabular}

Notes: To determine what is leading to the decreases in price per prescription, we reprice the prescriptions using coarser and coarser drug classifications. Each column presents the contribution of further repricing to the decrease in price per prescription from MCOs. For example, column (1) implies that the price decreases from MCOs would have been 8.4 percentage points smaller if there was no price variation within 9 digit NDC. The coefficient in column (2) implies that the price decrease from MCOs would have been 1.8 percentage points smaller if there was no price variation within molecule-generic versus than it would have been if there was no price variation within 9 digit NDC. The large coefficients in columns (1) and (5) imply that the main was in which MCOs obtain a lower price per prescription by obtaining lower prices for identical 9 digit NDCs and by engaging in generic substitution within-VA class but across-molecule. Drug sample is limited to drugs matched to both the FDA and VA data. Unit of observation is the state-quarter. Specification is limited to treatment states that privatize pharmacy benefits and control states with no MCO pharmacy benefits. Unreported controls includes state fixed effects and quarter fixed effects. The transition quarter in which a state privatizes is omitted. Observations are weighted by state Medicaid drug spending in the second quarter of 2010. Standard errors are clustered by state. * $0.10 * * 0.05 * * * .01$

Figure A.9: Lags and leads of relationship between privatization and spending per enrollee (decomposing into prices and quantities)
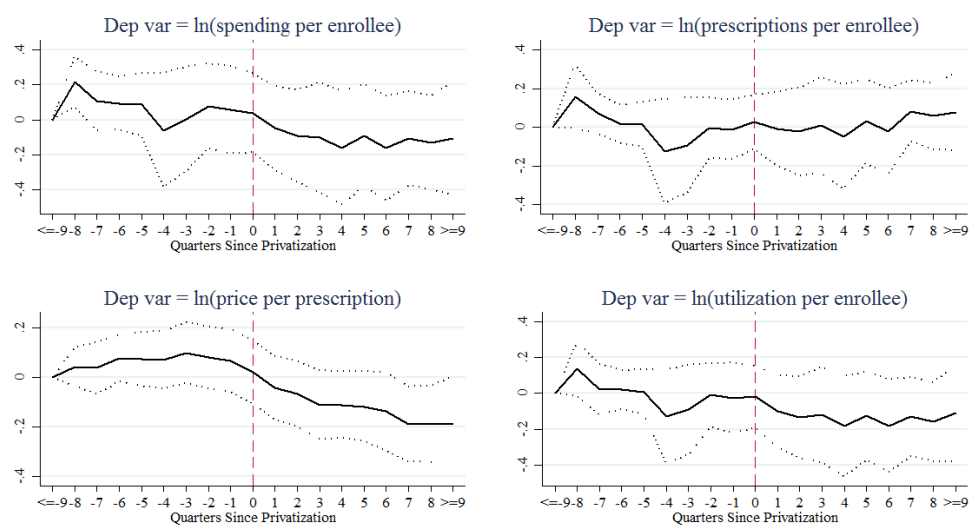

Notes: Specification is limited to treatment states that privatize pharmacy benefits and control states with no MCO pharmacy benefits. Includes state fixed effects, quarter fixed effects, and an indicator for whether the state has expanded Medicaid under the ACA. Observations are weighted by state Medicaid drug spending in the second quarter of 2010. Point estimates for the effect of quarter pre-post privatization is presented in the dark line and a 95 percent confidence interval for those coefficients, based upon standard errors that are clustered by state, is presented with the dotted lines. 
Figure A.10: Lags and leads of relationship between privatization and generic efficiency

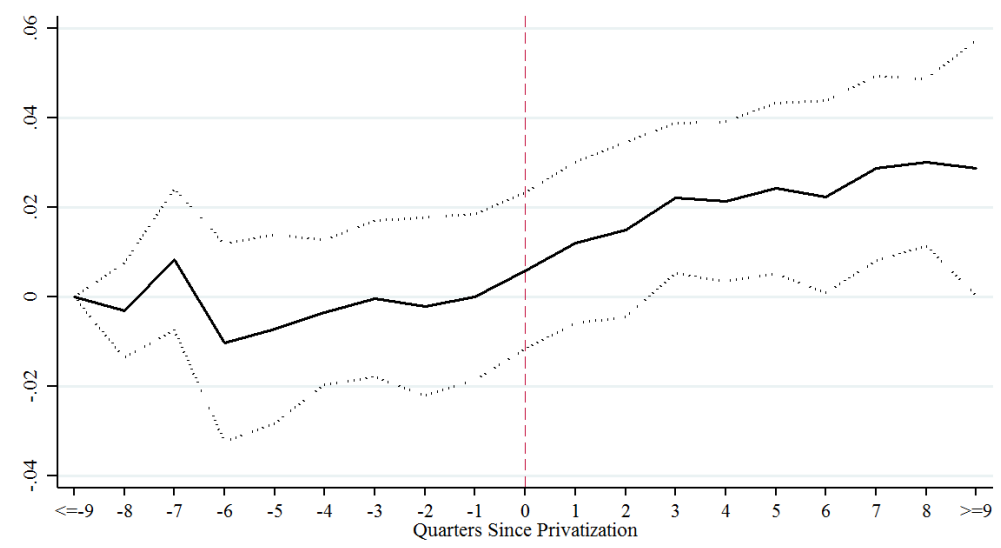

Notes: Specification is limited to treatment states that privatize pharmacy benefits and control states with no MCO pharmacy benefits. Includes state fixed effects, quarter fixed effects, and an indicator for whether the state has expanded Medicaid under the ACA. Observations are weighted by state Medicaid drug spending in the second quarter of 2010. Point estimates for the effect of quarter pre-post privatization is presented in the dark line and a 95 percent confidence interval for those coefficients, based upon standard errors that are clustered by state, is presented with the dotted lines.

Figure A.11: Lags and leads of relationship between privatization and generic accessibility

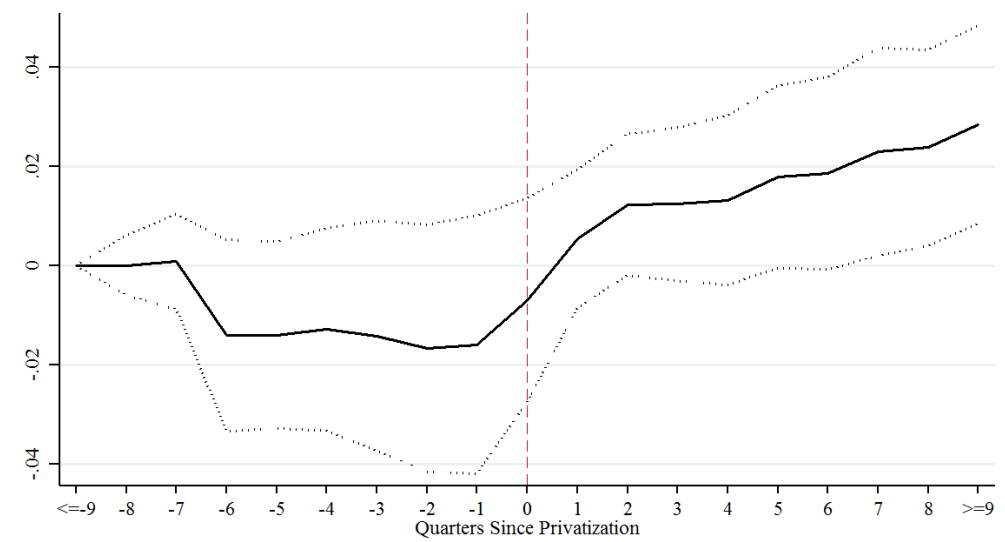

Notes: Specification is limited to treatment states that privatize pharmacy benefits and control states with no MCO pharmacy benefits. Includes state fixed effects, quarter fixed effects, and an indicator for whether the state has expanded Medicaid under the ACA. Observations are weighted by state Medicaid drug spending in the second quarter of 2010. Point estimates for the effect of quarter pre-post privatization is presented in the dark line and a 95 percent confidence interval for those coefficients, based upon standard errors that are clustered by state, is presented with the dotted lines. 
Figure A.12: Lags and leads of relationship between privatization and Simulated generic accessibility

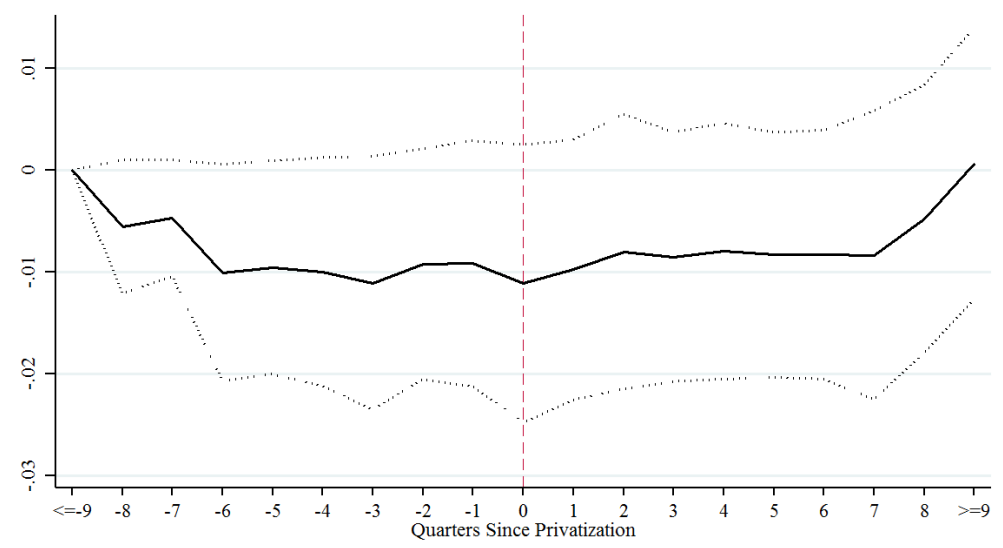

Notes: Specification is limited to treatment states that privatize pharmacy benefits and control states with no MCO pharmacy benefits. Includes state fixed effects, quarter fixed effects, and an indicator for whether the state has expanded Medicaid under the ACA. Observations are weighted by state Medicaid drug spending in the second quarter of 2010. Point estimates for the effect of quarter pre-post privatization is presented in the dark line and a 95 percent confidence interval for those coefficients, based upon standard errors that are clustered by state, is presented with the dotted lines.

Figure A.13: Lags and leads of relationship between privatization and $\ln$ (High offset utilization per enrollee)

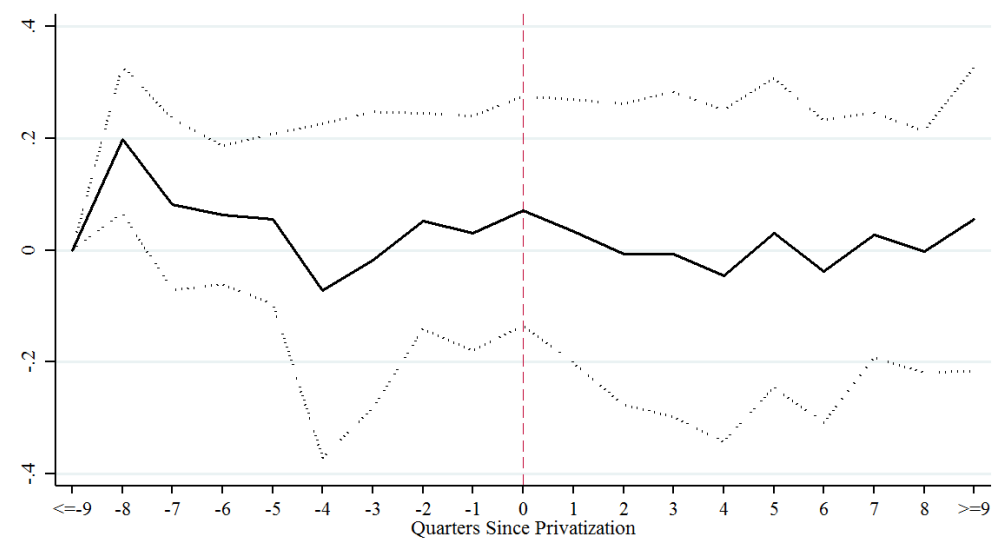

Notes: Specification is limited to treatment states that privatize pharmacy benefits and control states with no MCO pharmacy benefits. Includes state fixed effects, quarter fixed effects, and an indicator for whether the state has expanded Medicaid under the ACA. Point estimates for the effect of quarter pre-post privatization is presented in the dark line and a 95 percent confidence interval for those coefficients, based upon standard errors that are clustered by state, is presented with the dotted lines. 
Figure A.14: Lags and leads of relationship between privatization and $\ln$ (Non-high offset utilization per enrollee)

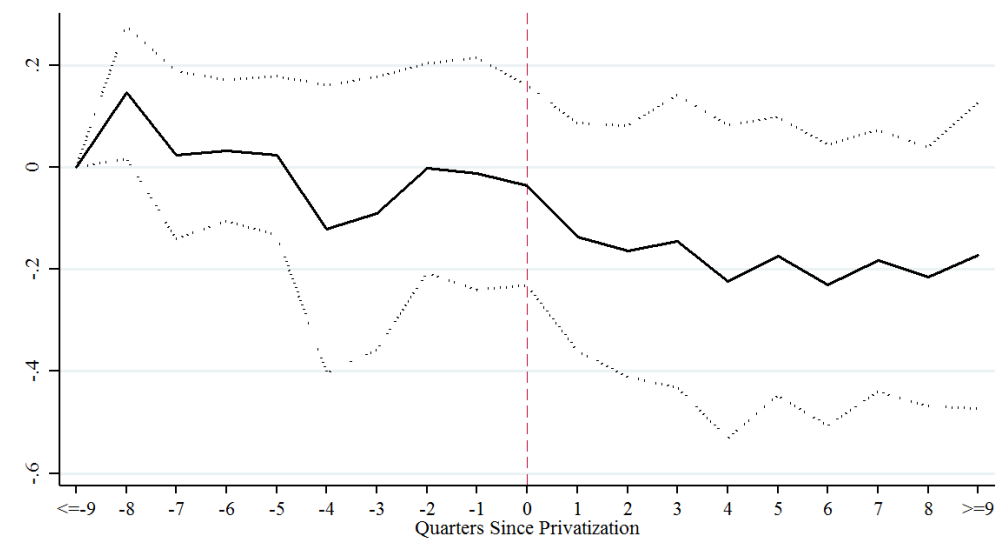

Notes: Specification is limited to treatment states that privatize pharmacy benefits and control states with no MCO pharmacy benefits. Includes state fixed effects, quarter fixed effects, and an indicator for whether the state has expanded Medicaid under the ACA. Point estimates for the effect of quarter pre-post privatization is presented in the dark line and a 95 percent confidence interval for those coefficients, based upon standard errors that are clustered by state, is presented with the dotted lines.

Figure A.15: Effect of privatization for high offset drugs
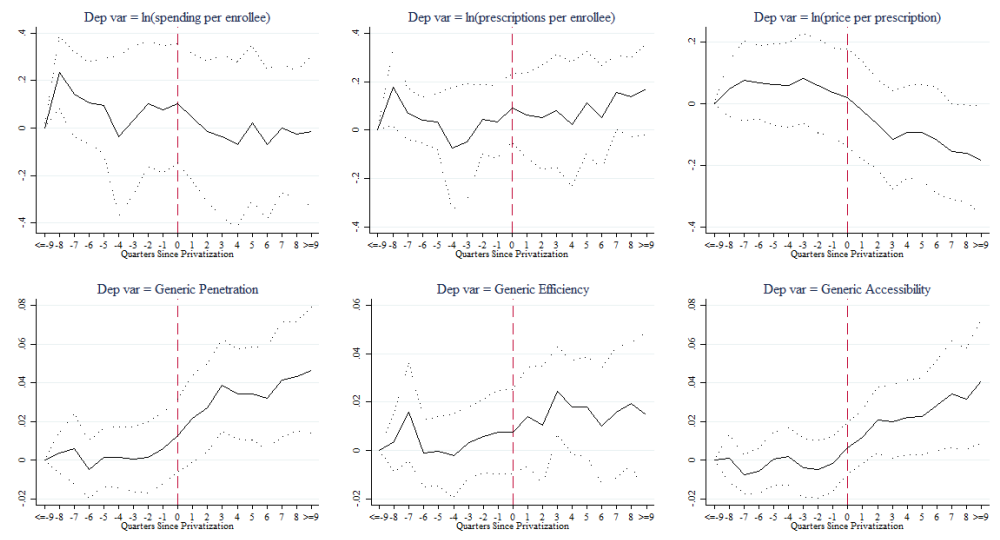

Notes: Specification is limited to treatment states that privatize pharmacy benefits and control states with no MCO pharmacy benefits. Includes state fixed effects, quarter fixed effects, and an indicator for whether the state has expanded Medicaid under the ACA. Point estimates for the effect of quarter pre-post privatization is presented in the dark line and a 95 percent confidence interval for those coefficients, based upon standard errors that are clustered by state, is presented with the dotted lines. 
Figure A.16: Effect of privatization for non-high offset drugs
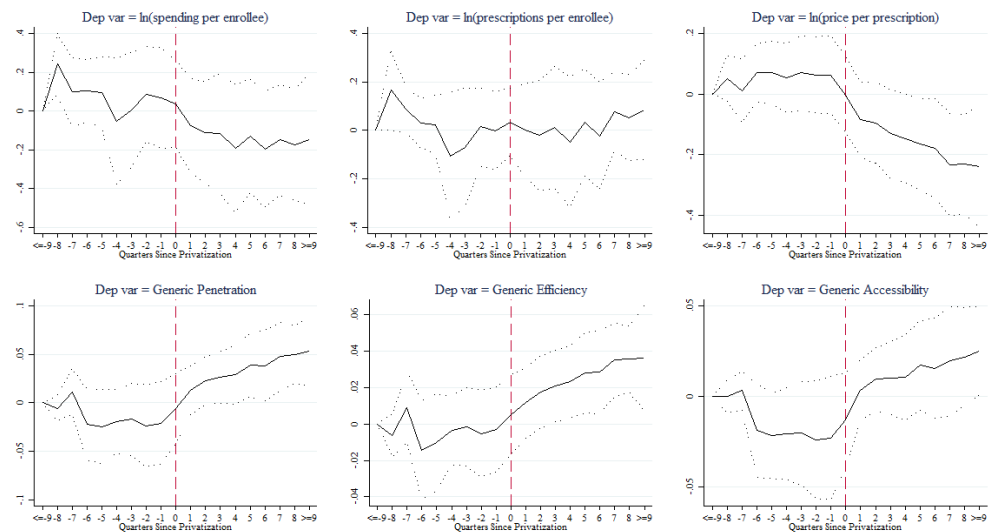

Notes: Specification is limited to treatment states that privatize pharmacy benefits and control states with no MCO pharmacy benefits. Includes state fixed effects, quarter fixed effects, and an indicator for whether the state has expanded Medicaid under the ACA. Point estimates for the effect of quarter pre-post privatization is presented in the dark line and a 95 percent confidence interval for those coefficients, based upon standard errors that are clustered by state, is presented with the dotted lines.

Figure A.17: Heterogeneity in effect of privatization by whether MCOs can design PDLs
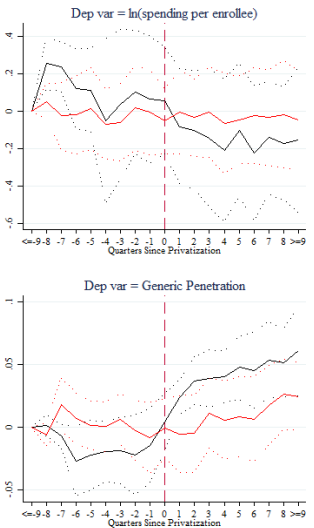
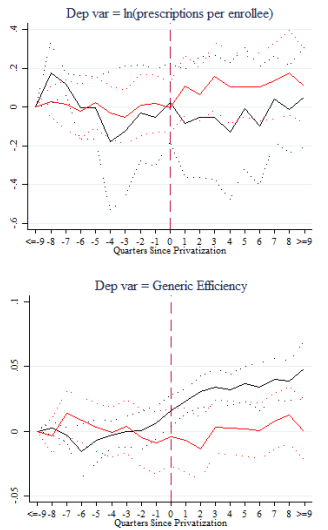

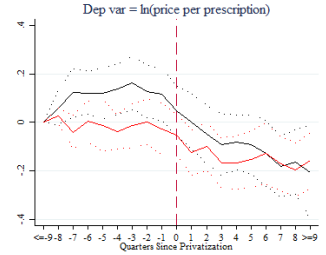

Dep var $=$ Generic Accessibility

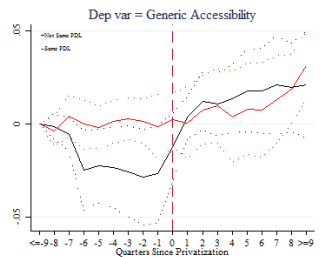

Notes: Specification is limited to treatment states that privatize pharmacy benefits and control states with no MCO pharmacy benefits. Includes state fixed effects, quarter fixed effects, and an indicator for whether the state has expanded Medicaid under the ACA. There are more lags and leads than states (which we cluster standard errors by). Therefore, the lags and leads for the two groups of states are from separate regressions. When we include lags and leads of the privatization decision for those states where MCOs do not need to use the state's PDL, we include a pooled indicator for privatization for those states where MCOs must use the state's PDL (and visa versa). Point estimates for the effect of quarter pre-post privatization for states in which the MCO can design its own PDL is presented in the dark line and a 95 percent confidence interval for those coefficients, based upon standard errors that are clustered by state, is presented with the dotted lines. 
Figure A.18: Lags and leads of relationship between privatization and $\ln$ (Medicaid enrollment)

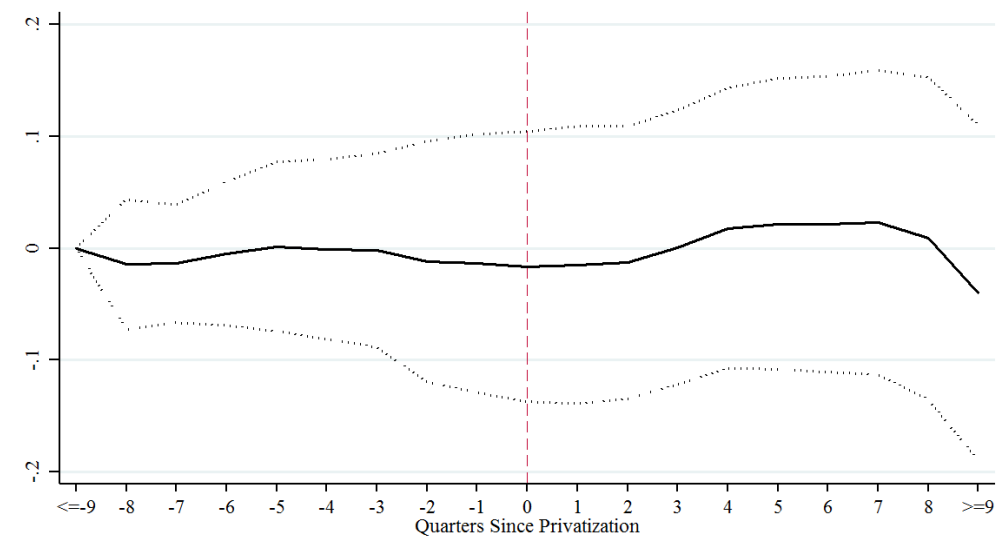

Notes: Specification is limited to treatment states that privatize pharmacy benefits and control states with no MCO pharmacy benefits. Includes state fixed effects, quarter fixed effects, and an indicator for whether the state has expanded Medicaid under the ACA. Point estimates for the effect of quarter pre-post privatization is presented in the dark line and a 95 percent confidence interval for those coefficients, based upon standard errors that are clustered by state, is presented with the dotted lines. 